\title{
Anything New under the Sun? An Update on Modulation of Bioactive Compounds by Different Wavelengths in Agricultural Plants
}

\author{
Marco Santin ${ }^{1}\left(\mathbb{D}\right.$, Annamaria Ranieri ${ }^{1,2}$ and Antonella Castagna $1,2, *$ (D) \\ 1 Department of Agriculture, Food and Environment, University of Pisa, I-56124 Pisa, Italy; \\ marco.santin@agr.unipi.it (M.S.); anna.maria.ranieri@unipi.it (A.R.) \\ 2 Interdepartmental Research Center "Nutraceuticals and Food for Health", University of Pisa, \\ Via del Borghetto 80, I-56124 Pisa, Italy \\ * Correspondence: antonella.castagna@unipi.it
}

check for updates

Citation: Santin, M.; Ranieri, A.; Castagna, A. Anything New under the Sun? An Update on Modulation of Bioactive Compounds by Different Wavelengths in Agricultural Plants. Plants 2021, 10, 1485. https:// doi.org/10.3390/plants10071485

Academic Editor: Suresh Awale

Received: 23 June 2021

Accepted: 18 July 2021

Published: 20 July 2021

Publisher's Note: MDPI stays neutral with regard to jurisdictional claims in published maps and institutional affiliations.

Copyright: (c) 2021 by the authors. Licensee MDPI, Basel, Switzerland. This article is an open access article distributed under the terms and conditions of the Creative Commons Attribution (CC BY) license (https:// creativecommons.org/licenses/by/ $4.0 /)$.

\begin{abstract}
Plants continuously rely on light as an energy source and as the driver of many processes in their lifetimes. The ability to perceive different light radiations involves several photoreceptors, which in turn activate complex signalling cascades that ultimately lead to a rearrangement in plant metabolism as an adaptation strategy towards specific light conditions. This review, after a brief summary of the structure and mode of action of the different photoreceptors, introduces the main classes of secondary metabolites and specifically focuses on the influence played by the different wavelengths on the content of these compounds in agricultural plants, because of their recognised roles as nutraceuticals.
\end{abstract}

Keywords: photoreceptors; plants; bioactive compounds; ultraviolet; visible light; secondary metabolism

\section{Introduction}

Plants rely on an uncountable number of secondary metabolites during their lifespans in order to perform several fundamental functions, such as attracting pollinators, mechanical support, protection from solar UV radiation, deterrents against pests, pathogens, and herbivores, interaction with other plants, and response to environmental stimuli/stresses [1]. Thanks to a network of photoreceptors and the following complex signalling routes, the different light wavelengths may impact the content of these metabolites by up- or downregulating specific sets of biosynthetic and regulatory genes.

\section{Photoreceptors}

Light and plants are an inseparable pair. Light-in addition to playing a crucial role as the energy source for photosynthesis-controls a wide variety of processes during the whole plant life cycle, from seed germination to senescence. Therefore, plants have developed fine-tuning strategies to differentially perceive the wavelengths of the solar spectrum that reach the Earth's surface, and to detect light intensity and direction. The mechanisms that allow plants to respond and adapt to the changing light environment involve several photoreceptors that perceive wavelengths from ultraviolet (UV) to far-red, and transfer the information through a downstream complex network of signals.

Generally, photoreceptors control gene expression by regulating the activity and stability of transcription factors [2-5] that culminate with modifications at transcriptional, translational, post-translational, and enzymatic levels. Such molecular and biochemical responses determine a rearrangement in the plant's primary and secondary metabolism as an adaptation strategy towards specific light conditions.

As depicted in Figure 1, phytochromes (phy) are responsible for red/far-red perception, and cryptochromes (cry), phototropins (phot), and zeitlupe are the receptors of blue 
light. Cryptochromes also perceive green wavelengths. The UVR8 receptor is specifically involved in UV-B sensing, while UV-A is perceived by the blue light receptors, though very recently the involvement of UVR8 in mediating UV-A perception was demonstrated in Arabidopsis [6]. Despite plant responsiveness to green light being observed, presently, there is less known about the mechanism at the basis of green or yellow light perception.

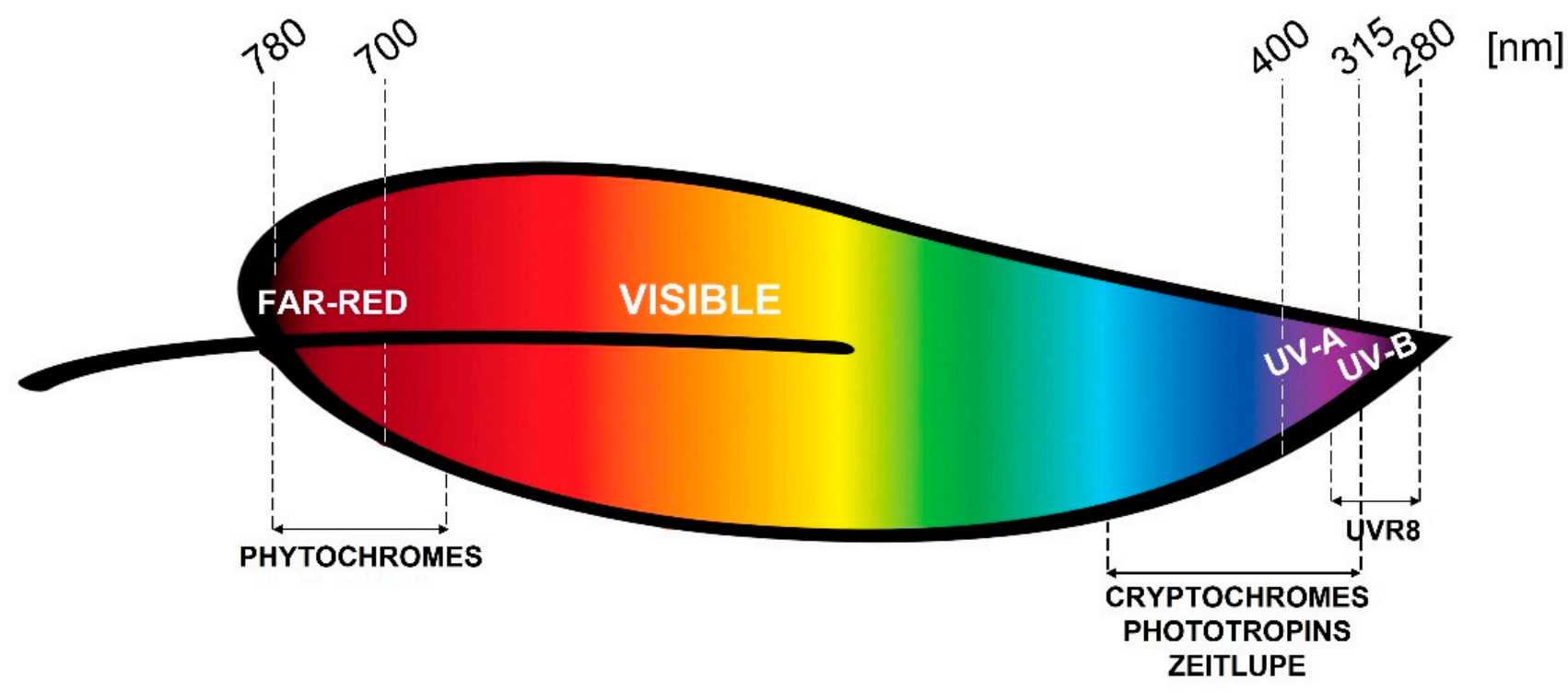

Figure 1. Wavelength ranges within the solar spectrum perceived by the different photoreceptors in plants.

Although the implication of phototropins, cryptochromes, and phytochromes in absorbing certain light ranges has been recognised for decades, the development of new technologies, in terms of molecular and cell biology, photobiology, and biochemistry, together with an integrated approach that combines different research fields, e.g., biology and ecology, have uncovered structures, functions, implications, and metabolic networks of photoreceptors that were still unknown.

The following section will briefly summarise the mechanisms of light perception by the different photoreceptors.

\subsection{Phytochromes}

Phytochromes are dimeric kinase proteins involved in several plant processes, such as seed germination, de-etiolation, stomata development, stem growth, pigmentation, flowering, senescence, and shade avoidance [7,8]. Phytochromes are the specific red/farred photoreceptors, though they are also known to absorb blue light and to regulate blue light response [9]. The hydrophilic apoproteins, synthesised in the cytoplasm, links a tetrapyrrole chromophore (phytochromobilin), giving rise to the biologically inactive (Pr) form [10,11]. After red light absorption (around $665 \mathrm{~nm}$ ), Pr is converted to the active (Pfr) form and translocates into the nucleus [12]. Following far-red irradiation (around $730 \mathrm{~nm}$ ), Pfr is quickly converted back to the Pr form. Dark conditions also slowly revert Pfr to Pr form.

The apoprotein contains an N-terminal photosensory module (PSM), in turn, comprising an N-terminal extension (NTE) and the three domains: period/Arnt/SIM (PAS), cGMP phosphodiesterase/adenylyl cyclase/FhlA (GAF), and phytochrome-specific domain (PHY). A conserved cysteine residue of the GAF domain covalently binds the chromophore, which also interacts non-covalently with NTE, PHY, and PAS domains. The C-terminal module (CTM) consist of two PAS domains and a histidine kinase-related domain (HKRD) [13]. Upon red light perception, a $Z$ to $E$ isomerization of the chromophore occurs, triggering the structural modifications of the protein that allow its transport into the nucleus and the subsequent interaction with transcription factors of the PHYTOCHROME 
INTERACTING FACTOR (PIF) family and ubiquitin E3 ligase complexes. Specifically, Pfr-dependent phosphorylation of PIFs triggers their degradation via the ubiquitin $26 \mathrm{~S}$ proteasome pathway; thus, removing the negative regulators of photomorphogenesis. Pfr also induces the disassembly of the ubiquitin E3 ligase complex, resulting in the accumulation of transcription factors, such as HY5 (ELONGATED HYPOCOTYL 5), a promoter of photomorphogenic development. Pfr also possesses an autocatalytic activity leading to the phosphorylation of the phytochrome itself $[14,15]$. This mechanism provides an instrument for attenuation of the phyA-mediated light signalling by accelerating phy protein degradation, while phyB phosphorylation leads to a reduced signalling via accelerated dark reversion [16].

\subsection{Cryptochromes}

Cryptochromes are blue/UV-A photoreceptors involved in many physiological responses, such as photomorphogenesis, seedling development and de-etiolation, flowering, circadian rhythms [17,18], plant stress responses to pathogens, and shade avoidance [19]. Some responses to green wavebands are cryptochrome-dependent as well [20]. Cryptochromes exist as inactive monomers in dark conditions. The apoprotein can bind to two different chromophores: a flavin (in the form of flavin adenine dinucleotide, FAD) absorbing at $450 \mathrm{~nm}$, and a pterin (5,10-methenyltetrahydrofolic acid, MTHF) absorbing at $380 \mathrm{~nm}$ [21]. Upon light absorption, conformational changes occur, leading to homooligomerization, a modification that changes the affinity with signalling proteins to form various cryptochrome complexes, generically referred to as the cryptochrome complexome [22]. Cry1 and Cry2 are both located in the nucleus, and Cry3 probably acts in chloroplasts and mitochondria [5]. While the photoexcited Cry1 migrates in the cytosol, and is stable and functions under high-fluence irradiance, Cry2 remains in the nucleus [23], is quickly downregulated by blue light, and works at lower light intensities [24]. A detailed description of the different mechanisms of action of cryptochromes and the signalling components involved in the Cry signal transduction pathway is reported in Mishra and Khurana [21].

\subsection{Phototropins}

Phototropins-differently from the other photoreceptors-are primarily located on the plasma membrane. Phototropins have a serine/threonine kinase domain and two chromophore-binding N-terminus LOV (light, oxygen, and voltage) domains [25]. Following light absorption by the flavin mononucleotide (FMN) chromophores bound to LOV1 and LOV2, a conformational change occurs. This activates the kinase domain and phototropin undergoes autophosphorylation [26], a mandatory mechanism for the phototropin function $[26,27]$.

Phototropins mediate plant responses to blue light and UV-A radiation at the subcellular, cellular, organ, and tissue level, controlling primarily those processes involved in promotion of photosynthetic light absorption and utilization, such as phototropism, stomata opening, chloroplast movement and orientation, and leaf expansion and flattening [26].

\subsection{Zeitlupe Family}

The zeitlupe photoreceptors are localised in the cytosol or in the nucleus and perceive UV-A and blue radiations. The three members of this family, namely zeitlupe (ztl), flavinbinding kelch repeat F-box 1 (fkf1), and LOV kelch protein 2 (lkp2), present a LOV domain at the N-terminus, an F-box, and six kelch repeats at their C-terminus [18]. Members of the zeitlupe family participate in the photoperiodic control of flowering, in the regulation of the circadian clock and the control of hypocotyl elongation [28]. These actions are carried out thanks to the participation of the F-box domain in the E3 ubiquitin ligase Skp-Cullin-F-box (SCF) complex, which triggers a controlled light-mediated protein degradation [18]. 


\subsection{UVR8}

The UV RESISTANCE LOCUS 8 (UVR8) is the specific receptor of UV-B radiation [29], though very recently, a role in the perception of short wavelength UV-A $(315-350 \mathrm{~nm})$ was demonstrated in Arabidopsis [6]. UVR8, in its inactive form, is a dimeric protein located in the cytosol. Upon light perception, UVR8 monomerizes and migrates into the nucleus, where it initiates the signal transduction, ultimately leading to up- or downregulation of target genes. This photoreceptor does not bind a chromophore. Light sensing is carried out by the UVR8 tryptophan residues. In particular, the tryptophan residue in the position 285 (Trp-285) seems to be the key element in UVR8 monomerization. Once it enters the nucleus, UVR8 monomer interacts with CONSTITUTIVELY PHOTOMORPHOGENIC 1 (COP1) [30], dissociating the COP1-SPA core from the CUL4-DDB1-based E3 ubiquitin ligase complex. Therefore, HY5 accumulates and promotes the transcription of many UV-B-induced genes [31,32] involved in the photomorphogenic responses and UV-B acclimation [33-35]. Interestingly, among the UVR8-induced gene, there are the REPRESSOR OF UV-B PHOTOMORPHOGENESIS (RUP) 1 and 2. RUP1 and RUP2 proteins promote UVR8 dimerization, thus acting as negative regulators of UV-B signalling [36].

\section{Signal Transduction Pathways}

Independently from the light quality and kind of photoreceptor involved in light perception, the downstream event proceeds via a complex network of early signalling factors, central integrators, and final effectors. Please refer to some recent reviews [37-40] for a detailed summary of the current knowledge of the transcriptional network and mechanisms regulating the response to the different light spectral composition. Interestingly, CONSTITUTIVE PHOTOMORPHOGENIC 1 (COP1), which promotes the proteasomemediates degradation of key factors involved in light signalling, is involved in the response to any light radiation, from UV to far-red wavelengths [41]. Similarly, the transcription factor ELONGATED HYOCOTYL 5 (HY5) has a central role as a final effector of all the light-dependent signalling routes, being able to bind to the promoters of about 4000 genes in Arabidopsis [41].

Figure 2 represents a simplified scheme of the signal transduction pathways leading to gene regulation in response to blue, red/far-red, and UV-B radiation. Briefly, under dark conditions, COP1/SPA (suppressor of Phytochrome A) ubiquitin ligase complex promotes the ubiquitination and degradation of HY5 via the 26S-proteasome pathway [39]. Upon light perception, the active blue- and red/far-red-photoreceptors (cryptochromes and phytochromes) interact with the COP1/SPA complex binding to SPA; thus, leading to COP1 disassembly and migration outside the nucleus. This prevents HY5 ubiquitination and subsequent degradation, so that HY5 may bind the promoter sequence of the light inducible target genes. Similarly, UVR8, after UVB-induced monomerization, can bind to COP1, leading to a functional disruption of the COP1/SPA complex and a consequent HY5 stabilization and functioning [33,42]. 


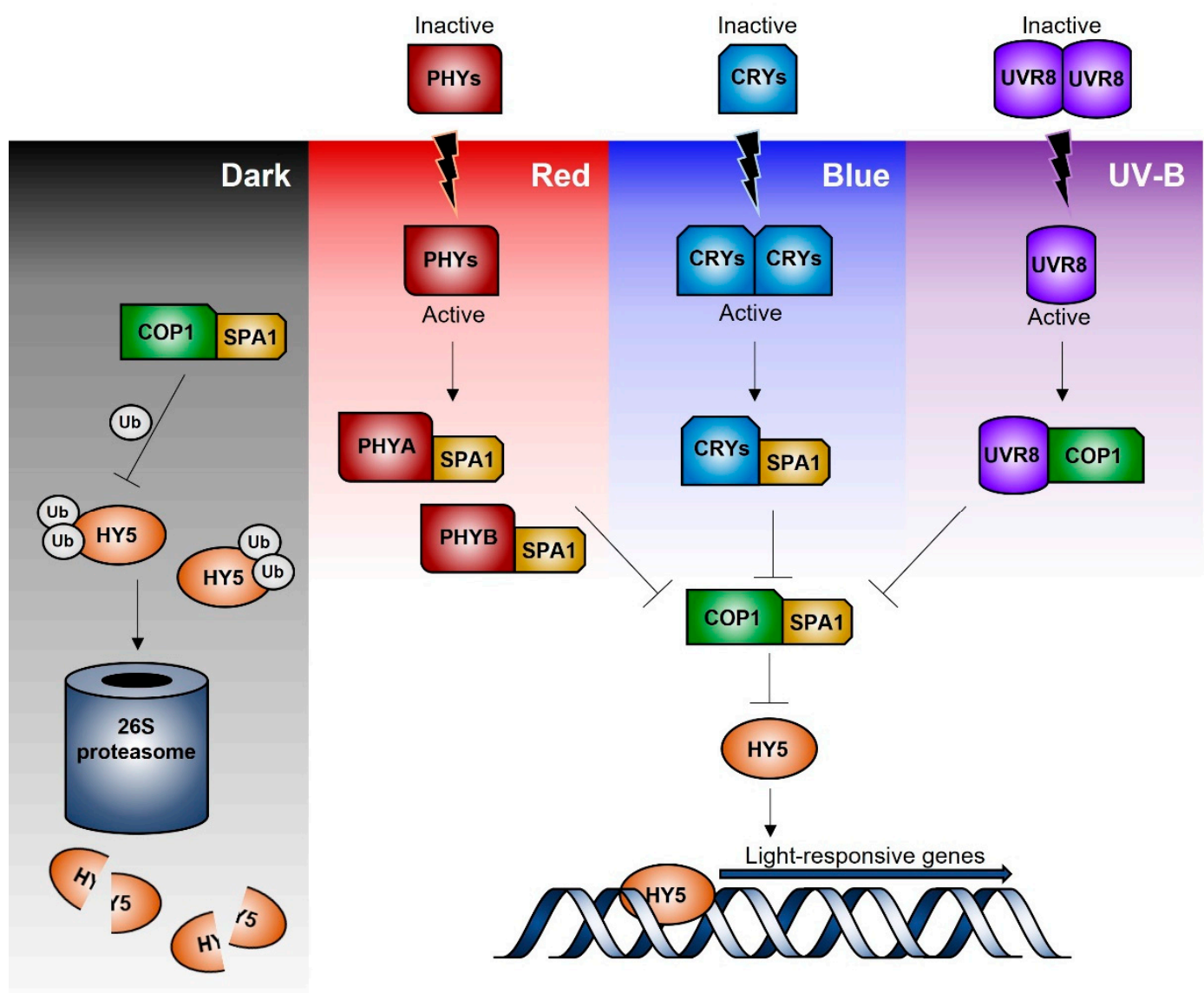

Figure 2. Simplified plant perception mechanisms of different types of solar radiation (dark, red, blue, and UV-B), together with the intracellular rearrangements leading to the transcription of specific light-responsive genes.

\section{Plant Metabolism and Light}

This review specifically focuses on the influence of the different light radiations, from red-far-red to UV-B, on the main classes of secondary metabolites, such as phenolic compounds, terpenoids, tocopherols, glucosinolates, and ascorbic acid in agricultural plant species, because of the recognised role that these compounds generally play as promoters of human wellness [43-46]. UV-C radiation was reported to modulate accumulation of health-promoting compounds in different plants and fruits of food interest, such as tomato fruit [47], bean seedlings [48] and peanut sprouts [49], this review exclusively discusses the effects of those wavelengths that reach the Earth's surface, and to which plants have adapted fine-tuning perception mechanisms and consequent molecular and biochemical responses through evolution.

Examples of the chemical structures of the biomolecule classes described below, and whose content is under the control of the different light wavelengths, are presented in Figure 3.

\subsection{Phenolic Compounds}

Phenolic compounds constitute an extremely huge family (more than 8000 members currently found) of secondary metabolites, which is ubiquitous in vascular plants and bryophytes [50]. Structurally, phenolic compounds consist of one (phenols) or more (polyphenols) aromatic rings linked with one or more hydroxyl groups, and possible other functional substituents (e.g., glycosides), whose number and position within the molecule determine their specific activity. According to their carbon skeleton, the wide class of phenolics can be classified as: C6 (simple phenol, benzoquinones), $\mathrm{C} 6-\mathrm{C} 1$ (phenolic acid), C6-C2 (acetophenone, phenylacetic acid), C6-C3 (hydroxycinnamic acids, coumarins, 
phenylpropanes, chromones), C6-C4 (naphthoquinones), C6-C1-C6 (xanthones), C6-C2C6 (stilbenes, anthraquinones), C6-C3-C6 (flavonoids, isoflavonoids), (C6-C3)2 (lignans, neolignans), (C6-C3-C6)2 (biflavonoids), (C6-C3)n (lignins), (C6)n (catechol melanins), (C6-C3-C6)n (condensed tannins) [51]. All the plant phenolics originate from pentose phosphate, shikimate, and phenylpropanoid pathways [52].

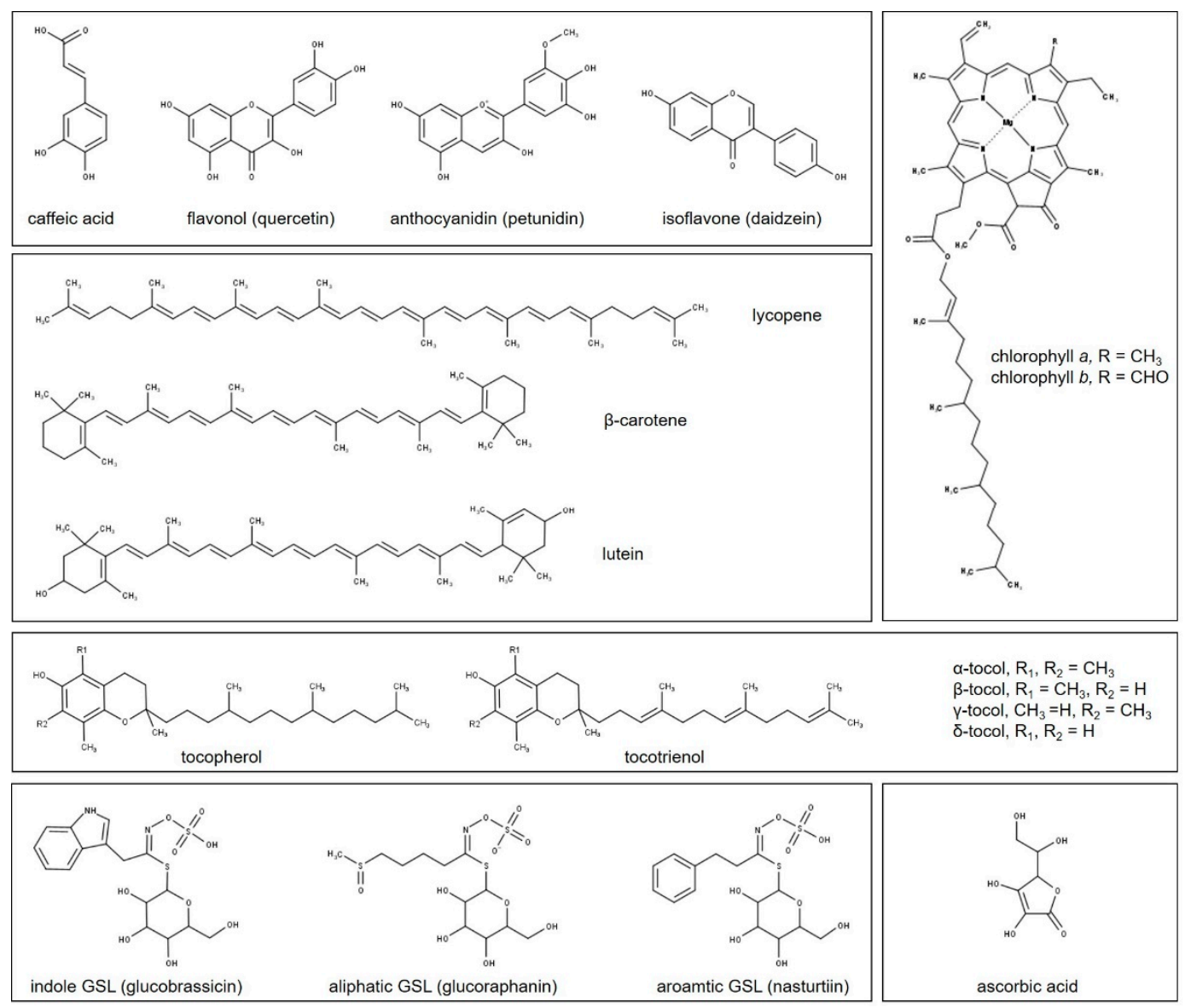

Figure 3. Examples of secondary metabolites whose content is modulated by the different light wavelengths: phenolic compounds (hydroxycinnamic acids and flavonoids), carotenoids, chlorophylls, tocopherols and tocotrienols, ascorbic acid, and glucosinolates. Marvin was used for drawing the chemical structures (Marvin 17.21.0, ChemAxon. Budapest, Hungary).

In recent decades, phenolics have gained popularity with consumers thanks to their benefits for human health [53], particularly due to their anti-allergenic, anti-cancerogenic, anti-atherogenic, anti-inflammatory, anti-microbial, antioxidant, anti-thrombotic, cardioprotective, and vasodilatory properties [54-57]. The main sources of phenolics in the human diet are fruit and vegetable products, although they have also been found in teas, wine, chocolate, herbs and spices, grain, and seeds [58-62] Among phenolics, the widest subfamily is represented by flavonoids, which counts more than 7000 different molecules, and their number keeps on increasing [63]. Flavonoids are the phenolics exhibiting the strongest pharmacological activity and antioxidant capacity $[64,65]$ and, therefore, their consumption within the diet is strongly recommended. Flavonoid subclasses, which differ based on the type of substituents on the central ring of the molecule, are flavonols, flavones, flavanones, flavan-3-ols, isoflavones, and anthocyanidins, while the substituents linked to the aromatic rings (e.g., hydroxyl groups or post-translational modifications such as glycosylation, sulphonation, and acylation) determined the individual members of each flavonoid subclass. 


\subsection{Terpenoids}

Terpenoids constitute the largest family of secondary metabolites, counting more than 60,000 members [66]. Although they show an extreme variability in chemical structures, all terpenoids derive from the same five carbon isoprene (C5) units, whose number is the main criteria for their classification: C5 (hemiterpenoids), C10 (monoterpenoids), C15 (sesquiterpenoids), C20 (diterpenoids), C25 (sesterterpenoids), C30 (triterpenoids), C40 (tetraterpenoids), and C $>40$ (polyterpenoids). Terpenoids $C 5$ precursors, the isopentenyl diphosphate (IPP). and its isomer dimethylallyl diphosphate (DMAPP), are synthesised through two distinct and independent pathways, the mevalonic acid (MVA), and the methylerythritol phosphate (MEP) pathways, which took place in the cytosol and in the plastids, respectively [66-69].

According to their chemical structures, terpenoids fulfil essential functions during plant life as, e.g., direct/indirect defensive compounds against biotic stressors, deterrent towards herbivores, photosynthetic pigments, signalling molecules mediating plant-plant, and plant-environment interaction [66,69-71].

As health-promoting compounds in humans, terpenoids have been discovered to have strong antifungal, antimicrobial, antiviral, anti-inflammatory, immunomodulatory, gastroprotective, and anticarcinogenic properties [66,72-74]; thus, their use for medicinal and pharmaceutical purposes has increased in the last decades. Besides, most of them, being volatile, contribute toward giving the peculiar flavour and aroma of many fruits and vegetables and their food derivatives, thus influencing the overall organoleptic quality and marketability of plant-based products [72,75-79].

Among terpenoids, carotenoids represent a large group of metabolites (more than 600) playing a key role both in plant organisms and for human health [80]. Carotenoids are natural pigments ranging from yellow to red colours, which have been found in animals, plants, and microorganisms [81,82]. Furthermore, in photosynthetic organisms, their role in the pigmentation is crucial for photoprotection and light absorption mechanisms, thus contributing to the overall photosynthetic process [83]. Humans cannot synthesize carotenoid compounds; therefore, they must be introduced through the diet or via supplementation [84]. Few carotenoids (particularly $\beta$-carotene, lutein, and lycopene) were reported to have concrete benefits for human health, being associated with a reduced risk of several pathologies, such as cardiovascular diseases, different types of cancer, immunodeficiencies, fertility, and eye-related problems [85-90].

\subsection{Tocopherols and Tocotrienols}

Vitamin E represents another essential bioactive compound with beneficial effects in human metabolism. Chemically, vitamin E refers to four tocopherols $\left(\alpha-, \beta-, \gamma-\right.$, and $\left.\delta_{-}\right)$ and four tocotrienols $(\alpha-, \beta-, \gamma-$, and $\delta-)$, which are altogether known as tocochromanols or tocols, and are all characterised by a chromanol headgroup and a prenyl side chain [91]. The tocotrienols, unlike the tocopherols, exhibit three unsaturations in the hydrophobic chain, while differences among tocopherols and tocotrienols are due to the number and position of alkyl substituents on the chromanol moiety [92]. Vitamin E compounds exhibit a hydrophobic nature; thus, they are present in lipidic structure within the cells (e.g., cell membranes), fat deposits, poly- and mono-unsaturated fatty acids (PUFA and MUFA, respectively), and lipoproteins [92].

Vitamin $\mathrm{E}$ has been widely studied due to its high antioxidant activity, especially preventing the oxidation of mono- and poly-unsaturated lipids. In addition, vitamin $\mathrm{E}$ compounds were shown to have hypolipidemic, antiatherogenic, antihypertensive, neuroprotective, anti-inflammatory, and many other beneficial effects for human health [93-97]. The main plant sources of tocopherols and tocotrienols are seeds (especially oilseeds) and nuts. In addition, they can be found in many plants and fruits, although their concentrations are limited due to their low lipid content [98]. 


\subsection{Ascorbic Acid}

Another essential antioxidant micronutrient, not only for humans, but also for other animals and plant organisms, is the ascorbic acid, also known as vitamin C. All plants and many animals, including several mammals, have the ability to synthesize the vitamin $\mathrm{C}$ molecule, although others, including primates, guinea pigs, humans, and different bird species, have lost such capacity through evolution [99]. Ascorbate molecule is a C6 compound that derives through different biosynthetic pathways, such as the D-glucose, L-galactose, uronic acid, L-gulose, and myo-inositol pathways [100], but the vitamin C biosynthesis relies mainly on the Smirnoff-Wheeler (SW) pathway [101]. Moreover, ascorbate availability within the cell also depends on its recycling process, which is ensured by the Foyer-Halliwell-Asada cycle [102,103].

Vitamin C, like the majority of the hydrosoluble vitamins, participates as a cofactor for many enzymes, e.g., members of the mono- and dioxygenases family [99], essentially contributing to the maintenance of the cell redox state, together with several other antioxidant molecules and enzymes. In plants, vitamin $C$ is involved in many pathways and processes, e.g., the xanthophyll cycle, the flavonoids, and the glucosinolates pathways, and in the biosynthesis of plant hormones, such as ethylene, gibberellins, and abscisic acid [104-108]. Studies on the role of vitamin $C$ role and its benefits in humans started when it was first noticed that vitamin $C$ deficiency determined a potentially lethal disease called scurvy [109], negatively affecting the immune system, the collagenous architecture, and the regeneration process from wounds. Moreover, pharmacological effects of ascorbic acid against cancer and cardiovascular diseases were also observed [110,111]. The main dietary sources of vitamin $C$ are fresh fruits and vegetables; therefore, their consumption has been widely encouraged by the main food and health organisations (e.g., the Food and Nutrition Board of the National Academy of Sciences, the European Food Safety Authority (EFSA), and the Food and Drug Administration (FDA)) throughout the years, and vitamin $\mathrm{C}$ deficiency symptoms have progressively reduced worldwide.

\subsection{Glucosinolates}

Glucosinolates (GSLs) are an important class of secondary metabolites, widely spread within all of the species of the order Brassicales, including the model plant Arabidopsis thaliana. The backbone of a GSL molecule consists of a sulphonated oxime group bound to a thioglucose substituent, and an amino acid-derived R group. GSLs include more than 200 compounds, classified as aromatic (from tyrosine or phenylalanine), aliphatic (from methionine, valine, alanine, leucine or isoleucine), or indolic (from tryptophan), according to the R group of the molecule [112]. Their concentration within the Brassica species can vary, extremely, based on several internal (e.g., genotype and developmental stage of the plant) and external (e.g., temperature, fertigation, light, cultivation method, storage condition) factors [113-118].

GSLs represent essential defensive molecules against biotic factors, due to their strong antibacterial and antifungal properties $[119,120]$. However, to be converted into their active, toxic form (called isothiocyanates), thus performing their biological function, the thioglucose residue of the GSL molecule needs to be removed by the activity of specific $\beta$-thioglucosidases called myrosinases [119]. Due to the high toxicity of the aglycones, myrosinases and GSLs are located in distinct intracellular compartments to avoid accidental formation of isothiocyanates. This way, the plant ensures that the formation of such defensive molecules occurs only when a plant tissue is damaged, e.g., by the attack of pests and herbivores. Moreover, their role against several abiotic stresses, such as drought and salinity, has been elucidated [121-124]. In humans, many studies have demonstrated the beneficial effects of GSLs as antibacterial, antifungal, antitumoral, and antioxidant compounds [125-127]. 


\section{Red and Far-Red Light}

Although the impact of red/far-red light application on plants is well known in terms of growth performance, morphological and physiological parameters, and productivity, its influence on plant secondary metabolites (e.g., phenolics and terpenoids) are controversial. Examples of the variegated effects induced by these radiations are reported below and summarised in Table 1.

\subsection{Phenolics}

Increased content of total phenolics and flavonoids was observed in common buckwheat (Fagopyrum esculentum Möench) sprouts grown under red light LEDs (625 nm, $16 \mathrm{~h}$ a day, 7 days) as compared to dark-grown sprouts [128]. However, their content was lower than under fluorescent or blue light, the latter inducing the highest accumulation of these molecules.

A study conducted on two varieties of lettuce (Lactuca sativa L.), a red leafy one (cv. Sunmang) and a green leafy one (cv. Grand Rapid TBR) grown under red light (655 nm, $171 \pm 7 \mu \mathrm{mol} \mathrm{m}{ }^{-2} \mathrm{~s}^{-1}$, light-emitting diode (LED) lighting sources), for 4 weeks, showed a significant decrease in total phenolics and antioxidant capacity in the red leaf cultivar, while total flavonoids were significantly higher compared to the control level [129]. On the contrary, the green leafy variety did not show any variation in terms of total phenolics, flavonoids, and antioxidant capacity, indicating a genotype-dependent responsiveness to red light of this biosynthetic pathway. Another study on the same green leafy variety of lettuce confirmed the inefficacy of a 25-day red-light treatment $\left(661 \mathrm{~nm}, 200 \mu \mathrm{mol} \mathrm{m}{ }^{-2} \mathrm{~s}^{-1}\right.$, LED lighting sources) in modifying the content of total phenolics and flavonoids [130]. Effectiveness of red-light irradiation in improving the nutraceutical quality of red leafy lettuce was also previously found by Li and Kubota (2009) [131], on the cultivar Red Cross. The authors observed a significantly higher content of phenolics in plants grown for 12 days under cool white fluorescent lamps supplemented with red light $(658 \mathrm{~nm}$, $130 \pm 10 \mu \mathrm{mol} \mathrm{m}{ }^{-2} \mathrm{~s}^{-1}$, LED lighting sources). Despite such an increase, anthocyanins concentration was unchanged in respect to the control. Moreover, when the same lettuce cultivar was irradiated with supplemental far-red light $\left(734 \mathrm{~nm}, 160 \pm 5 \mu \mathrm{mol} \mathrm{m}^{-2} \mathrm{~s}^{-1}\right.$, LED lighting sources), anthocyanin concentration decreased, although the phenolics level did not vary.

Table 1. Biochemical responses of crops and plants of food interest to red and far-red light wavelengths considered in this review. Tot, total phenolics; Flav, flavonoids; Ant, anthocyanins; AC, antioxidant capacity; T, terpenoids; AA, ascorbic acid; TP, tocopherols; GSL, glucosinolates. For each plant species and cultivar, and for each secondary metabolite or metabolic class considered, the symbols " $\downarrow$ ", “ $\uparrow "$ and " $=$ " mean a decrease, increase or no variations, respectively, compared to the control plants of each study.

\begin{tabular}{|c|c|c|c|c|c|c|c|c|c|c|}
\hline \multirow{2}{*}{ Species } & \multirow{2}{*}{ Cultivar } & \multicolumn{3}{|c|}{ Phenolics } & \multirow{2}{*}{$\mathrm{AC}$} & \multirow{2}{*}{$\mathrm{T}$} & \multirow{2}{*}{ AA } & \multirow{2}{*}{ TP } & \multirow{2}{*}{ GSL } & \multirow{2}{*}{ Ref. } \\
\hline & & Tot & Flav & Ant & & & & & & \\
\hline \multirow{3}{*}{ Red leafy lettuce (Lactuca sativa. L.) } & Sunmang & $\downarrow$ & $\uparrow$ & & $=$ & & & & & [129] \\
\hline & Red Cross & $\uparrow /=$ & & $=/ \downarrow$ & & $=/ \downarrow$ & $=$ & & & {$[131]$} \\
\hline & Red Fire & & & & & $\downarrow /=$ & & & & [132] \\
\hline \multirow{2}{*}{ Green leafy lettuce (Lactuca sativa. L.) } & Grand Rapid TBR & $=$ & $=$ & & $=$ & & & & & {$[129,130]$} \\
\hline & Thumper & & & & & $\downarrow$ & & $\uparrow$ & & [133] \\
\hline \multirow{2}{*}{ Lamb's lettuce (Valerianella locusta L.) } & Noordhollandse & & & $\uparrow$ & & & & & & {$[134]$} \\
\hline & Holländisher & & & $\downarrow$ & & & & & & [119] \\
\hline \multirow{2}{*}{ Pea (Pisum sativum L.) } & & & & & $\uparrow$ & $=/ \uparrow$ & & & & [135] \\
\hline & Meteor & $\uparrow$ & $\uparrow$ & & $=$ & & $\uparrow$ & & & [136] \\
\hline
\end{tabular}


Table 1. Cont.

\begin{tabular}{|c|c|c|c|c|c|c|c|c|c|}
\hline \multirow{2}{*}{ Species } & \multirow{2}{*}{ Cultivar } & \multicolumn{3}{|c|}{ Phenolics } & \multirow{2}{*}{$\mathrm{AC}$} & \multirow{2}{*}{$\mathbf{T}$} & \multirow{2}{*}{ AA } & \multirow{2}{*}{ GSL } & \multirow[b]{2}{*}{ Ref. } \\
\hline & & Tot & Flav & Ant & & & & & \\
\hline Amaranth (Amaranthus cruentus L.) & Red Army & $\downarrow$ & $\uparrow$ & & $=$ & & $\uparrow$ & & {$[1261201$} \\
\hline Basil (Ocimum basilicum L.) & Genovese & $\uparrow$ & $=/ \uparrow$ & & $\uparrow$ & $\downarrow$ & $\downarrow$ & & {$[130-130]$} \\
\hline Kale (Brassica oleracea L.) & Red Russian & $\uparrow$ & $\uparrow$ & & $\uparrow$ & & $\uparrow$ & $\uparrow$ & {$[136,139]$} \\
\hline \multirow{2}{*}{$\begin{array}{l}\text { Chinese kale (Brassica oleracea L. var. } \\
\text { alboglabra Bailey) }\end{array}$} & $\mathrm{DSCH}$ & & & & & & $\uparrow$ & & [140] \\
\hline & DFZC & & & & & & & $=$ & [141] \\
\hline Broccoli (Brassica oleracea L.) & & $\uparrow$ & $\uparrow$ & & $=$ & & $\uparrow$ & & \multirow{7}{*}[136,142]{} \\
\hline Mustard (Brassica juncea L.) & Red Lion & $\uparrow$ & $\downarrow$ & & $\uparrow$ & & $\uparrow$ & & \\
\hline Tatsoi (Brassica rapa L.) & Rosularis & $\uparrow$ & $\uparrow$ & & $\uparrow$ & & $=$ & & \\
\hline Orach (Atriplex hortensis L.) & & $\uparrow$ & & & $=$ & & & & \\
\hline Borage (Borago officinalis L.) & & $\uparrow$ & $\downarrow$ & & $\uparrow$ & & $\downarrow$ & & \\
\hline Beet (Beta vulgaris L.) & Bulls Blood & $\uparrow$ & $\downarrow$ & & $\downarrow$ & & $=$ & & \\
\hline Parsley (Petroselinum crispum Mill.) & & $\uparrow$ & $\uparrow$ & & $\uparrow$ & & $=$ & & \\
\hline Parsley (Petroselinum crispum Mill.) & & & & & & $\uparrow$ & & & [137] \\
\hline Strawberry $($ Fragaria $\times$ Ananassa $)$ & Elsinore & $=$ & $\downarrow$ & & $=$ & & & & {$[138]$} \\
\hline Cranberry (Vaccinium macrocarpon Ait) & Early Black & & & $\uparrow$ & & & & & {$[143]$} \\
\hline Red clover (Trifolium pratense L.) & & & & & & $\downarrow /=$ & & & {$[144]$} \\
\hline Buckwheat (Fagopyrum esculentum) & Möench & $\uparrow$ & $\uparrow$ & & & & & & {$[128]$} \\
\hline Spinach (Spinacia oleracea L.) & Okame & & & & & $\downarrow$ & & & [132] \\
\hline Wheat (Triticum aestivum L.) & & $=$ & & & & & & & {$[145]$} \\
\hline $\begin{array}{l}\text { Tartary buckwheat } \\
\text { (Fagopyrum tataricum Gaertn.) }\end{array}$ & Hokkai T8 & & & & & $\downarrow$ & & & [146] \\
\hline Cowpea (Vigna unguiculata L. Walp.) & & & & & & $\downarrow$ & & & {$[147]$} \\
\hline Bilberry (Vaccinium myrtillus L.) & & & & $\uparrow$ & & & & & {$[148]$} \\
\hline Tomato (Solanum lycopersicum L.) & Red Ruby & & & & & $\uparrow$ & & & {$[47]$} \\
\hline Tea leaves (Camellia sinensis) & Jinxuan & & & & & $\uparrow$ & & & {$[149]$} \\
\hline Pak choi (Brassica rapa ssp. chinensis) & & & & & & $\downarrow$ & & & {$[150]$} \\
\hline (Brassica rapa ssp. pekinensis) & Chiifu & & & & & & & $\uparrow$ & [151] \\
\hline $\begin{array}{l}\text { Satsuma mandarin fruit } \\
\text { (Citrus unshiu Marc.) }\end{array}$ & & & & & & $\downarrow / \uparrow$ & & & [152] \\
\hline
\end{tabular}

A study conducted on cranberry plants grown under either red (photon fluence rate of $12 \mu \mathrm{mol} \mathrm{m}^{-2} \mathrm{~s}^{-1}$, fluorescent lamps as lighting sources filtered through a red plastic sheet) or far-red (photon fluence rate of $5 \mu \mathrm{mol} \mathrm{m}^{-2} \mathrm{~s}^{-1}$, halogen double ended quartz bulbs as lighting sources filtered through a $3 \mathrm{~mm}$ far-red plastic) light showed that fruit anthocyanins were significantly higher when compared to fruits grown under white light (by 6.44 and 3.68-fold, respectively, for red and far-red light) [143].

Similarly, when bilberries (Vaccinium myrtillus L.), plants were exposed to monochromatic red light $\left(7.8 \mu \mathrm{mol} \mathrm{m}^{-2} \mathrm{~s}^{-1}\right)$ during the berry ripening period, a significant increment of total anthocyanins occurred, due to the positive effect of this radiation on petudinins and delphinidins, while peonidins decreased, and cyanidins and malvidins were unaffected [148]. This finding underlines an interesting aspect of the light-phenolic interaction, i.e., the diversity of response to the same stimulus shown by different subclasses of molecules belonging to the same metabolic class. A similar phytochemical specificity of response was also observed in wheat (Triticum aestivum $\mathrm{L}$.) sprouts grown under a 16-h 
light/8-h dark photoperiod under white, red, or blue light, for up to 12 days. Specifically, red light, at the end of the growing period, did not lead to a significant increase in the content of total phenylpropanoids in comparison to white light, but modified their composition, inducing an increase in quercetin and a decrease in 4-hydroxybenzoic acid [145].

Phenolic compounds, and flavonoids in particular, are recognised for their beneficial influence on human health, thanks to their ability to reduce the radical accumulation via the radical-scavenging or chain-breaking activities; thus, preventing the oxidation of many biomolecules [153].

A study by Wu et al. [135] found that antioxidant activity of pea (Pisum sativum L.) seedlings grown under red light (625-630 nm, $128 \pm 4.38$ lx, LED lighting sources) increased when compared to the seedlings grown under white light. Diversity of responses considering antioxidant properties was clearly highlighted by the study of Samuoliene et al. (2012) [136], which compared the impact of a supplementary short-term red LEDs lighting $\left(638 \mathrm{~nm}, 170 \mu \mathrm{mol} \mathrm{m} \mathrm{m}^{-2} \mathrm{~s}^{-1}\right.$ ) on microgreen from different plant species (amaranth (Amaranthus cruentus L.), basil (Ocimum basilicum L.), tatsoi (Brassica rapa L.), mustard (Brassica juncea L.), spinach (Spinacia oleracea L.), broccoli, kale (Brassica oleracea L.), borage (Borago officinalis L.), beet (Beta vulgaris L.), parsley (Petroselinum crispum Mill.), and pea). Enhanced antiradical activity was observed in seven of the ten species tested, and the treatment determined an increase in total phenolics in almost all the plant species, ranging from $9.1 \%$ in mustard to $40.8 \%$ in tatsoi seedlings. Amaranth was the only species registering a decrease in phenolic concentration $(-14.8 \%)$. However, the effect of red light on total anthocyanins was more variable, displaying an overall increase in broccoli, kale, amaranth, tatsoi, parsley, and pea (from $14.6 \%$ in pea to $45.1 \%$ in broccoli), while in borage, mustard and beet total anthocyanins underwent a marked decrease (from $43.3 \%$ in beet to $51.8 \%$ in borage).

Positive effect of red-light irradiation (635-700 nm, $200 \mu \mathrm{mol} \mathrm{m}{ }^{-2} \mathrm{~s}^{-1}$, LED lighting sources) was observed also on basil leaves, in which the antioxidant capacity, the total phenolics, and the flavonoid concentration increased by 14, 30, and 52\%, respectively [138]. In the same study, however, it was reported that the red-light treatment did not affect phenolics content and antioxidant capacity of strawberry (Fragaria $\times$ ananassa) fruit, even leading to a decreased flavonoid content. The few examples reported above witness the potential of red and far-red to interact with the phenylpropanoid biosynthesis, but, at the same time, highlight the complexity of this response, that involves a highly co-ordinated control of regulatory and structural biosynthetic genes in a species- and tissue-specific way.

\subsection{Terpenoids and Chlorophylls}

As for phenolics, the effect of red/far-red light on terpenoids, in particular on carotenoids, is highly variable, and strictly depends on the plant species and cultivar considered.

A 7-day exposure of red clover (Trifolium pratense L.) sprouts to red-light $(630 \mathrm{~nm}$, $150 \mu \mathrm{mol} \mathrm{m} \mathrm{m}^{-2} \mathrm{~s}^{-1}$, LEDs as lighting sources) induced a significant decrease in zeaxanthin concentration, while $\beta$-carotene and lutein were unaffected by the treatment [144]. A negative impact of this radiation on $\beta$-carotene concentration $(-42.5 \%)$ was instead observed in Romaine green baby leaf lettuce (cv. Thumper) treated with supplemental red light $(638 \mathrm{~nm}$, $150 \mu \mathrm{mol} \mathrm{m} \mathrm{m}^{-2} \mathrm{~s}^{-1}$, LEDs lighting sources) for 3 days [133]. These results differed from the ones by Li and Kubota (2009) [131], who found that 12 days of supplemental far-red light, but not red-light, irradiation determined a decrease in xanthophylls and $\beta$-carotene concentration in "Red Cross" baby leaf lettuce. Moreover, red light $\left(380 \mu \mathrm{mol} \mathrm{m}{ }^{-2} \mathrm{~s}^{-1}\right.$, LED lighting sources) was ineffective in modifying the carotenoid content of another lettuce cultivar ("Red Fire") when compared to white light [132].

A dramatic decrease of all carotenoids (13Z- $\beta$-carotene, E- $\beta$-carotene, $9 Z$ - $\beta$-carotene, $\alpha$-carotene, and lutein), with the exception of zeaxanthin, was observed in cowpea ( $\mathrm{Vi}$ gna unguiculata L. Walp.) sprouts exposed to red light $\left(660 \mathrm{~nm}, 50 \mu \mathrm{mol} \mathrm{m}^{-2} \mathrm{~s}^{-1}\right)$ irradiation for 2 weeks [147]. Similarly, tartary buckwheat (Fagopyrum tataricum Gaertn., cv. Hokkai T8) sprouts exposed to red light $\left(660 \mathrm{~nm}, 50 \mu \mathrm{mol} \mathrm{m}^{-2} \mathrm{~s}^{-1}\right)$ for $16 \mathrm{~h}$ a day accumulated 
lower amounts of carotenoids as compared to sprouts grown under white light, again with the exception of zeaxanthin [146]. However, when considering etiolated pea seedlings, a $96 \mathrm{~h}$-red-light irradiation induced a significant increase in $\beta$-carotene content, though only in leaf tissues, but not in stems [135]. An increased $\beta$-carotene content was also reported by Samuolienè et al. [137] in parsley (Petroselinum crispum) microgreens under additional $(638 \mathrm{~nm})$ or unique $(638$ or $665 \mathrm{~nm})$ red lightning. However, the same conditions led to decreased $\beta$-carotene content in basil (cv Sweet Genovese) microgreens and lowered the lutein accumulation on both species. It is therefore evident that, with few exceptions, red light never plays a positive effect on carotenoid accumulation in leafy vegetables and sprouts. This aspect should be taken in consideration anytime the interest of the production chain is the obtainment of high-quality plant foods. Carotenoids contribute in fact to the aesthetical aspect of the product, which is the first attribute that orientates the consumer's choice. Of pivotal importance are also the nutraceutical properties of carotenoids, due to their general antioxidant power and the provitamin A activity of $\alpha$ - and $\beta$-carotene, and $\beta$-cryptoxanthin [81,154,155].

Irradiation on fruits with red wavelengths was more successful as compared to leafy vegetables. Specifically, a significant increment of $\beta$-cryptoxanthin level, though still accompanied by a decreased content of $\beta$ - and $\alpha$-carotene, was evident in Satsuma mandarin (Citrus unshiu Marc.) fruits treated for 6 days with $50 \mu \mathrm{mol} \mathrm{m}{ }^{-2} \mathrm{~s}^{-1}$ of red $(660 \mathrm{~nm})$ light [152], and a noteworthy increase of lycopene, but not of $\beta$-carotene, concentration was induced in tomato (Solanum lycopersicum L. cv. Red Ruby) fruits after 21 days of post-harvest exposure to red light $(610-750 \mathrm{~nm})$ for $24 \mathrm{~min}$ per day [47].

Interestingly, a 3-day exposure of tea leaves (Camellia sinensis var. Jinxuan) to red light $\left(660 \mathrm{~nm}, 70-80 \mu \mathrm{mol} \mathrm{m}^{-2} \mathrm{~s}^{-1}\right)$ increased the volatile terpenes (such as geraniol, linalool, linalool oxide, and diendiol I) levels in respect to the dark conditions [149], suggesting that monochromatic irradiation in pre-harvest could represent a powerful and promising strategy to modify the aroma of tea leaves. However, a prolonged exposure (14 days) did not affect or even decreased these volatiles and a post-harvest irradiation with the same light irradiance was less efficient than in pre-harvest, probably due to the limited irradiation period ( $4 \mathrm{~h}$ at maximum).

Chlorophylls, besides giving the typical green pigmentation to leafy vegetables, may contribute to the antioxidant potential of the produce [156]. Unfortunately, red light seems to play a negative effect on chlorophyll concentration, as indicated by the study carried out by Son and Oh (2013) [129], who reported that red-light-irradiated lettuce exhibited a significantly lower chlorophyll content in both the red leafy cv, "Sunmang", and in the green leafy one, "Grand Rapid TBR". Similarly, Ohashi-Kaneko et al. [132], observed a significant reduction of chlorophyll concentration in lettuce (cv Red Fire) and Komatsuna (Brassica campestris L. cv. Komatsuna) irradiated with red light $\left(380 \mu \mathrm{mol} \mathrm{m}^{-2} \mathrm{~s}^{-1}\right.$, LED lighting sources). The same treatment, however, did not have any effect on spinach (Spinacia oleracea L. cv. Okame) [132]. However, Li and Kubota (2009) [131] found that 12 days of supplemental far-red light, but not red-light, irradiation determined a decrease in chlorophyll concentration in "Red Cross" baby leaf lettuce. Recently, a decrease in chlorophyll concentration was observed also in pak choi (Brassica rapa ssp. chinensis) sprouts cultivated under red (peak at $663 \mathrm{~nm}$ ) LEDs [150].

\subsection{Other Secondary Metabolites}

The influence of light spectral quality on plant secondary metabolism is not limited to the biosynthesis of phenolic and terpenoids compounds, but it may also affect other bioactive compounds, as tocopherols, ascorbic acid, glucosinolates, etc. The potential modification of different classes of metabolites by changing the light environment is particularly important because, despite the attention is often focused on specific compounds, the nutraceutical power of a plant food derives from its unique combination of many different hydrophilic and lipophilic molecules. 
Tocopherols are reported to be influenced by red light. Exposure to supplemental red light (638 nm, $150 \mu \mathrm{mol} \mathrm{m} \mathrm{m}^{-2} \mathrm{~s}^{-1}$, LEDs lighting sources, 3 days) was effective in significantly increasing $\alpha$ - and $\gamma$-tocopherols of Romaine green baby leaf lettuce (cv. Thumper) [133]. The same authors [137] also detected significant accumulation of $\alpha$ tocopherol in basil microgreens grown under increased or sole red radiation $(638 \mathrm{~nm})$. However, increased red radiation lowered the $\alpha$-tocopherol content of parsley microgreens, which was instead incremented when cultivation occurred with sole red lightning. It is therefore evident that, as observed for phenolic compounds, tocopherols are also influenced by red radiation in a species-depending way.

Variability of response was evident also for ascorbic acid. No effect on its concentration was indeed detected in "Red Cross" baby leaf lettuce treated with either red or far-red irradiation [131]. Similarly, a 3-day exposure to supplemental red-light (638 nm, $170 \mu \mathrm{mol} \mathrm{m}{ }^{-2} \mathrm{~s}^{-1}$, LEDs lighting sources) had no significant effect in tatsoi, beet, and parsley microgreens, while it resulted in increased ascorbic acid content in microgreens of amaranth, pea, kale, broccoli, and mustard (by 79.5, 65.2, 60.6, 59.1, and 25\%, respectively), and in a decreased content in basil and borage ones (by 53.9 and $46.9 \%$, respectively) [47]. When considering the Chinese kale (B. oleracea var. alboglabra Bailey cv. DSCH), a 24 h-red light irradiation (660 nm, $80 \mu \mathrm{mol} \mathrm{m}{ }^{-2} \mathrm{~s}^{-1}$, LEDs lighting sources) in pre-harvest was effective in enhancing the vitamin C content up to two days of storage after harvesting [140]. A 4-day treatment of mature broccoli heads with red LED light $(660 \mathrm{~nm})$ was also effective in reducing the ascorbate loss occurring after the harvest [142], a very desirable result in the light of the high degradation rate of this vitamin.

The limited data available on light quality influence on glucosinolates show that the effect is highly dependent on the wavebands and the plant species. Under red irradiation (730 and $640 \mathrm{~nm}$ ) sinigrin content of kale was higher as compared to plants grown under blue light [139]. Similarly, when three Chinese cabbage varieties were exposed for $24 \mathrm{~h}$ to fluorescent light supplemented with red LEDs $(625 \mathrm{~nm})$, the content of total glucosinolates increased in the variety characterised by a low content of these metabolites, while the variety with high glucosinolates positively reacted to supplemental blue radiation [151]. These authors also reported that different set of genes involved in glucosinolates biosynthesis were upregulated by red or blue radiations in Chinese cabbage. To confirm the genotype dependence of the light influence on glucosinolates biosynthesis, Qian et al. [141] did not observe any variation in the content of these compounds in Chinese kale sprouts exposed to red LED light.

\section{Green Light}

Green light, among the whole solar spectrum reaching the Earth's surface, was considered of less importance in the past, since it was a common belief that it did not affect plants' growth and development. It has been instead observed that plants reflect just $10-50 \%$ of green light [157], contributing to the green appearance of most plant organisms, while the remaining part is mainly absorbed by cryptochromes and by a putative, yet uncharacterised, green-light photoreceptor, and weakly by chlorophylls [20,158,159]. By consequence, green light plays several key roles during plant lifespan, e.g., the shade avoidance responses across the bottom layers of the canopies [158,160]. The LED technology, which is progressively replacing the conventional greenhouse lighting that mostly relies on high-pressure sodium lamps or fluorescent tubes, has allowed researchers worldwide to deepen the knowledge on individual wavelengths, which were previously less considered, e.g., the green light. However, few studies have investigated the effects of green light supplementation on the biosynthesis of bioactive compounds in crops so far (Table 2); therefore, this section will include the most recent literature in the field, without splitting phenolics, terpenoids, and other secondary metabolites.

The tea yellow-leaf mutant plants (O. Kuntze 'Zhonghuang 3' (ZH3)) irradiated during the dark period with supplemental green light $\left(520 \mathrm{~nm}, 300 \mu \mathrm{mol} \mathrm{m}^{-2} \mathrm{~s}^{-1}\right.$, LEDs lighting sources) for $4 \mathrm{~h}$ daily up to 12 days showed enhanced concentration of procyanidin B2/B3, 
and L-ascorbate [161]. However, when the green light was applied together with the blue light, the increase in secondary metabolites (especially anthocyanins and catechins) was more pronounced than when the green light was applied alone, mainly due to the activation of structural genes of the phenylpropanoid pathway.

When lettuce (var. youmaicai) was grown by cutting out the green light (480-560 nm), the content of photosynthetic pigments and the chlorophylls/carotenoids ratio were reduced, consequently decreasing the $\mathrm{CO}_{2}$ assimilation and the growth of the plants [162] Similar to these findings, another study on lettuce (cv. Butterhead) [163] showed that supplementation of green light $\left(200 \mu \mathrm{mol} \mathrm{m} \mathrm{m}^{-2} \mathrm{~s}^{-1}\right.$, LEDs lighting sources) to a 48 -h continuous blue and red lighting resulted in increasing the chlorophyll content by inducing an overexpression of photosynthetic genes $\mathrm{LHCb}$ and $\mathrm{Psb}$; thus, enhancing the photosynthetic rates and the maximal photosynthetic capacity. The positive role of green light in stimulating the accumulation of photosynthetic pigments was also observed in tomato plants (cv. 'Komeett') irradiated with 7, 20, or 39\% of green light (531 $\pm 19 \mathrm{~nm}, 171 \mu \mathrm{mol} \mathrm{m}^{-2} \mathrm{~s}^{-1}$, LEDs lighting sources) [164]. The authors found an increased chlorophyll $a / b$ ratio and carotenoids content in the middle leaf layer of the canopy together with the increase of the percentage of green light provided.

Very few studies have investigated the effects of green light irradiation on other secondary metabolites, e.g., phenolic compounds. A comparative study on two basil cultivars, a green leaf (cv. 'Improved Genovese Compact'), and a purple leaf (cv. 'Red Rubin') one, irradiated with increasing proportions of supplemental green light $\left(220 \pm 10 \mu \mathrm{mol} \mathrm{m}{ }^{-2} \mathrm{~s}^{-1}\right)$ resulted in a progressively greater decrease of several bioactive compounds, e.g., phenolics, flavonoids, and anthocyanins [165]. Considering the importance of the genetic background in driving the metabolic responses to the different light radiations, such a negative influence of green light on these metabolites needs to be confirmed in other species and cultivars.

Table 2. Biochemical responses of crops and plants of food interest to green light wavelengths considered in this review. Tot, total phenolics; Flav, flavonoids; Ant, anthocyanins; AC, antioxidant capacity; T, terpenoids; AA, ascorbic acid; TP, tocopherols; GSL, glucosinolates. For each plant species and cultivar, and for each secondary metabolite or metabolic class considered, the symbols " $\downarrow$ ", " $\uparrow "$ and " =" mean a decrease, increase or no variations, respectively, compared to the control plants of each study.

\begin{tabular}{|c|c|c|c|c|c|c|c|c|c|c|}
\hline \multirow{2}{*}{ Species } & \multirow{2}{*}{ Cultivar } & \multicolumn{3}{|c|}{ Phenolics } & \multirow{2}{*}{$\mathrm{AC}$} & \multirow{2}{*}{$\mathbf{T}$} & \multirow{2}{*}{ AA } & \multirow{2}{*}{$\mathbf{T P}$} & \multirow{2}{*}{ GSL } & \multirow{2}{*}{ Ref. } \\
\hline & & Tot & Flav & Ant & & & & & & \\
\hline \multirow{2}{*}{ Lettuce (Lactuca sativa. L.) } & Youmaicai & & & & & $\uparrow$ & & & & {$[162]$} \\
\hline & Butterhead & & & & & $\uparrow$ & & & & [163] \\
\hline Tea leaves (Camellia sinensis L.O. Kuntze) & Zhonghuang 3 & & $\uparrow$ & & & & $\uparrow$ & & & {$[161]$} \\
\hline Tomato plants (Solanum lycopersicum L.) & Komeett' & & & & & $=/ \uparrow$ & & & & {$[164]$} \\
\hline \multirow[t]{2}{*}{ Basil (Ocimum basilicum L.) } & $\begin{array}{l}\text { Improved } \\
\text { Genovese Compact }\end{array}$ & $=/ \downarrow$ & $=/ \downarrow$ & $=/ \downarrow$ & $=/ \downarrow$ & & & & & \multirow[t]{2}{*}[165]{} \\
\hline & Red Rubin & $=/ \downarrow$ & $=/ \downarrow$ & $=/ \downarrow$ & $=/ \downarrow$ & & & & & \\
\hline
\end{tabular}

\section{Blue Light}

While effects of red and far-red light on phytochemicals accumulation are strictly dependent on the plant species considered, blue light irradiation has been generally reported to enhance the content of most nutraceutical substances, especially in terms of phenolic compounds. However, genotype- and structure-dependent specificity of response was observed as well, as commented in this specific paragraph and depicted in Table 3.

\subsection{Phenolics}

In buckwheat sprouts cultivated in the dark or under blue, red, or fluorescent light, the highest content of total phenolic compounds and total flavonoids was detected following 
irradiation with blue light ( $460 \mathrm{~nm}, 16 \mathrm{~h}$ a day, 7 days). An overall increase of the six individual flavonoids resolved by HPLC analysis was observed in blue-irradiated sprouts, their content being about 1.6- to 2.9-fold higher than in dark-grown sprouts [128]. Similarly, soybean (Glycine max L. cv. "Dongnong 690") microgreens exposed for 2 or 4 days to blue light LEDs ( $450 \mathrm{~nm}$ ) with a $12 \mathrm{~h} / 12 \mathrm{~h}$ (light/dark) photoperiod had higher phenolic content than dark- and white light-grown seedlings. Flavonoid content was instead lowered by 2-day irradiation with blue light, which was, however, effective in increasing this metabolic class when lightning was prolonged up to 4 days [166]. A detailed HPLC-MS analysis highlighted differences in the profile of phenolic compounds, with increased abundance of 6,7,3,4-tetrahydroxyisoflavone, galangin and apigenin 7-O-glucoside and decreased content of dihydrodaidzein 7-O-glucuronide. These changes overall led to enhanced antioxidant activity of seedlings grown under blue light [166].

Table 3. Biochemical responses of crops and plants of food interest to blue light wavelengths considered in this review. Tot, total phenolics; Flav, flavonoids; Ant, anthocyanins; AC, antioxidant capacity; T, terpenoids; AA, ascorbic acid; TP, tocopherols; GSL, glucosinolates. For each plant species and cultivar, and for each secondary metabolite or metabolic class considered, the symbols " $\downarrow$ ", " $\uparrow "$ and "=" mean a decrease, increase or no variations, respectively, compared to the control plants of each study.

\begin{tabular}{|c|c|c|c|c|c|c|c|c|c|c|}
\hline \multirow{2}{*}{ Species } & \multirow{2}{*}{ Cultivar } & \multicolumn{3}{|c|}{ Phenolics } & \multirow{2}{*}{ AC } & \multirow{2}{*}{$\mathbf{T}$} & \multirow{2}{*}{ AA } & \multirow{2}{*}{ TP } & \multirow{2}{*}{ GSL } & \multirow{2}{*}{ Ref. } \\
\hline & & Tot & Flav & Ant. & & & & & & \\
\hline \multirow{3}{*}{ Green leafy lettuce (Lactuca sativa. L.) } & Thumper & $\downarrow$ & & $=$ & & & $\downarrow / \uparrow$ & $\uparrow$ & & [133] \\
\hline & & & & & & & $\uparrow$ & & & [167] \\
\hline & Grizzly & & & & & & $\uparrow$ & & & [168] \\
\hline Red leafy lettuce (Lactuca sativa. L.) & Red Cross & $=$ & & $\uparrow$ & & & & & & [131] \\
\hline Red clover (Trifolium pratense L.) & & & & & & $\uparrow$ & & & & [144] \\
\hline Chinese cabbage (Brassica campestris L.) & & & & & & & $\uparrow$ & & & [169] \\
\hline Mustard (Brassica juncea L.) & Red Lion & & & & & $\uparrow$ & & $\uparrow$ & & \multirow{3}{*}{ [170] } \\
\hline Beet (Beta vulgaris L.) & Bulls Blood & & & & & $\uparrow$ & & $\uparrow$ & & \\
\hline Parsley (Petroselinum crispum Mill.) & Plain Leaved or French & & & & & $\uparrow$ & & $\uparrow$ & & \\
\hline Buckwheat (Fagopyrum esculentum) & Möench & $\uparrow$ & $\uparrow$ & & & & & & & [128] \\
\hline Wheat (Triticum aestivum L.) & & & $\uparrow / \downarrow$ & & & & & & & [145] \\
\hline Soybean (Glycine max L.) & Dongnong 690 & $\uparrow$ & $\downarrow$ & & & & & & & [166] \\
\hline Bilberry fruit (Vaccinium myrtillus L.) & & & & $\uparrow \uparrow$ & & & & & & [148] \\
\hline \multirow{2}{*}{ Apple fruit (Malus domestica Borkh.) } & Mishima Fuji & & & $\uparrow \uparrow$ & & & & & & \multirow{2}{*}{ [171] } \\
\hline & Jonathan & & & $\uparrow$ & & & & & & \\
\hline \multirow{2}{*}{ Strawberry $($ Fragaria $\times$ Ananassa) } & & & & $\uparrow$ & & & & & & {$[172,173]$} \\
\hline & Fengguang & & & & & & $\uparrow$ & & & [174] \\
\hline Cowpea (Vigna unguiculata L. Walp.) & & & & & & \multicolumn{2}{|l|}{$\downarrow / \uparrow /=$} & & & [147] \\
\hline $\begin{array}{l}\text { Tartary buckwheat } \\
\text { (Fagopyrum tataricum Gaertn.) }\end{array}$ & & & & & & $\downarrow$ & & & & [146] \\
\hline Pak choi (Brassica rapa ssp. chinensis) & & & & & & $\downarrow /=$ & & & & [150] \\
\hline Tomato fruit (Solanum lycopersicum L.) & Micro-Tom & & & & & $\uparrow$ & & & & [175] \\
\hline Satsuma mandarin fruit (Citrus unshiu Marc.) & & & & & & $\downarrow / \uparrow /=$ & & & & [152] \\
\hline Tea leaves (Camellia sinensis) & Jinxuan & & & & & $\uparrow$ & & & & [149] \\
\hline Basil (Ocimum basilicum L.) & Genovese & & & & & $\uparrow$ & & & & [176] \\
\hline Satsuma mandarin fruit (Citrus unshiu Marc.) & & & & & & & $\uparrow$ & & & \\
\hline Valencia orange fruit (Citrus sinensis Osbeck) & & & & & & & $\uparrow$ & & & [177] \\
\hline Lisbon lemon fruit (Citrus limon Burm.f.) & & & & & & & $\uparrow$ & & & \\
\hline Canola (Brassica napus L.) & & & & & & & & & $\uparrow /=$ & [178] \\
\hline Mustard (Brassica juncea L.) & & & & & & & & $\downarrow$ & & [179] \\
\hline
\end{tabular}


A structure-dependent response to blue radiation $(470 \mathrm{~nm})$ was also observed in wheat sprouts irradiated for up to 12 days (a 16-h light/8-h dark photoperiod). This treatment led in fact to a decreased accumulation of p-coumaric acid and epicatechin while gallic acid and quercetin content increased in comparison to sprouts irradiated with white light [145]. It should be noted that what the authors call "white light" is a treatment with $380 \mathrm{~nm}$ radiation, i.e., long wave $\mathrm{UV}-\mathrm{A}$ radiation.

On the contrary, adding blue light LEDs $\left(455,470 \mathrm{~nm}, 30 \mu \mathrm{mol} \mathrm{m}{ }^{-2} \mathrm{~s}^{-1}\right)$ to standard high-pressure sodium (HPS) lamps in Romaine green baby leaf lettuce (cv. Thumper) determined a decrease in total phenols concentration compared to the HPS alone, while no effects in anthocyanin content was registered [133]. Cultivar and treatments, however, might result in completely different responses in terms of phenolics accumulation. Indeed, a 12-day blue light supplementation (476 nm, $130 \pm 10 \mu \mathrm{mol} \mathrm{m}^{-2} \mathrm{~s}^{-1}$, LEDs lighting sources) on baby leaf lettuce (cv, Red Cross) was effective in stimulating anthocyanin accumulation without increasing the total phenolic content [131]

Blue light was generally reported to stimulate anthocyanin biosynthesis, resulting in marked accumulation of these metabolites, particularly in fruits. In bilberries, 48- $h$ irradiation with blue light (400-500 nm, $\left.8.10 \mu \mathrm{mol} \mathrm{m} \mathrm{m}^{-2} \mathrm{~s}^{-1}\right)$ was effective in inducing anthocyanins accumulation over the control fruits grown under white light [148]. However, the effect induced by blue light on total anthocyanin and delphinidins content did not differ markedly from that induced by red or far-red irradiation. Moreover, when considering the other subclasses, cyanidins, peonidins, and malvidins were unaffected, while petudinins increased, but less than under red and far-red lightning.

Irradiation for $96 \mathrm{~h}$ with blue LEDs $(430,450,470$, and $490 \mathrm{~nm}$ ) of apple (Malus domestica Borkh.) fruits harvested at the mature green stage induced an increased accumulation of anthocyanins and the development of the red colour, in both "Mishima Fuji" and "Jonathan" cultivars, though, because of the different genetic background, Jonathan cV accumulated more anthocyanins that Fuji under blue light [171]. The involvement of the blue light photoreceptor cryptochrome of apple in promoting anthocyanin accumulation was demonstrated using MdCRY2 transgenic Arabidopsis [180]. Moreover, CRY1, CRY2, and CRY3, and PHOT1 and PHOT2 were all downregulated in strawberry fruits treated with blue light [172] and a decreased transcription of photoreceptor genes, except PHOT2, occurred during fruit development from green to red ripe stage, suggesting a role of PHOT2 in blue light-induced anthocyanin accumulation [181]. Indeed, total anthocyanins, as well as the individual anthocyanins pelargonidin 3-glucoside (accounting for more than 80\% of total anthocyanins) and pelargonidin 3-malonylglucoside, were more concentrated in strawberries ripened in planta under blue $(450 \mathrm{~nm}, 8 \mathrm{~h}$ dark-16 h light photoperiod) than under white light [172]. Blue light irradiation $\left(40 \mu \mathrm{mol} \mathrm{m} \mathrm{m}^{-2} \mathrm{~s}^{-1}\right.$ for up to 12 days at $\left.5{ }^{\circ} \mathrm{C}\right)$ was also effective in improving total anthocyanin content of strawberries when applied in post-harvest [173], suggesting that supplemental blue light during storage could be helpful in preserving or even improve the quality of post-harvest fruits.

\subsection{Terpenoids and Chlorophylls}

The effect of blue radiation on carotenoids was a little bit more variable than on phenolic compounds. A 7-day supplementation of blue light $\left(440 \mathrm{~nm}, 150 \pm 5 \mu \mathrm{mol} \mathrm{m}^{-2} \mathrm{~s}^{-1}\right.$, LEDs lighting sources) on red clover sprouts was effective in significantly enhancing the concentration of the main carotenoids ( $\beta$-carotene, lutein, and zeaxanthin) compared to irradiation with only white light [144]. Similarly, cowpea sprouts grown under blue LEDs irradiation ( $16 \mathrm{~h}$ photoperiod, $470 \mathrm{~nm}, 50 \mu \mathrm{mol} \mathrm{m}{ }^{-2} \mathrm{~s}^{-1}$ ) contained the highest levels of total carotenoids and of lutein, $13 Z$ - $\beta$-carotene, and E- $\beta$-carotene as compared to sprouts grown under white, red, or blue-red mix. Moreover, $\alpha$-carotene and 9Z- $\beta$-carotene level was higher than in sprouts cultivated under red- and blue-red mixed radiation, and unchanged in comparison to white light treated samples, while zeaxanthin was decreased by this light radiation [147]. An opposite behaviour was shown in tartary buckwheat sprouts grown under blue LEDS (470 nm, $50 \mu \mathrm{mol} \mathrm{s}{ }^{-1} \mathrm{~m}^{-2}, 16 \mathrm{~h}$ photoperiod), where total 
carotenoids, as well as individual xanthophylls and carotenes, except for zeaxanthin, were less concentrated than in samples grown under white light [146].

When considering microgreens, blue light $\left(445 \mathrm{~nm}, 300 \pm 3 \mu \mathrm{mol} \mathrm{m}^{-2} \mathrm{~s}^{-1}\right.$, LED lighting sources) supplementation ( $+33 \%$ to the standard light conditions) determined an increased content of several carotenoids ( $\alpha$ - and $\beta$-carotenes, lutein, violaxanthin, and zeaxanthin) ranging from 1.2 to 4.3 times in mustard, beet, and parsley [170]. A structurespecific effect of blue LED (peak at $453 \mathrm{~nm}$ ) irradiation was observed in pak choi sprouts that exhibited a lower concentration of lutein and total carotenoids, while $\beta$-carotene and violanthin were unaffected by this radiation [150].

Blue light irradiation (12 days, $476 \mathrm{~nm}, 130 \pm 10 \mu \mathrm{mol} \mathrm{m}^{-2} \mathrm{~s}^{-1}$ ) increased the concentration of total xanthophylls and $\beta$-carotene also in baby leaf lettuce (cv. Red Cross) [131], while a decreased accumulation of both $\alpha$ - and $\beta$-carotenes was observed following the addition of blue light (445 or $470 \mathrm{~nm}, 30 \mu \mathrm{mol} \mathrm{m}^{-2} \mathrm{~s}^{-1}$, LEDs lighting sources) during cultivation of Romaine baby leaf lettuce [133].

Carotenoid content can be modified by blue radiations also in fruits, as shown by the research carried out by Xie et al. [175] on tomato fruit (cv. Micro-Tom) ripened in planta under supplemental blue light $(430 \mathrm{~nm}, 12 \mathrm{~h}$ photoperiod). These authors detected higher concentrations of lycopene in fruits exposed to blue light supplementation when compared to natural light conditions and red light $(660 \mathrm{~nm})$ supplementation at 42,48 , and 54 DAA (days after anthesis), and of $\beta$-carotene at 48 and 54 DAA, while lutein was more concentrated than in control fruits only at 36 DAA. Involvement of HY5 in mediating the increased transcription of PSY1 (phytoene synthase 1) gene, the key limiting step for carotenoid synthesis in tomato ripening fruit [182], was proposed [175].

An unchanged level of total carotenoids was observed in the flavedo of Satsuma mandarin fruits irradiated in post-harvest irradiated with blue $(470 \mathrm{~nm})$ LEDs $(50 \mu \mathrm{mol}$ $\mathrm{m}^{-2} \mathrm{~s}^{-1}$ ) for 6 days. This apparent absence of blue light-induced effects was indeed due to different trends of variations experienced by the individual carotenoids present in this fruit as compared by dark-treated ones. Specifically, the content of $\alpha$ - and $\beta$-carotene, lutein, and all-trans-violaxanthin increased, while all-cis-violaxanthin decreased and $\beta$ cryptoxanthin was unaffected [152], highlighting once again the complexity of modulation of the secondary metabolism by specific light wavelengths.

As already reported for red light treatment, a 3-day exposure to blue light (470 $\mathrm{nm}, 70-80 \mu \mathrm{mol} \mathrm{m} \mathrm{m}^{-2} \mathrm{~s}^{-1}$ ) induced increased production of some volatile terpenes in tea leaves. Geraniol, linalool, linalool oxide, and diendiol I were all produced at higher concentration than in dark-treated leaves and linalool and diendiol I reached the highest concentration also when compared to leaves exposed to red light [149]. Cultivation of basil with supplemental LED treatments with progressive blue/red ratios $(447 \mathrm{~nm} / 627 \mathrm{~nm}$, from $10 / 90$ to $60 / 40$ blue/red) increased the concentration of eucalyptol, linalool, (R)-(+)- and (S)(-)- limonene, and $\alpha$ - and $\beta$-pinene in comparison to natural light controls [176], indicating the great potential to influence the production of volatile molecules and, consequently the flavour quality of beverage plants and herbs, by manipulating the growth light environment.

This portion of the light spectrum is able to modulate chlorophyll content as well. An increased content of both chlorophyll $a$ and $b$ in mustard, beet, and parsley microgreens was induced by blue light supplementation [170]. However, chlorophyll content of baby leaf lettuce (cv, Red Cross) irradiated by blue light (12 days, $476 \mathrm{~nm}, 130 \pm 10 \mu \mathrm{mol} \mathrm{m}^{-2} \mathrm{~s}^{-1}$ ) was unchanged [131], while in pak choi sprouts cultivated under blue LEDs (peak at $453 \mathrm{~nm}$ ) chlorophyll $b$ (but not chlorophyll $a$ ) concentration was lower than in control sprouts grown under white light [150]. As for the other metabolites, a genotype-specific response to blue radiation seems to occur also for chlorophylls.

\subsection{Other Secondary Metabolites}

The influence of increasing dosage of blue light (from 0 to $33 \%, 445 \mathrm{~nm}$ ) to the LED-based lighting conditions composed by a mix of $638+660+731 \mathrm{~nm}$ (total PPFD $300 \pm 3 \mu \mathrm{mol} \mathrm{m}{ }^{-2} \mathrm{~s}^{-1}$ ) on tocopherols concentration was investigated in mustard, beet, 
and parsley microgreens [170]. In all species, the best effect on total tocopherols level was induced by a $16 \%$ blue light enrichment, because of a significant enhancement of specific compounds in the different microgreens: $\alpha$ - and $\beta$-tocopherol in mustard, $\gamma$ - and $\delta$-tocopherol in beet and $\beta-, \gamma-$, and $\delta$-tocopherol in parsley [170]. Increasing of blue light to $33 \%$ further increased total tocopherols in beet, but not in mustard and parsley.

Similarly, a positive effect of blue light LEDs (455 and $470 \mathrm{~nm}, 30 \mu \mathrm{mol} \mathrm{m}{ }^{-2} \mathrm{~s}^{-1}$ ) was observed in Romaine green baby leaf lettuce cv. Thumper, where a higher $\alpha$ - and $\gamma$-tocopherols content were detected as compared to HPS alone [133].

The current literature reports evidence that the blue portion of the light spectrum may modify the concentration of ascorbic acid as well, though it was not a general effect, but it depended on the plant species or cultivar considered, and/or the specific wavelength. In Romaine green baby leaf lettuce (cv. Thumper) the content of ascorbic acid showed indeed an opposite response to supplemental irradiation with 455 or $470 \mathrm{~nm}$ blue light, specifically, a decrease or an increase respectively [133]. Considering the Red Cross cultivar, however, ascorbic acid content was unaffected after a 12-day blue light supplementation (476 nm, $130 \pm 10 \mu \mathrm{mol} \mathrm{m} \mathrm{m}^{-2} \mathrm{~s}^{-1}$, LEDs lighting sources) [131].

However, most studies highlighted the ability of blue light to enhance ascorbate levels. Zha et al. [167] observed a positive influence of increased proportion of blue light on ascorbate concentration in lettuce cultivated with different red/blue light ratios (75/25, 50/50, 25/75 R/B) for 12 days (24 h a day, $\left.200 \mu \mathrm{mol} \mathrm{m} \mathrm{m}^{-2} \mathrm{~s}^{-1}\right)$. Such an increase was accompanied by a transient overexpression of many genes involved in ascorbate biosynthesis, and a more consistent increase in the activity of enzymes involved in ascorbate regeneration, leading the authors to conclude that the higher levels of ascorbate observed in the $25 / 75 \mathrm{R} / \mathrm{B}$ growth condition were the consequence of a better regeneration activity rather than enhanced biosynthesis under blue light. Similarly, vitamin $\mathrm{C}$ concentration was 2.25-fold higher in lettuce (cv. Grizzly) under 100\% blue light irradiation (460-475 nm, $14 \mathrm{~h}$ photoperiod, $300 \mu \mathrm{mol} \mathrm{m} \mathrm{m}^{-2} \mathrm{~s}^{-1}$ ) as compared to ambient light [168]. A positive influence of blue radiation was also observed in non-heading Chinese cabbage seedlings, where the concentration of ascorbate was highest under blue/red mixed irradiation (11.1/88.9 ratio) followed by $100 \%$ blue lightening [169].

Irradiation of the juice sacs of Satsuma mandarin (Citrus unshiu Marc.), Valencia orange (C. sinensis Osbeck), and Lisbon lemon (C. limon Burm. f.) with blue LEDs (470 nm) was effective in increasing the ascorbate content in comparison to the dark- and red-light exposed samples after both 2 and 4 weeks of treatment [177]. Interestingly, continuous lightening was more effective than pulsed irradiation in all three species. Moreover, postharvest blue light irradiation $\left(470 \mathrm{~nm}, 40 \mu \mathrm{mol} \mathrm{m} \mathrm{m}^{-2} \mathrm{~s}^{-1}\right)$ promoted higher accumulation of vitamin C in strawberry fruits in comparison to dark-stored fruits [174].

A positive influence of blue radiation $\left(470 \mathrm{~nm}, 16 \mathrm{~h}\right.$ photoperiod, $50 \mu \mathrm{mol} \mathrm{m} \mathrm{m}^{-2} \mathrm{~s}^{-1}$ for 14 days) on glucosinolates was detected in canola (Brassica napus L.) sprouts [178]. Although the total content did not differ among sprouts grown under blue, red, or white light, some specific individual glucosinolates were highly accumulated following blue irradiation. Specifically, these sprouts contained the highest levels of glucoraphanin, and shared the primacy with white light-grown sprouts relative to glucoalyssin and gluconapin, and with red light-grown sprouts relative to progoitrin and neoglucobrassicin. Conversely, blue light led to the lowest levels of sinigrin and glucobrassicin. Park et al. [179] investigated the influence of blue light $\left(450 \mathrm{~nm}, 16 \mathrm{~h}\right.$ photoperiod, $\left.90 \mu \mathrm{mol} \mathrm{m}{ }^{-2} \mathrm{~s}^{-1}\right)$ on glucosinolate content of Brassica juncea sprouts cultivated for up to 3 weeks. Sprouts grown under blue radiation had the lowest content of total glucosinolates, independently on the growth period $(1,2$, or 3 weeks). Only glucoiberin and gluconasturtiin were unchanged as compared to both red and white light treatments, while, generally, the other specific molecules were less concentrated. A species-specific, as well as a structure-dependent influence of blue radiation on these bioactive molecules, is evident. 


\section{UV-A Radiation}

The physiological and biochemical effects of UV-A radiation are strictly dependent on both the plant species and the UV-A dose. Endemic plants (and crops) from high altitude areas and/or low latitude regions are well acclimated to high UV (-A and -B) condition and, therefore, care must be given when establishing the UV dose needed to stimulate their secondary metabolism further. Table 4 lists some main biochemical responses observed in different plant species or cultivars subjected to UV-A irradiation, as detailed in the following paragraph.

\subsection{Phenolics}

Like blue light, most relevant researches carried out by supplying or depriving the plants of UV-A observed a general positive effect of this radiation in stimulating the accumulation of health-promoting flavonoids in many species. Irradiation of a red- and a green-leaf cultivar of pak choi with 12-h daily UV-A $\left(380 \mathrm{~nm}, 100 \mu \mathrm{mol} \mathrm{m}{ }^{-2} \mathrm{~s}^{-1}\right.$, LEDs lighting sources) for 10 days resulted in increased content of total phenolics, flavonoids, and anthocyanins in the red cultivar, whereas only anthocyanins were enhanced in the green cultivar [183]. However, when UV-A wavelength was $400 \mathrm{~nm}$, the green leaf variety positively responded in terms of total phenolics and flavonoids. Moreover, antioxidant capacity of both cultivars significantly increased regardless the UV-A wavelength used [183]. The discrepancy of responses in terms of phenolics and flavonoids is most likely due to the genetic predisposition of the red cultivar, over the green cultivar, to naturally synthesize and accumulate phenolic compounds in the leaves.

Positive effect of UV-A exposure $\left(320-400 \mathrm{~nm}, 3.0 \mathrm{~W} \mathrm{~m}^{-2}, 24 \mathrm{~h}\right.$, fluorescent lamp as lighting source) in enhancing the anthocyanin content was observed also in turnip seedlings (Brassica rapa subsp. rapa, cv. Tsuda) [184]. Another work on 7-day-old broccoli sprouts (Brassica oleracea L., var. italica, cv. Waltham 29) exposed for 120 min to either 3.16 (low dose) or 4.05 (high dose) $\mathrm{W} \mathrm{m}^{-2} \mathrm{UV}$-A radiation (UV-A lamp as lighting source) found structure-dependent responses among the 22 phenolic compounds identified [164]. Moreover, the low dose of UV-A was more effective than the high dose in stimulating the phenolics accumulation, particularly gallic acid hexoside, 4-O-caffeoylquinic acid, gallic acid derivative, and 1-sinapoyl-2,2-diferulolyl-gentiobiose, when plants were harvested $2 \mathrm{~h}$ after the UV treatment [185]. Another study on a different cultivar of broccoli (cv. Monopoly) exposed to two different UV-A conditions (365 nm, $61 \pm 3 \mu \mathrm{mol} \mathrm{m}^{-2} \mathrm{~s}^{-1}$; $385 \mathrm{~nm}, 15 \pm 3 \mu \mathrm{mol} \mathrm{m}{ }^{-2} \mathrm{~s}^{-1}$, LEDs lighting sources) found that the shortest UV-A wavelength $(365 \mathrm{~nm})$ induced a significant reduction of all the hydroxycinnamic acids identified, while the $385 \mathrm{~nm}$ UV-A irradiation had no effect [186]. Moreover, the $365 \mathrm{~nm}$ UV-A exposure determined a structure-dependent response by quercetin and kaempferol glycosides since several of them decreased, while others were unaffected by the treatment. Contrarily, the longest UV-A wavelength did not induce almost any variation in the level of these compounds [186]. Such a specificity of response by the individual flavonoids was observed also in Brussels sprout plants (B. oleracea var. gemmifera DC) exposed to $\mathrm{UV}-\mathrm{A}$ radiation $(365 \mathrm{~nm})$, that underwent a decrease in the concentrations of sinapic acid acylated kaempferol tri- and tetraglycosides, while kaempferol-3-O-disinapoyl-triglucoside7-diglucoside accumulated at higher level than in control samples [187]. 
Table 4. Biochemical responses of crops and plants of food interest to UV-A wavelengths considered in this review. Tot, total phenolics; Flav, flavonoids; Ant, anthocyanins; AC, antioxidant capacity; T, terpenoids; AA, ascorbic acid; TP, tocopherols; GSL, glucosinolates. For each plant species and cultivar, and for each secondary metabolite or metabolic class considered, the symbols " $\downarrow$ ", " $\uparrow "$ and "=" mean a decrease, increase or no variations, respectively, compared to the control plants of each study.

\begin{tabular}{|c|c|c|c|c|c|c|c|c|c|c|}
\hline \multirow{2}{*}{ Species } & \multirow{2}{*}{ Cultivar } & \multicolumn{3}{|c|}{ Phenolics } & \multirow{2}{*}{$\mathrm{AC}$} & \multirow{2}{*}{$\mathrm{T}$} & \multirow{2}{*}{ AA } & \multirow{2}{*}{ TP } & \multirow{2}{*}{ GSL } & \multirow{2}{*}{ Ref. } \\
\hline & & Tot & Flav & Ant & & & & & & \\
\hline \multirow{2}{*}{$\begin{array}{l}\text { Pak-choi (Brassica rapa ssp. chinensis } \\
\text { var. communis) }\end{array}$} & Red leaf cv. & $\uparrow /=$ & $\uparrow$ & $\uparrow$ & $\uparrow$ & $\uparrow /=$ & $\uparrow / \downarrow$ & $\uparrow$ & $\uparrow$ & \multirow{2}{*}[183,188]{} \\
\hline & Green leaf cv. & $\uparrow /=$ & $\uparrow /=$ & $\uparrow$ & $\uparrow$ & $=$ & $\downarrow$ & & $\uparrow$ & \\
\hline Turnip (Brassica rapa subsp. rapa) & Tsuda & & & $\uparrow$ & & & & & & [184] \\
\hline \multirow{2}{*}{ Broccoli (Brassica oleracea L., var. italica) } & Waltham 29 & $=/ \downarrow$ & & & & & & & $=/ \downarrow$ & [185] \\
\hline & Monopoly & $=/ \downarrow$ & & & & & & & $=$ & {$[186]$} \\
\hline $\begin{array}{l}\text { Broccoli (Brassica oleracea L., var. } \\
\text { gemmifera DC) }\end{array}$ & & $\uparrow / \downarrow$ & & & & & & & $\uparrow /=$ & {$[187]$} \\
\hline \multirow{6}{*}{ Lettuce (Lactuca sativa. L.) } & Yanzhi & $=$ & $\uparrow$ & $\uparrow$ & $\uparrow$ & $\downarrow$ & $\uparrow$ & & & \multirow{2}{*}{ [189] } \\
\hline & Red butter & $\uparrow$ & $\uparrow$ & $\uparrow$ & $=$ & $\downarrow$ & $\uparrow$ & & & \\
\hline & Klee & $\uparrow /=$ & $\uparrow /=$ & $\uparrow$ & & & $\uparrow$ & & & [190] \\
\hline & Red leaf cvs. & & & & & $=$ & & & & [1011] \\
\hline & Green leaf cvs. & & & & & $=$ & & & & [191] \\
\hline & Hongyeom & $\uparrow /=$ & & $\uparrow /=$ & $\uparrow /=$ & & & & & [192] \\
\hline \multirow{4}{*}{ Tomato plant (Solanum lycopersicum L.) } & Oxheart & $\downarrow$ & & $=$ & $=$ & $=$ & & & & \multirow{3}{*}[193]{} \\
\hline & Cherry & $=$ & & $\downarrow$ & $\downarrow$ & $\downarrow /=$ & & & & \\
\hline & Roma & $=$ & & $=$ & $\downarrow$ & $\uparrow /=$ & & & & \\
\hline & MicroTom & & & $\uparrow$ & & & & & & {$[194]$} \\
\hline \multirow{4}{*}{ Tomato fruit (Solanum lycopersicum L.) } & Budenovka & $\uparrow$ & $\uparrow$ & & & $\uparrow /=$ & & & & \multirow{3}{*}{ [195] } \\
\hline & Bull Heart & $\uparrow$ & $\uparrow$ & & & $\uparrow /=$ & & & & \\
\hline & Gina & $\uparrow$ & $\uparrow$ & & & $\uparrow /=$ & & & & \\
\hline & Micro-Tom & & & $\uparrow$ & & & & & & {$[194]$} \\
\hline Sowthistle (Ixeris dentata Nakai) & & $\uparrow /=$ & $\uparrow /=$ & & $\uparrow /=$ & & & & & [196] \\
\hline Grape berry (Vitis vinifera L.) & $\begin{array}{l}\text { Cabernet } \\
\text { Sauvignon }\end{array}$ & & $\uparrow$ & & & & & & & [197] \\
\hline Blueberry (Vaccinium corymbosum L.) & Duke & $\downarrow$ & & $=$ & & & & & & [198] \\
\hline \multirow{2}{*}{ Peach fruit (Prunus persica L. Batsch) } & Hujingmilu & & & $\uparrow$ & & & & & & \multirow{2}{*}{ [199] } \\
\hline & Yulu & & & $=$ & & & & & & \\
\hline Basil (Ocimum basilicum L.) & Genovese & $\uparrow /=$ & & & & $\uparrow$ & $\downarrow$ & $\uparrow / \downarrow$ & & {$[188,200-203]$} \\
\hline Beet (Beta vulgaris L.) & Bulls Blood & & & & & & $\uparrow / \downarrow$ & $\uparrow$ & & [188] \\
\hline \multirow{3}{*}{ Rice (Oryza sativa L.) } & Kanchana & $\uparrow$ & & & & $\uparrow$ & & & & \multirow{3}{*}{ [204] } \\
\hline & Mattatriveni & & & & & $\downarrow /=$ & & & & \\
\hline & Harsha & & & & & $\uparrow /=$ & & & & \\
\hline Broccoli (Brassica oleracea L. var. italica) & Waltham 29 & $=$ & & & & & & & $\uparrow$ & [205] \\
\hline Wheat (Triticum aestivum L.) & Sumai188 & $\uparrow$ & & & & & & & & [206] \\
\hline Mung bean (Vigna radiata) & & $\uparrow / \downarrow$ & $\uparrow$ & & & & $\uparrow$ & & & [207] \\
\hline Peppermint (Mentha piperita L.) & Rubescens & $\uparrow$ & & & & $\uparrow / \downarrow$ & & & & [208] \\
\hline
\end{tabular}


A comparative study on two lettuce cultivars (cvs. Yanzhi and Red butter) irradiated with UV-A (380 $\pm 10 \mathrm{~nm}, 10 \mu \mathrm{mol} \mathrm{m} \mathrm{m}^{-2} \mathrm{~s}^{-1}$, LEDs lighting sources) found that the treatment positively affected the content of total polyphenols, flavonoids, and anthocyanins, increasing the antioxidant activity (using the 2,2-diphenyl-1-picrylhydrazyl (DPPH) assay) in Yanzhi cultivar, leading to a higher nutraceutical value of the UV-A-treated plants [189]. The same positive results were also obtained in the red-leaf lettuce cv. Hongyeom irradiated for 7 days continuously (352 nm, 3.7 $\mathrm{W} \mathrm{m}^{-2}$, fluorescent lamp as lighting source) in enhancing the anthocyanin content (fluorescent lamps as a lighting source was observed) that underwent a transient enhancement of total phenolic and anthocyanin concentration, as well as antioxidant capacity, within the first 2-3 days of treatment [192]. Other research carried out on lettuce (cv. Klee) treated with three different UV-A doses (365 nm; 10, 20, $30 \mu \mathrm{mol} \mathrm{m} \mathrm{m}^{-2} \mathrm{~s}^{-1}$, LEDs lighting sources) confirmed the positive influence of UV-A radiation on phenolic compounds and highlighted a dose-response effect. Specifically, the highest dose was effective in enhancing the total phenolic, flavonoid, and anthocyanin content, the intermediate dose increased the total flavonoid and phenolic content, while the lowest dose stimulated only the accumulation of anthocyanins [190], suggesting the high sensitivity of this flavonoid class to UV-A radiation.

In contrast to the results above, treating tomato seedlings of three different cultivars (Solanum lycopersicum L., cvs. Oxheart, Cherry, and Roma) with 2 h daily of UV-A (368 nm, $0.45 \mathrm{~W} \mathrm{~m}^{-2}$, UV-A blacklight lamps as lighting source) resulted in decreasing the anthocyanin content in cv. Cherry, while no changes were observed for the other two cultivars [193]. In addition, total phenolic content was not affected by the treatment in cvs. Roma and Cherry, whereas a decrease was observed in cv. Oxheart, while antioxidant activity decreased in cvs. Cherry and Roma. Contrasting results were obtained irradiating tomato seedlings (Solanum lycopersicum L. cv. MicroTom) with 24-h UV-A (365 nm, $7 \mathrm{~W} \mathrm{~m}^{-2}$, fluorescent tubes as lighting sources) [194]. Indeed, a significant accumulation of anthocyanins were observed whether both the seedlings were exposed to only UV-A or a combination of visible light + UV-A. Moreover, such significant anthocyanin accumulation started from 1-h irradiation in the cotyledon, and started from $3 \mathrm{~h}$ in the hypocotyl, reaching the maximum level after $12 \mathrm{~h}$ of UV-A exposure. In sowthistle plants (Ixeris dentata Nakai), a 7-day, 24-h continuously UV-A exposure (352 nm, no UV-A dose specified, fluorescent tubes as lighting source) determined a transient increase in phenolics concentration and antioxidant activity after 3 days from the beginning, together with a transient increase in flavonoid content after 5 days [196].

Some research on the influence played by UV-A on fruit phenolics were also published. Generally, the effect was positive, leading to higher accumulation of total phenolics and flavonoids in irradiated fruits, though with differences ascribable to genotype and wavelength. Specifically, three tomato cvs (Budenovka, Bull Heart, and Gina) irradiated at the red ripe stage with UV-A lamps emitting 353, 365, and $400 \mathrm{~nm}$ (irradiance 0.33, 0.28 and $0.28 \mathrm{~W} \mathrm{~m}^{-2}$, respectively) for 10,180 , or $360 \mathrm{~min}$ showed an increased concentration of phenolics and flavonoids, starting from $180 \mathrm{~min}$ of irradiation and reaching the maximum levels at the highest exposure time. Independently from the duration of the treatment, irradiation with $365 \mathrm{~nm}$ induced the highest phenolic and flavonoid accumulation in all the cvs, while some differences among the cvs were observed in the phenolic reaction to the other wavelengths. However, after $360 \mathrm{~min}$ of irradiation, no difference among the three wavelengths was detected, with the only exception of flavonoid content of cv. Budenovka, which was unchanged following the irradiation with the shortest wavelength [195]. Grape berries (Vitis vinifera L. cv. Cabernet Sauvignon) harvested at different developmental stages and exposed to UV-A radiation for $20 \mathrm{~min}$ (total dose of $1.8 \mathrm{~kJ} \mathrm{~m}^{-2}$, corresponding to $1.5 \mathrm{~W} \mathrm{~m}^{-2}$ ) accumulated higher flavan-3-ols than control and showed increased transcription of three biosynthetic genes [197]. Increased anthocyanin accumulation was observed in the peel of the peach (Prunus persica L. Batsch) cv. Hujingmilu, but not in cv. Yulu, irradiated in post-harvest with UV-A $\left(315-400 \mathrm{~nm}, 10 \mathrm{~W} \mathrm{~m}^{-2}\right)$ for 2 days before turning stage. Such an accumulation (four-fold higher than in control) was accompanied by 
an evident reddening of the fruit peel [199]. Similarly, UV-A irradiation ( $365 \mathrm{~nm}, 7 \mathrm{~W} \mathrm{~m}^{-2}$ ) of tomato fruits (cv Micro-Tom) was successful in promoting a significant increment in anthocyanin content, which reached a maximum after $6 \mathrm{~h}$ of irradiation [194]. However, post-harvest irradiation of blueberries (Vaccinium corymbosum L.) with $10 \mathrm{~W} \mathrm{~m}^{-2} \mathrm{UV}-\mathrm{A}$ $\left(\lambda_{\max } 352 \mathrm{~nm}\right.$ ) for $10 \mathrm{~min}$ on the top and $10 \mathrm{~min}$ on the bottom side of the fruits did not induce any increase in anthocyanin accumulation during the 28-day storage period, and even led to a slight transient decrease of total phenolic content [198]. Despite UV-A was generally found to play a positive influence on phenolic biosynthesis, interaction among genotype, radiation wavelength, and duration of exposure is ultimately responsible of the observed response. Therefore, establishing the most adequate irradiation protocol for any specific species or cultivar is mandatory to obtain the desired improvement of the nutritional quality.

\subsection{Terpenoids and Chlorophylls}

While influence of visible light on carotenoids is expected, due to their spectrum of absorbance, the impact of UV radiation on these compounds is less obvious. Similar to what reported for blue light, UV-A seems to affect carotenoids in a very variable way, depending on specific compound, plant species, organ, UV-A wavelength, and dose. However, the few examples reported below suggest that UV-A is not so efficient in inducing carotenoid overproduction. Such a positive result was observed only with long UV-A wavelengths $(400 \mathrm{~nm})$, at the border with blue portion of the solar spectrum. Indeed, in pak choi plants, the red-leaf cultivar underwent a significant increase in carotenoid content when irradiated with $400 \mathrm{~nm}$ UV-A (100 $\mu \mathrm{mol} \mathrm{m}{ }^{-2} \mathrm{~s}^{-1}$, LEDs lighting sources), but not with $380 \mathrm{~nm}$ UV-A at the same irradiance. Moreover, no variations were observed in the green cultivar for any of the UV-A wavelength considered [183].

Two research studies were recently published, reporting different effects induced by UV-A radiation on lettuce carotenoids. Specifically, UV-A treatment $(380 \pm 10 \mathrm{~nm}$, $10 \mu \mathrm{mol} \mathrm{m}{ }^{-2} \mathrm{~s}^{-1}$, LEDs lighting sources) led to a significant decrease in carotenoid content in cvs. Yanzhi and Red butter [189]. Contrarily, another lettuce cultivar (cv. Klee) exposed to three different UV-A doses ( $365 \mathrm{~nm} ; 10,20,30 \mu \mathrm{mol} \mathrm{m}^{-2} \mathrm{~s}^{-1}$, LEDs lighting sources), did not show any variation in terms of total carotenoid content [190]. Because of the different wavelengths used in the two experiments, the behaviour exhibited by the three cultivars cannot be univocally attributed to genotype. This is a common problem found when comparing results obtained by applying different irradiation protocols.

A comprehensive study on eight red lettuce varieties (cvs.: Black Jack, Galactic, Impuls, Dark Lollo Rossa, New Red Fire, Rave, Red Sails, and Vulcan) and eight green lettuce varieties (cvs.: Black-Seeded Simpson, Concept, Crisp and Green, Envy, Marin, Simpson Elite, Two Star, and Waldmann's Dark Green) exposed to supplemental UV-A radiation (320-400 nm) clearly showed that no variety, regardless of the leaf colours, was affected by the treatment [191]. Unfortunately, however, due to the lack of information on the UV-A exposure conditions, it is impossible to state whether the undetected changes in carotenoid accumulation were due to an insufficient UV-A irradiation or other reasons.

A confirmation of the incapacity of UV-A to increase the leaf carotenoid content derives from a study carried out by exposing seedlings of three tomato cultivars (Solanum lycopersicum L., cvs. Oxheart, Cherry, and Roma) to UV-A radiation ( $2 \mathrm{~h}$ daily treatment, $368 \mathrm{~nm}$, $0.45 \mathrm{~W} \mathrm{~m}^{-2}$, UV-A blacklight lamps as lighting source). In fact, carotenoids concentration was unaffected in cv. Oxheart and Roma and even decreased in cv. Cherry [193]. This work also clearly underlines the diversity of response towards UV-A radiation within the same species, but among different cultivars.

Differently, in tomato fruits, UV-A irradiation for $360 \mathrm{~min}$ with 365 and $400 \mathrm{~nm}$ led to a significant increase in total carotenoids level in all the three cvs. studied (Budenovka, Bull Heart, and Gina). However, $353 \mathrm{~nm}$ was never effective in inducing modification in carotenoid content, while $365 \mathrm{~nm}$ played a positive influence on carotenoid levels already after 10 min of irradiation, but only in cv Budenovka [195], again indicating the importance 
of both light energy and genotype in determining the outcome. The same authors also found a structure-dependent response to the three UV-A radiations employed in their research. Indeed, for any cultivar, while $\beta$-carotene, lycopene, lutein increased starting from $180 \mathrm{~min}$ of irradiation with $365 \mathrm{~nm}$, after $360 \mathrm{~min}$ of irradiation the longest wavelength was effective only for $\beta$-carotene and lutein.

UV-A radiation had an impact also on chlorophylls, as observed in two lettuce cultivars (Yanzhi and Red butter) exposed to $10 \mu \mathrm{mol} \mathrm{m}^{-2} \mathrm{~s}^{-1}$ (380 nm) that exhibited an increased content of these pigments [189]. However, no change in chlorophyll $a+b$ concentration was reported in cv. Klee following irradiation with three different UV-A doses $(365 \mathrm{~nm}$; $10,20,30 \mu \mathrm{mol} \mathrm{m}^{-2} \mathrm{~s}^{-1}$ [190]. Similarly, UV-A-dependent accumulation of chlorophylls was induced in the tomato cv. Roma, but not in cv. Oxheart and cv. Cherry, following $2 \mathrm{~h}$ daily irradiation with $368 \mathrm{~nm}\left(0.45 \mathrm{~W} \mathrm{~m}^{-2}\right)$ [193], due to the different responsiveness to this radiation linked to genotype.

A study carried out in fruits of three tomato cultivars (Budenovka, Bull Heart, and Gina) highlighted the dependence of chlorophyll accumulation on UV-A wavelength. Indeed, 180- and 360-min treatment with $365 \mathrm{~nm}$ increased chlorophyll concentration in all cultivars, while the highest wavelength induced a positive effect only after 360-min exposure and only for two of the three cultivars, while $353 \mathrm{~nm}$ was always ineffective [195]. A similar finding was also reported by Brazaityte et al. [188] in red pak choi seedlings grown under supplemental UV-A radiation $(366,390$, or $402 \mathrm{~nm}$, the latter already falling into the blue region of the spectrum) given at two different doses ( 6.2 or $12.4 \mu \mathrm{mol} \mathrm{m}{ }^{-2} \mathrm{~s}^{-1}$ ). An increased chlorophyll accumulation was in fact observed after irradiation with any of the three wavelengths at the lowest dose, but only with $390 \mathrm{~nm}$ at the highest one.

\subsection{Other Secondary Metabolites}

Effects of UV-A on different classes of metabolites is highly variable in relation to the treatment condition and crop species. The content of $\alpha$-tocopherol increased in fact in microgreens of beet (Beta vulgaris L., cv. Bulls Blood) and red pak choi (cv. Rubi) grown under $12.4 \mu \mathrm{mol} \mathrm{m}{ }^{-2} \mathrm{~s}^{-1}$ supplemental UV-A radiation $(366,390$, or $402 \mathrm{~nm}$, the latter wavelength indicated by the authors as UV-A, though it should be considered already as blue radiation). However, in basil (cv. Sweet Genovese) microgreens, only the shortest wavelength had a positive effect, while the other two led to a reduced $\alpha$-tocopherol content [188]. Moreover, irradiation with $6.2 \mu \mathrm{mol} \mathrm{m}{ }^{-2} \mathrm{~s}^{-1} \mathrm{UV}-\mathrm{A}$ at any wavelength resulted in a significant decrement of $\alpha$-tocopherol content, except in pak choi under supplemental 390 or $402 \mathrm{~nm}$ irradiance. At the lowest UV-A irradiance, the balance between the stressful potential of the radiation and its capacity to stimulate the biosynthetic pathway was, perhaps, unbalanced towards the former.

In the same experiment, a variable influence of UV-A radiation on ascorbic acid was observed, depending on plant species, wavelength, and irradiance level. For example, in basil, the treatment with $366 \mathrm{~nm}$ always had a negative outcome, in pak choi-a positive influence, while in beet seedlings, this radiation increased or decreased the level of ascorbic acid when given at the highest or the lowest dose, respectively [188]. When considering lettuce (cvs. Yanzhi and Red butter), irradiation with UV-A (380 $\pm 10 \mathrm{~nm}, 10 \mu \mathrm{mol} \mathrm{m}^{-2} \mathrm{~s}^{-1}$, LEDs lighting sources), resulted in remarkably increasing the vitamin C content in both the cultivar considered [189]. This effect is also confirmed in another lettuce cultivar (Klee), where all three UV-A doses tested $\left(365 \mathrm{~nm} ; 10,20,30 \mu \mathrm{mol} \mathrm{m}^{-2} \mathrm{~s}^{-1}\right.$, LEDs lighting sources) were effective in significantly enhancing the ascorbic acid content [190]. Conversely, when irradiated with 380 and $400 \mathrm{~nm}$ UV-A (100 $\mu \mathrm{mol} \mathrm{m}^{-2} \mathrm{~s}^{-1}$, LEDs lighting sources), both green and red cultivars of pak choi underwent a depletion of vitamin C concentration [183].

However, the same treatments led to increased accumulation of glucosinolates, another class of secondary metabolites found to be sensitive to UV-A irradiation. The influence of UV-A on glucosinolates depended on the irradiance level, as reported in a study on broccoli sprouts (cv. Waltham 29), where a low irradiation (3.16 $\mathrm{W} \mathrm{m}^{-2}$, UV-A lamp as lighting source) determined a decrease in glucoiberin, glucoraphanin, and 4-hydroxy- 
glucobrassicin, while a high irradiation $\left(4.05 \mathrm{~W} \mathrm{~m}^{-2}\right)$ was effective in increasing these glucosinolates, as well as glucoerucin, glucobrassicin, and 4-methoxy-glucobrassicin compared to the control, when plants were sampled $2 \mathrm{~h}$ after the treatment [185]. Moreover, the authors showed the concentration of several glucosinolates changed if plants were sampled $24 \mathrm{~h}$ after the irradiation. A difference response in glucosinolates content was observed in another broccoli cultivar (cv. Monopoly) subjected to two UV-A treatments (365 nm, $61 \pm 3 \mu \mathrm{mol} \mathrm{m}^{-2} \mathrm{~s}^{-1} ; 385 \mathrm{~nm}, 15 \pm 3 \mu \mathrm{mol} \mathrm{m}{ }^{-2} \mathrm{~s}^{-1}$, LEDs lighting sources) [186]. Indeed, both the aliphatic and the indolic glucosinolate were unaffected by UV-A, except 4-methoxy3-indolylmethyl, which increased after the $365 \mathrm{~nm}$ UV-A irradiation. Acharya et al. [187] observed an increased concentration of total indole, but not aliphatic, glucosinolates, in Brussels sprouts grown with supplemental UV-A radiation $(365 \mathrm{~nm})$. Moreover, within the indole glucosinolates class, some specific compounds were unaffected, indicating a structure-dependent influence of UV-A radiation.

\section{UV-B Radiation}

Similar to the findings reported for the other wavelengths, the influence of UV-B radiation on the content of bioactive compounds in different species and cultivars is variable and often dependent on the dose and metabolite considered. Examples of these specific responses are reported in the following paragraphs and listed in Table 5.

\subsection{Phenolics}

Most current literature on crop plants agree that UV-B exposure, in dependence on the UV-B-dose applied, triggers the biosynthesis of phenolics compounds, particularly flavonoids. This is mainly due to the biochemical properties of these metabolites, being strong reactive oxygen species (ROS) scavengers and UV-B-absorbers, thus acclimating the plant towards ambient UV-B conditions.

UV-B supplementation (290-320 $\mathrm{nm}, 14.4 \mathrm{~kJ} \mathrm{~m}^{-2} \mathrm{~d}^{-1}$, corresponding to $0.17 \mathrm{~W} \mathrm{~m}^{-2}$, broadband UV-B lamp as lighting source) for 4 days was effective at increasing the epidermal flavonoid content of basil plants, both after the treatment and after 7 days of storage. Moreover, concentration of rosmarinic, caffeic, and cichoric acids, catechin derivative, and total hydroxycinnamic acids was higher in leaves of treated plants after the 7-day storage [201]. Another study on basil plants [200] investigated the influence of different UV-B doses $\left(8.5,34,68,102 \mathrm{~kJ} \mathrm{~m}^{-2} \mathrm{~d}^{-1}\right.$, corresponding to $0.1,0.4,0.8$, and $1.18 \mathrm{~W} \mathrm{~m}^{-2}$, respectively, broadband UV-B lamp as lighting source) given as acute (a single UV-B irradiation the first day +3 days of recovery), sub-acute (multiple UV-B irradiations the first day +3 days of recovery), or sub-chronic (a single UV-B irradiations per day for 6 consecutive days +3 days of recovery) treatment on phenolic content. The authors found that the acute and sub-acute exposures resulted in increasing phenolics concentration regardless the UV-B dose, especially after 48 and $72 \mathrm{~h}$ from the beginning of recovery phase, except for the lowest UV-B dose in the sub-acute treatment. The phenolics accumulation found during the recovery period is somehow expected, due to the time needed to induce gene transcription and the following biochemical rearrangements of the biosynthetic machinery. Indeed, when the sub-chronic treatment, lasting 6 days, was applied, the highest doses $\left(34,68\right.$, and $102 \mathrm{~kJ} \mathrm{~m}^{-2} \mathrm{~d}^{-1}$, i.e., $0.4,0.8$, and $1.18 \mathrm{~W} \mathrm{~m}^{-2}$, respectively) also induced a phenolics accumulation regardless the recovery time considered but, contrary to the acute and sub-acute irradiations, the enhanced phenolics level was observed already during the irradiation period.

The influence of genotype, UV-B dose, and chemical structure of the target metabolites was evident in a research carried out on green- and red-leaf lettuce (cv. Salad Bowl) plantlets exposed for two weeks to daily UV-B irradiation $\left(1.69 \mathrm{~W} \mathrm{~m}^{-2}, 1 \mathrm{hr}\right.$ per day, UV-B lamp tubes). In UV-B-treated green plants, quercetin and luteolin glycosides, caffeoyltartaric acid, caffeoylmalic acid and caffeoylquinic acid accumulated at a higher level than in the control lettuce after two weeks of exposure, while only the latter increased after 1 week. The red-leaf lettuce was more responsive to UV-B treatments, showing increased contents 
of quercetin and luteolin glycosides, as well as caffeoyltartaric acid and caffeoylquinic acid already after one week of exposure. The content of the anthocyanin cyanidin-3malonylglucoside, present only in red lettuce, also accumulated at higher levels after both one and two weeks of UV-B treatment. However, caffeoylmalic acid was negatively affected by both UV-B doses [209].

A significant increase in total phenolic content regardless the UV-B-dose applied (7, $14,21,28 \mathrm{~kJ} \mathrm{~m}^{-2} \mathrm{~d}^{-1} \mathrm{UV}_{\mathrm{BE}}$ ) was detected in rice (Oryza sativa L., cv. Kanchana) seedlings grown under supplemental UV-B irradiation for one week continuously $(280-320 \mathrm{~nm}$, $300 \mu \mathrm{mol} \mathrm{m}^{-2} \mathrm{~s}^{-1}$, UV-B lamp as lighting source) [204]. Despite UV-B is frequently reported to stimulate phenolic accumulation, this is not a general rule. One reason could be the structure-dependent influence of this radiation on specific molecules that, leading to an increase of some compounds and to a decrease of some others, ultimately results in an invariance of the total phenolics content. Indeed, 7-day-old broccoli sprouts exposed to 120 min UV-B radiation (7.16 $\mathrm{W} \mathrm{m}^{-2}$, UV-B broadband lamps as lighting source) did not show any significant variation in total phenolic concentration, although some individual phenolic compounds registered either an increase (gallic acid hexoside II) or a decrease (3-O-hexoside kaempferol, 1,2-disinapoyl-2-ferulolylgentiobiose, 5-sinapoylquinic acid, 1,2-diferulolylgentiobiose) [205]. Similarly, in peppermint (Mentha piperita L. $\mathrm{nm}$ rubescens) plants, grown either in open field and in growth chambers, and exposed to 1-h UV-B radiation a few days after full bloom $\left(310 \mathrm{~nm}, 7.1 \mathrm{~kJ} \mathrm{~m}^{-2}\right.$ day $^{-1} \mathrm{UV}_{\mathrm{BE}}$, UV-B broadband lamps as UV-B source), the total phenolic content increased regardless the growing condition, but with differences in the individual phenolic response [208]. Such a specificity of response by different molecules was observed also in chili pepper (Capsicum annuum, cv. Coronel) plants exposed to 4-h-daily supplemental UV-B radiation $\left(80 \mathrm{~mW} \mathrm{~m}^{-2}, \mathrm{UV}-\mathrm{B}\right.$ broadband lamps as lighting source), which underwent an increase in the content of chlorogenic acid, luteolin 8-C-hexoside, and apigenin 8-C-hexoside both after 7 and 14 days of treatment, while apigenin 6-C-pentoside-8-C-hexoside accumulated only after 14 days of UV-B exposure [210].

Other examples of the complexity of the phenolic response to UV-B radiation are present in literature. For example, the positive effect of UV-B in wheat seedlings depended on the moment and the duration of application of UV-B irradiation $\left(0.1 \mathrm{~W} \mathrm{~m}^{-2}, \mathrm{UV}-\mathrm{B}\right.$ lamps as lighting source) after the seeds germination [206]. A heterogeneity of response in relation to the UV-B dose applied $\left(0.205 \mathrm{~W} \mathrm{~m}^{-2}\right.$, from $0.5 \mathrm{~h}$ to $3.5 \mathrm{~h}$, UV-B lamps as lighting source) was observed in mung bean (Vigna radiata) sprouts. Indeed, the shortest irradiation periods induced a decrease in phenolic content, which contrarily increased over the control level following 2.5-h exposure. However, flavonoid content increased regardless the UV-B dose [207].

One of the most evident effects of UV-B on phenolics compounds is the positive influence played on anthocyanins biosynthesis, which leads to enhanced pigmentation of both leafy vegetables and fruits. A bright and intense colour is perceived by consumers as a marker of quality and freshness of the products, and therefore, it orientates food preference and acceptability. Zhao et al. [199] reported a successful increase in cyanidin3-glucoside levels, accompanied by a reddenish, in the peel of peach fruits subjected to UVB (280-315 nm, $\left.0.58 \mathrm{~W} \mathrm{~m}^{-2}\right)$ irradiation for 2 days. This response was more evident in cv. Yulu than in cv. Hujingmilu, the latter also being responsive to UV-A radiation. Anthocyanin accumulation was paralleled by a coordinated upregulation of genes involved in anthocyanin biosynthesis. 
Table 5. Biochemical responses of crops and plants of food interest to UV-B wavelengths considered in this review. Tot, total phenolics; Flav, flavonoids; Ant, anthocyanins; AC, antioxidant capacity; T, terpenoids; AA, ascorbic acid; TP, tocopherols; GSL, glucosinolates. For each plant species and cultivar, and for each secondary metabolite or metabolic class considered, the symbols " $\downarrow$ ", " $\uparrow "$ and "=" mean a decrease, increase or no variations, respectively, compared to the control plants of each study.

\begin{tabular}{|c|c|c|c|c|c|c|c|c|c|c|}
\hline \multirow{2}{*}{ Species } & \multirow{2}{*}{ Cultivar } & \multicolumn{3}{|c|}{ Phenolics } & \multirow{2}{*}{ AC } & \multirow{2}{*}{$T$} & \multirow{2}{*}{ AA } & \multirow{2}{*}{ TP } & \multirow{2}{*}{ GSL } & \multirow{2}{*}{ Ref. } \\
\hline & & Tot & Flav & Ant & & & & & & \\
\hline \multirow{2}{*}{ Basil (Ocimum basilicum L.) } & Genovese & $\uparrow /=$ & & & & $\uparrow /=$ & & & & [200-203] \\
\hline & Cinnamon & & & & & $\uparrow / \downarrow$ & \multicolumn{2}{|c|}{$\uparrow /=/ \downarrow$} & & [211] \\
\hline \multirow{3}{*}{ Rice (Oryza sativa L.) } & Kanchana & $\uparrow$ & & & & $\uparrow$ & & & & \multirow{3}{*}{ [204] } \\
\hline & Mattatriveni & & & & & $\downarrow /=$ & & & & \\
\hline & Harsha & & & & & $\uparrow /=$ & & & & \\
\hline Broccoli (Brassica oleracea L. var. italica) & Waltham 29 & $=$ & & & & $\uparrow /=$ & & & $\uparrow$ & {$[185,205,212]$} \\
\hline $\begin{array}{l}\text { Broccoli (Brassica oleracea var. } \\
\text { gemmifera DC) }\end{array}$ & & & & & & & & & $=$ & [187] \\
\hline Wheat (Triticum aestivum L.) & Sumai188 & $\uparrow$ & & & & & & & & [206] \\
\hline Mung bean (Vigna radiata) & & $\uparrow / \downarrow$ & $\uparrow$ & & & & $\uparrow$ & & & [207] \\
\hline Peppermint (Mentha piperita L.) & Rubescens & $\uparrow$ & & & & $\uparrow / \downarrow$ & & & & [208] \\
\hline \multirow{2}{*}{ Lettuce (Lactuca sativa. L.) } & Red leaf cvs. & $\uparrow$ & $\uparrow$ & $\uparrow$ & & $\downarrow$ & & & & \multirow{2}{*}[191,209]{} \\
\hline & Green leaf cvs. & $\uparrow$ & $\uparrow$ & & & $\uparrow$ & & & & \\
\hline \multirow{6}{*}{ Peach fruit (Prunus persica L.) } & Suncrest & $\uparrow /=1$ & & $\downarrow / \uparrow$ & & & $=/ \downarrow$ & & & \multirow{3}{*}[213,214]{} \\
\hline & Big Top & $\uparrow /=$ & $\downarrow \downarrow / \uparrow$ & $\uparrow$ & & & & & & \\
\hline & Babygold 7 & $\downarrow$ & $\downarrow / \uparrow$ & $=$ & & & & & & \\
\hline & Fairtime & $\downarrow / \uparrow$ & $\downarrow / \uparrow$ & $\downarrow / \uparrow$ & & $\downarrow$ & & & & {$[215,216]$} \\
\hline & Yulu & & & $\uparrow$ & & & & & & \multirow{2}{*}{ [199] } \\
\hline & Hujingmilu & & & $\uparrow$ & & & & & & \\
\hline \multirow{2}{*}{ Tomato fruit (Solanum lycopersicum L.) } & Money Maker & & & & & $\uparrow$ & $\uparrow$ & & & {$[217,218]$} \\
\hline & Zhenfen 202 & & & & & & $\downarrow$ & & & [219] \\
\hline Bell pepper fruit (Capsicum annum L.) & Angus & & & & & $\uparrow$ & & & & [220] \\
\hline Green lime fruit (Citrus latifolia Tan.) & & & & & & $\uparrow$ & & & & [221] \\
\hline Spinach (Spinacia oleracea L.) & Meridian & & & & & & & $\uparrow$ & & [222] \\
\hline Maize (Zea mays L.) & & & & & & & & $\downarrow$ & & [223] \\
\hline Cucumber (Cucumis sativus L.) & Long green & & & & & & & $\downarrow$ & & [224] \\
\hline Apple fruit (Malus domestica Borkh.) & Aroma & & & & & & $\uparrow$ & & & [225] \\
\hline
\end{tabular}

Another study carried out on post-harvest peach (cvs. Suncrest and Babygold 7) and nectarine (cv. Big Top) fruits treated with $1.69 \mathrm{~W} \mathrm{~m}^{-2}$ UV-B (lamp tubes) for 12, 24, or $36 \mathrm{~h}$ reported a genotype-dependent response to irradiation. Dose- and structure-dependent effects were also observed. Flavonols and hydroxycinnamic acids of Suncrest and Big Top behaved similarly, decreasing or being unaffected following the lowest dose but accumulating at higher concentration after 24- or 36-h irradiation, respectively. Anthocyanins were generally positively influenced by the treatment irrespective of the UV-B dose, except in Suncrest after 12-h treatment. A quite different response was evident in Babygold 7, where phenolics were generally negatively affected by the treatment [213].

The effectiveness of UV-B radiation in promoting phenolics accumulation in the peel of peach (cv. Fairtime) fruits was confirmed by Santin et al. [216] by exposing the fruits to $2.3134 \mathrm{~W} \mathrm{~m}^{-2} \mathrm{UV}-\mathrm{B}$ for 10 or $60 \mathrm{~min}$. The authors observed that most metabolites 
down-accumulated $24 \mathrm{~h}$ after the end of the treatment, attributing this effect to their consumption during detoxification of UVB-induced ROS. However, afterwards, an overall increase occurred, particularly evident for anthocyanins, flavones, and dihydroflavonols. Such an increase was attributed to the increased transcription of gene involved in UV-B signalling and in phenylpropanoid biosynthesis (both structural and regulatory genes) occurring $6 \mathrm{~h}$ after the treatment [215]. Interestingly, despite UV-B radiation being unable to penetrate below the peach peel [226], the content of pulp phenolics also underwent a general increase. Such an effect was particularly intense for flavanols, flavonols, and flavones, and, differently from what was observed in the peel, it occurred $24 \mathrm{~h}$ after the end of the treatment. As in the peel, however, flavonoid biosynthetic and regulatory genes were upregulated by UV-B after $6 \mathrm{~h}$ from the irradiation [227]. This finding is particularly interesting because it demonstrates the capability of UV-B treatments in improving the nutraceutical properties of peach pulp —-that is the only part usually consumed due to the custom of peeling the fruit.

\subsection{Terpenoids and Chlorophylls}

The studies carried out on the impact of UV-B radiation on terpenoids are less numerous than those dealing with phenolics. However, as described for the other wavelengths in the previous chapters, also UV-B can influence this metabolic class. In broccoli sprouts, exposure to UV-B radiation $\left(7.16 \mathrm{~W} \mathrm{~m}^{-2}\right)$ for $120 \mathrm{~min}$ induced a significant accumulation of lutein and neoxanthin [205]. In the same plant species, however, $\beta$-carotene was unchanged $24 \mathrm{~h}$ after the end of the UV-B irradiation $\left(0.042 \mathrm{Wh} \mathrm{m}^{-2}, 4 \mathrm{~h}\right)$ [212], probably due to the lower dose applied. UV-B supplementation (9 days) during the growth of lettuce plants already receiving UV-A radiation resulted in a different effect in green- or red-leafy cultivars. Specifically, the response was generally positive in the eight green leaf cultivars, except for neoxanthin content of one only cultivar. Conversely, all eight red leaf cultivars underwent a significant depletion of lutein, neoxanthin, and $\beta$-carotene [191].

The capacity of UV-B to affect carotenoid content was also demonstrated in fruits. Tomato fruits (cv Money Maker) harvested at a mature green or turning stage, and allowed to ripen under $1 \mathrm{~h}$ daily UV-B radiation $\left(1.69 \mathrm{~W} \mathrm{~m}^{-2}\right)$, exhibited a higher carotenoid content in the peel, which was independent from the harvesting stage (and therefore from the duration of the treatment) for $\beta$-carotene and lycopene, but not for lutein. Interestingly, lycopene increased also in the fruit flesh. However, the positive effect observed in the peel of cv. Money Maker was not detected in the photomorphogenic $h p-1$ mutant, characterised by a constitutively high pigmentation [217]. Differently, a metabolomic analysis of the peel of peach (cv. Fairtime) fruits treated in post-harvest with $2.3134 \mathrm{~W} \mathrm{~m}^{-2} \mathrm{UV}-\mathrm{B}$ for 10 or $60 \mathrm{~min}$ revealed a decreased concentration of several carotenoids in treated fruits $36 \mathrm{~h}$ after the end of the irradiation. The authors hypothesised a consumption of these molecule to counteract the UV-B-induced ROS formation, which could be followed by a later accumulation due to stimulation of biosynthetic genes, similarly to what detected for phenolics in the same fruits [216]. Consistent with this hypothesis, the same treatment (60 min irradiation), induced an increase of carotenoid concentration in the peach pulp already after $24 \mathrm{~h}$ of recovery, probably because the UV-B radiation, not passing through the outer skin, did not caused ROS production in the flesh beneath [226]. A positive influence of UV-B radiation on carotenoid accumulation was also reported in bell pepper (Capsicum annum L., cv. Angus) fruits, exposed to UV-B radiation $\left(8.94 \mathrm{~W} \mathrm{~m}^{-2}, 19 \mathrm{~min}\right.$ and $30 \mathrm{sec}$ ) 6 days after the harvest, and then kept under different light conditions for up to 4 days to simulate a retail sale period. The carotenoid profile highlighted that such a positive effect was particularly evident when UV-B treatment was followed by storage under fluorescent/blue-red LED day/night photoperiod [220].

A deep understanding on the UV-B-induced modulation of terpenoids represents a crucial aspect especially from an applicative point of view, since the terpenoid class include most volatiles that contribute to the aroma of plants and fruits of food interest. Hence, the consequent modification of organoleptic properties might alter the consumers' attitude 
towards the UV-B-irradiated plant products. A 1-h daily UV-B irradiation (UV-B broadband lamps as lighting source) on basil plants up to 15 days determined a significant increase in essential oil content (whose terpenoids were mainly represented by monoterpenes linalool and 1,8-cineole) both in mature and developing leaves, increasing the aroma of basil plants [202]. Another study on basil, treated with UV-B radiation $\left(2.23 \mathrm{~W} \mathrm{~m}^{-2}, 3 \mathrm{~h}\right.$ per day, UV-B broadband lamps as lighting source) for two weeks, found a significant increase in linalool and 1,8-cineole, although most of the volatile molecules did not vary after the treatment [203]. Similarly, a positive effect of a two-weeks UV-B treatment (UV-B broadband lamps as UV-B source) on basil plants was found considering the predominant essential oil components (e.g., linalool, 1,8-cineole, and trans- $\beta$-ocimene) [228]. UV-B radiation was also able to modulate terpenoid content in peppermint plants grown either in open field or in growth chambers. A 1-h UV-B irradiation $\left(310 \mathrm{~nm}, 7.1 \mathrm{~kJ} \mathrm{~m}^{-2} \mathrm{~d}^{-1} \mathrm{UV}_{\mathrm{BE}}\right.$, UV-B broadband lamps as UV-B source) performed some days before full bloom resulted in modulating the profile of essential oil and particularly the volatile compounds [208], with differences in the trend of response by specific volatiles. Considering the great importance of peppermint essential oil in many applicative aspects (e.g., cosmetic, flavouring, and medicinal), the possibility to alter both quality and quantity of singular constituents by inserting the UV-B radiation during plant growth deserves deeper studies.

Increased chlorophyll $a$ content was observed in broccoli sprouts exposed to UV-B (7.16 $\mathrm{W} \mathrm{m}^{-2}$ ) for $120 \mathrm{~min}$ [205] as well as in green-leaf lettuce cultivars grown in the presence of supplemental UV-B radiation [191]. However, also chlorophyll displayed a genotype-dependent response to this wavelength, as demonstrated by the decrease in its content in the red-leaf cultivars of lettuce [191]. Different results were obtained in basil as well. Indeed, Nascimento et al. [201] did not observe any variation in both chlorophyll $a$ and $b$ content of cv. Genovese cultivated under white light supplemented with $0.5 \mathrm{~W} \mathrm{~m}^{-2}$ UV-B (8 h per day, 4, days, UV lamps). Conversely, cv. Cinnamon exposed to a similar irradiance ( $0.571 \mathrm{~W} \mathrm{~m}^{-2}, 1$ or $2 \mathrm{~h}$ per day, 7 days) accumulated more chlorophylls as compared to control when treated at a juvenile stage (3-4 leaf pair growth), but underwent a chlorophyll depletion when irradiated at the flowering stage [211]. Therefore, genotype differences, but also the plant developmental stage, as well as UV-B dose, may influence the plant capacity to respond to irradiation.

In fruits, UV-B radiation $\left(7.33 \mathrm{~W} \mathrm{~m}^{-2}\right)$ was proven to delay chlorophyll degradation in mature green lime (Citrus latifolia Tan.) fruits when administered for $20 \mathrm{~min}$. The content of both chlorophyll $a$ and $b$ of treated fruits remained stable for up to 30 days of storage, differently from control fruits where both pigments started to decrease after 15 days. Differently, a 30-min exposure induced fruit yellowing [221]. Therefore, if adequately calibrated, UV-B treatments can be a valid method to prevent the loss of marketable quality during storage.

\subsection{Other Secondary Metabolites}

The potential of UV-B radiation to increase the content of health-promoting compounds other than phenolics and terpenoids was also studied, though reports present in literature are still scarce. In particular, to the best of our knowledge, UV-B influence on tocopherols content of fruits and vegetables was not investigated, though an increased accumulation of $\alpha$-tocopherol was detected in thylakoid membranes of spinach (Spinacia oleracea L. 'Meridian') plants irradiated with supplemental UV-B radiation ( $9 \mathrm{~h}$ daily for $12 \mathrm{~d}, 13.5 \mathrm{~kJ} \mathrm{~m}^{-2} \mathrm{~d}^{-1}$ of UV-B $\mathrm{BE}$ ) [222], while in maize (Zea mays L.) seedlings, as well as in cucumber (Cucumis sativus L. cv. Long green) cotyledons, UV-B exposure $\left(8.35 \mathrm{~kJ} \mathrm{~m}^{-2}\right.$ UV-B $B_{B E}$ per day for 9 days, or $0.2 \mathrm{~W} \mathrm{~m}^{-2}$ for $1 \mathrm{~h}$ per day for 3 days, respectively) was found to induce a significant decrease in $\alpha$-tocopherol content $[223,224]$.

UV-B radiation was found to be effective also in modulating ascorbic acid concentration. Mung bean seedlings exposed to eight UV-B exposure times, from 0 to $3.5 \mathrm{~h}$ (0.205 W m $\mathrm{m}^{-2}$, UV-B lamp as UV-B source) showed an enhanced content of ascorbic acid in the 0.5-h, 2-h and 2.5-h treatments [207]. In basil leaf, the UV-B effect depended on plant 
age and radiation dose: in young plants, the lowest dose, but not the highest one, induced an accumulation of ascorbate, while, at the flowering stage, ascorbic acid decreased or increased following the lowest or the highest UV-B dose, respectively [211].

The influence of UV-B on ascorbate content was observed also in peach [214] and tomato [218] fruits. In both cases, such effect was evident not only in the peel, but also in the flesh beneath, although not directly reached by UV-B radiation. In particular, in peach (cv. Suncrest) post-harvest irradiation (1.69 $\left.\mathrm{W} \mathrm{m}^{-2} \mathrm{UV}-\mathrm{B}\right)$ for $12 \mathrm{~h}$ led to a depletion ascorbic acid in both skin and flesh, but it induced an accumulation in the skin when applied for $36 \mathrm{~h}$. However, regardless of the trend of variation, no change in ascorbate redox state occurred following UV-B irradiation [214]. An increased content of ascorbic acid was previously detected also in shade-grown apples (cv. Aroma) peel, but not in the sun-exposed ones, following 10 days of post-harvest treatment with visible light $+0.17 \mathrm{~W} \mathrm{~m}^{-2} \mathrm{UV}-\mathrm{B}$ for $12 \mathrm{~h}$ per day in comparison to dark-stored fruits [225].

A different response attributable to genotype differences was observed in tomato fruits, where UV-B post-harvest treatment $\left(1.69 \mathrm{~W} \mathrm{~m}^{-2}, 1 \mathrm{~h}\right.$ per day until full ripening) induced an increased accumulation in both skin and flesh of Money Maker fruits, irrespective of the harvesting stage (mature green on turning), while in the $h p-1$ mutant an unchanged content was observed in the peel and a slight decrease occurred in the flesh of fruits irradiated at the mature green stage [218]. The genotype-dependence of ascorbate reaction to UV-B radiation is confirmed by the findings of Liu et al. [219] who observed a lower content of this antioxidant compound in UVB-treated tomato (cv. Zhenfen 202) fruits harvested at the MG stage and subjected to irradiation with different UV-B doses. In addition to the genotype effect, the mode of irradiation undoubtedly contributes to different outcomes, as exemplified by the comparison of these last two articles, with the former applying a long-term exposure to low-intensity UV-B, and the latter irradiating the fruits with an acute application at the beginning of the storage period.

Studies were published on the positive effect played by UV-B radiation on glucosinolates. Exposing broccoli sprouts (cv. Waltham 29) to UV-B radiation (280-320 nm, $7.16 \mathrm{~W} \mathrm{~m}^{-2}$, UV-B broadband as lighting source) for $120 \mathrm{~min}$ led to a significant increase in total glucosinolate concentration, and in particular glucoiberin, glucoraphanin, 4-hydroxyglucobrassicin, glucoerucin, glucobrassicin, and 4-methoxy-glucobrassicin [205]. Lower irradiations ( 2.28 and $3.34 \mathrm{~W} \mathrm{~m}^{-2}$ for $120 \mathrm{~min}$ ) were effective as well in increasing both indole and aliphatic glucosinolates of the same cv. of broccoli sprouts, particularly 2 and $24 \mathrm{~h}$ after the end of the irradiation, for the lowest and the highest dose, respectively [185]. Similarly, Mewis et al. [212], always in broccoli sprouts, detected an increase in the content of these metabolites even following a single and low UV-B dose $\left(0.042 \mathrm{Wh} \mathrm{m}^{-2}, 120 \mathrm{~min}\right)$, and did not find a greater accumulation of the aliphatic glucosinolates by applying higher doses or by replicating the single-dose exposure. Moreover, broccoli florets accumulated more glucosinolates in response to UV-B irradiation $\left(20.4 \mathrm{~W} \mathrm{~m}^{-2}\right.$, at the dose of 1.5 and $7.2 \mathrm{~kJ} \mathrm{~m}^{-2}$ ), particularly those belonging to the indole class, such as glucobrassicin. The increased glucosinolate content was accompanied by overexpression of some biosynthetic genes [229].

All of these examples highlight the general positive effect played by UV-B radiation on glucosinolates, with some differences attributable to the irradiation dose. Acharya et al. [187] reported instead on the absence of any variation in both indole and aliphatic classes following irradiation of broccoli sprouts with UV-B LEDs $\left(300 \mathrm{~nm}, 0.03 \mathrm{~kJ} \mathrm{~m}^{-2} \mathrm{~d}^{-1}\right.$, corresponding to $0.35 \mathrm{~mW} \mathrm{~m}^{-2}$ ) and the authors attributed the results to the low efficiency of UV-B LEDs, in respect to the UV-B emitting tubes used in the other experiments.

\section{Conclusions}

The light-induced modulation of plant secondary metabolism has gained great attention within the last decades, particularly in regard to enhancing the nutraceutical value of fruits and vegetables. In light of ever-increasing consumer demands (i.e., of healthpromoting plant-based foods), application of light treatments is considered a sustainable 
and eco-friendly way to achieve this goal, both pre- and post-harvest. Biosynthesis of any molecular class addressed in this review was found regulated by light. Though some responses of a certain class of bioactive compounds to a specific wavelength were recorded more frequently than others (i.e., accumulation vs. depletion), one common feature of the light influence on secondary metabolites, irrespective of the spectral radiations considered, is the species- or cultivar-dependent specificity of response. The genetic background witnesses the evolutionary pressure experienced by a plant. Specifically, the predominant light environment during evolution had led to the selection of different degrees of sensitivity to light intensity and quality, and resulted in different abilities to adapt to specific habitats. Geographical origin of the plant is therefore important in this context, though, in the case of domesticated species/cultivars, the breeding history (use of landraces or modern breeding programs) is of pivotal importance as well. Moreover, the radiation intensity and duration of exposure, as well as the chemical structure of compounds belonging to the same molecular class, were often important determinants of the output. In greenhouses, light has long been controlled and designed on specific crops to improve and standardize production, but the need to adopt a light environment that also improves the nutraceutical quality of products is now becoming even more important. This aspect is also critical in post-harvest when the products undergo an inevitable qualitative impoverishment during storage. The development of high-performing LEDs and the setup of specifically designed experiments will make it possible to furnish lighting recipes and irradiation protocols to optimize the production of plant foods with high added value.

Author Contributions: Conceptualization, M.S. and A.C.; writing-original draft preparation, M.S. and A.C.; writing-review and editing, M.S., A.R. and A.C. All authors have read and agreed to the published version of the manuscript.

Funding: This research received no external funding.

Data Availability Statement: No new data were created or analysed in this study. Data sharing is not applicable to this article.

Acknowledgments: The authors are members of the International Association of Plant UV Research UV4Plants. We apologise to the colleagues whose interesting research was not cited in this review due to space limitations.

Conflicts of Interest: The authors declare no conflict of interest.

\section{References}

1. Ashraf, M.A.; Iqbal, M.; Rasheed, R.; Hussain, I.; Riaz, M.; Arif, M.S. Environmental Stress and Secondary Metabolites in Plants: An Overview. In Plant Metabolites and Regulation under Environmental Stress; Elsevier: Amsterdam, The Netherlands, 2018; pp. 153-167. ISBN 9780128126905.

2. Jenkins, G.I. The UV-B Photoreceptor UVR8: From Structure to Physiology. Plant Cell 2014, 26, 21-37. [CrossRef]

3. Zoltowski, B.D.; Imaizumi, T. Structure and function of the ZTL/FKF1/LKP2 group proteins in arabidopsis. In Enzymes; Academic Press: Cambridge, MA, USA, 2014; Volume 35, pp. 213-239.

4. Xu, X.; Paik, I.; Zhu, L.; Huq, E. Illuminating Progress in Phytochrome-Mediated Light Signaling Pathways. Trends Plant Sci. 2015, 20, 641-650. [CrossRef] [PubMed]

5. Liu, H.; Liu, B.; Zhao, C.; Pepper, M.; Lin, C. The Action Mechanisms of Plant Cryptochromes. Trends Plant Sci. 2011, 16, 684-691. [CrossRef] [PubMed]

6. Rai, N.; O’Hara, A.; Farkas, D.; Safronov, O.; Ratanasopa, K.; Wang, F.; Lindfors, A.V.; Jenkins, G.I.; Lehto, T.; Salojärvi, J.; et al. The Photoreceptor UVR8 Mediates the Perception of Both UV-B and UV-A Wavelengths up to 350 Nm of Sunlight with Responsivity Moderated by Cryptochromes. Plant Cell Environ. 2020, 43, 1513-1527. [CrossRef] [PubMed]

7. Sakuraba, Y.; Jeong, J.; Kang, M.Y.; Kim, J.; Paek, N.C.; Choi, G. Phytochrome-Interacting Transcription Factors PIF4 and PIF5 Induce Leaf Senescence in Arabidopsis. Nat. Commun. 2014, 5. [CrossRef]

8. Leivar, P.; Monte, E. PIFs: Systems Integrators in Plant Development. Plant Cell 2014, 26, 56-78. [CrossRef]

9. Rösler, J.; Klein, I.; Zeidler, M. Arabidopsis Fhl/Fhy1 Double Mutant Reveals a Distinct Cytoplasmic Action of Phytochrome A. Proc. Natl. Acad. Sci. USA 2007, 104, 10737-10742. [CrossRef]

10. Matsushita, T.; Mochizuki, N.; Nagatani, A. Dimers of the N-Terminal Domain of Phytochrome B Are Functional in the Nucleus. Nature 2003, 424, 571-574. [CrossRef]

11. Smith, H. Phytochromes and Light Signal Perception by Plants-an Emerging Synthesis. Nature 2000, 407, 585-591. [CrossRef] 
12. Casal, J.J.; Candia, A.N.; Sellaro, R. Light Perception and Signalling by Phytochrome A. J. Exp. Bot. 2014, 65, 2835-2845. [CrossRef] [PubMed]

13. Burgie, E.S.; Vierstra, R.D. Phytochromes: An Atomic Perspective on Photoactivation and Signaling. Plant Cell 2014, 26, 4568-4583. [CrossRef]

14. Kircher, S.; Kozma-Bognar, L.; Kim, L.; Adam, E.; Harter, K.; Schäfer, E.; Nagy, F. Light Quality-Dependent Nuclear Import of the Plant Photoreceptors Phytochrome A and B. Plant Cell 1999, 11, 1445-1456. [PubMed]

15. Nagy, F.; Kircher, S.; Schäfer, E. Nucleo-Cytoplasmic Partitioning of the Plant Photoreceptors Phytochromes. Semin. Cell Dev. Biol. 2000, 11, 505-510. [CrossRef]

16. Hoang, Q.T.N.; Han, Y.J.; Kim, J. Plant Phytochromes and Their Phosphorylation. Int. J. Mol. Sci. 2019, 20, 3450. [CrossRef]

17. Yang, Z.; Liu, B.; Su, J.; Liao, J.; Lin, C.; Oka, Y. Cryptochromes Orchestrate Transcription Regulation of Diverse Blue Light Responses in Plants. Photochem. Photobiol. 2017, 93, 112-127. [CrossRef] [PubMed]

18. Christie, J.M.; Blackwood, L.; Petersen, J.; Sullivan, S. Plant Flavoprotein Photoreceptors. Plant Cell Physiol. 2015, 56, 401-413. [CrossRef]

19. Chen, M.; Chory, J.; Fankhauser, C. Light Signal Transduction in Higher Plants. Annu. Rev. Genet. 2004, 38, 87-117. [CrossRef]

20. Bouly, J.P.; Schleicher, E.; Dionisio-Sese, M.; Vandenbussche, F.; van der Straeten, D.; Bakrim, N.; Meier, S.; Batschauer, A.; Galland, P.; Bittl, R.; et al. Cryptochrome Blue Light Photoreceptors Are Activated through Interconversion of Flavin Redox States. J. Biol. Chem. 2007, 282, 9383-9391. [CrossRef] [PubMed]

21. Mishra, S.; Khurana, J.P. Emerging Roles and New Paradigms in Signaling Mechanisms of Plant Cryptochromes. Crit. Rev. Plant Sci. 2017, 36, 89-115. [CrossRef]

22. Wang, Q.; Lin, C. Mechanisms of Cryptochrome-Mediated Photoresponses in Plants. Annu. Rev. Plant Biol. 2020, 71, 103-129. [CrossRef] [PubMed]

23. Yu, X.; Klejnot, J.; Zhao, X.; Shalitin, D.; Maymon, M.; Yang, H.; Lee, J.; Liu, X.; Lopez, J.; Lina, C. Arabidopsis Cryptochrome 2 Completes Its Posttranslational Life Cycle in the Nucleus. Plant Cell 2007, 19, 3146-3156. [CrossRef]

24. Lin, C.; Yang, H.; Guo, H.; Mockler, T.; Chen, J.; Cashmore, A.R. Enhancement of Blue-Light Sensitivity of Arabidopsis Seedlings by a Blue Light Receptor Cryptochrome 2. Proc. Natl. Acad. Sci. USA 1998, 95, 2686-2690. [CrossRef] [PubMed]

25. Swartz, T.E.; Corchnoy, S.B.; Christie, J.M.; Lewis, J.W.; Szundi, I.; Briggs, W.R.; Bogomolni, R.A. The Photocycle of a FlavinBinding Domain of the Blue Light Photoreceptor Phototropin*. J. Biol. Chem. 2001, 276, 36493-36500. [CrossRef]

26. Christie, J.M. Phototropin Blue-Light Receptors. Annu. Rev. Plant Biol. 2007, 58, 21-45. [CrossRef] [PubMed]

27. Suetsugu, N.; Wada, M. Signalling Mechanism of Phototropin-Mediated Chloroplast Movement in Arabidopsis. J. Plant Biochem. Biotechnol. 2020, 29, 580-589. [CrossRef]

28. Kim, W.-Y.; Fujiwara, S.; Suh, S.-S.; Kim, J.; Kim, Y.; Han, L.; David, K.; Putterill, J.; Gil Nam, H.; Somers, D.E. ZEITLUPE Is a Circadian Photoreceptor Stabilized by GIGANTEA in Blue Light. Nature 2007, 449. [CrossRef]

29. Rizzini, L.; Favory, J.J.; Cloix, C.; Faggionato, D.; O’Hara, A.; Kaiserli, E.; Baumeister, R.; Schäfer, E.; Nagy, F.; Jenkins, G.I.; et al. Perception of UV-B by the Arabidopsis UVR8 Protein. Science 2011, 332, 103-106. [CrossRef]

30. Favory, J.J.; Stec, A.; Gruber, H.; Rizzini, L.; Oravecz, A.; Funk, M.; Albert, A.; Cloix, C.; Jenkins, G.I.; Oakeley, E.J.; et al. Interaction of COP1 and UVR8 Regulates UV-B-Induced Photomorphogenesis and Stress Acclimation in Arabidopsis. Embo J. 2009, 28, 591-601. [CrossRef]

31. Ulm, R.; Baumann, A.; Oravecz, A.; Máté, Z.; Ádám, É.; Oakeley, E.J.; Schäfer, E.; Nagy, F. Genome-Wide Analysis of Gene Expression Reveals Function of the BZIP Transcription Factor HY5 in the UV-B Response of Arabidopsis. Proc. Natl. Acad. Sci. USA 2004, 101, 1397-1402. [CrossRef]

32. Huang, X.; Ouyang, X.; Yang, P.; Lau, O.S.; Li, G.; Li, J.; Chen, H.; Deng, X.W. Arabidopsis FHY3 and HY5 Positively Mediate Induction of COP1 Transcription in Response to Photomorphogenic UV-B Light. Plant Cell 2012, 24, 4590-4607. [CrossRef]

33. Huang, X.; Yang, P.; Ouyang, X.; Chen, L.; Deng, X.W. Photoactivated UVR8-COP1 Module Determines Photomorphogenic UV-B Signaling Output in Arabidopsis. PLoS Genet. 2014, 10. [CrossRef]

34. Wargent, J.J.; Gegas, V.C.; Jenkins, G.I.; Doonan, J.H.; Paul, N.D. UVR8 in Arabidopsis Thaliana Regulates Multiple Aspects of Cellular Differentiation during Leaf Development in Response to Ultraviolet B Radiation. J. Compil. New Phytol. 2009, 183, 315-326. [CrossRef]

35. Hayes, S.; Velanis, C.N.; Jenkins, G.I.; Franklin, K.A. UV-B Detected by the UVR8 Photoreceptor Antagonizes Auxin Signaling and Plant Shade Avoidance. Proc. Natl. Acad. Sci. USA 2014, 111, 11894-11899. [CrossRef]

36. Heijde, M.; Ulm, R. Reversion of the Arabidopsis UV-B Photoreceptor UVR8 to the Homodimeric Ground State. Proc. Natl. Acad. Sci. USA 2013, 110, 1113-1118. [CrossRef] [PubMed]

37. Teixeira, R.T. Distinct Responses to Light in Plants. Plants 2020, 9, 894. [CrossRef]

38. Pierik, R.; Ballaré, C.L. Control of Plant Growth and Defense by Photoreceptors: From Mechanisms to Opportunities in Agriculture. Mol. Plant 2021, 14, 61-76. [CrossRef]

39. Han, X.; Huang, X.; Deng, X.W. The Photomorphogenic Central Repressor COP1: Conservation and Functional Diversification during Evolution. Plant Commun. 2020, 1, 1-13. [CrossRef]

40. Jing, Y.; Lin, R. Transcriptional Regulatory Network of the Light Signaling Pathways. New Phytol. 2020, 227, 683-697. [CrossRef]

41. Bhatnagar, A.; Singh, S.; Khurana, J.P.; Burman, N. HY5-COP1: The Central Module of Light Signaling Pathway. J. Plant Biochem. Biotechnol. 2020, 29, 590-610. [CrossRef] 
42. Ulm, R.; Jenkins, G.I. Q\&A: How Do Plants Sense and Respond to UV-B Radiation? BMC Biol. 2015, 13, 45. [CrossRef]

43. Amengual, J. Bioactive Properties of Carotenoids in Human Health. Nutrients 2019, 11, 2388. [CrossRef]

44. Fraga, C.G.; Croft, K.D.; Kennedy, D.O.; Tomás-Barberán, F.A. The Effects of Polyphenols and Other Bioactives on Human Health. Food Funct. 2019, 10, 514-528. [CrossRef]

45. Miekus, N.; Marszałek, K.; Podlacha, M.; Iqbal, A.; Puchalski, C.; Swiergiel, A.H. Health Benefits of Plant-Derived Sulfur Compounds, Glucosinolates, and Organosulfur Compounds. Molecules 2020, 25, 3804. [CrossRef]

46. Szewczyk, K.; Chojnacka, A.; Górnicka, M. Tocopherols and Tocotrienols-Bioactive Dietary Compounds; What Is Certain, What Is Doubt? Int. J. Mol. Sci. 2021, 22, 6222. [CrossRef]

47. Liu, L.H.; Zabaras, D.; Bennett, L.E.; Aguas, P.; Woonton, B.W. Effects of UV-C, Red Light and Sun Light on the Carotenoid Content and Physical Qualities of Tomatoes during Post-Harvest Storage. Food Chem. 2009, 115, 495-500. [CrossRef]

48. Hernandez-Aguilar, C.; Dominguez-Pacheco, A.; Tenango, M.P.; Valderrama-Bravo, C.; Hernández, M.S.; Cruz-Orea, A.; OrdonezMiranda, J. Characterization of Bean Seeds, Germination, and Phenolic Compounds of Seedlings by UV-C Radiation. J. Plant Growth Regul. 2021, 40, 642-655. [CrossRef]

49. Zhu, T.; Yang, J.; Zhang, D.; Cai, Q.; Zhou, D.; Tu, S.; Liu, Q.; Tu, K. Effects of White LED Light and UV-C Radiation on Stilbene Biosynthesis and Phytochemicals Accumulation Identified by UHPLC-MS/MS during Peanut (Arachis Hypogaea L.) Germination. J. Agric. Food Chem. 2020, 68, 5900-5909. [CrossRef]

50. Cheynier, V.; Comte, G.; Davies, K.M.; Lattanzio, V.; Martens, S. Plant Phenolics: Recent Advances on Their Biosynthesis, Genetics, Andecophysiology. Plant Physiol. Biochem. 2013, 72, 1-20. [CrossRef]

51. Lattanzio, V.; Lattanzio, V.M.T.; Cardinali, A.; Amendola, V. Role of Phenolics in the Resistance Mechanisms of Plants against Fungal Pathogens and Insects; Research Signpost: Kerala, India, 2006; Volume 661, ISBN 8130800349.

52. Randhir, R.; Lin, Y.T.; Shetty, K. Phenolics, Their Antioxidant and Antimicrobial Activity in Dark Germinated Fenugreek Sprouts in Response to Peptide and Phytochemical Elicitors. Asia Pac. J. Clin. Nutr. 2004, 13, 295-307. [CrossRef]

53. Martens, S.; Mithöfer, A. Flavones and Flavone Synthases. Phytochemistry 2005, 66, 2399-2407. [CrossRef]

54. Balasundram, N.; Sundram, K.; Samman, S. Phenolic Compounds in Plants and Agri-Industrial by-Products: Antioxidant Activity, Occurrence, and Potential Uses. Food Chem. 2006, 99, 191-203. [CrossRef]

55. Sies, H. Polyphenols and Health: Update and Perspectives. Arch. Biochem. Biophys. 2010, 501, 2-5. [CrossRef]

56. Samoylenko, A.; Hossain, J.; Mennerich, D.; Kellokumpu, S.; Hiltunen, J.K.; Kietzmann, T. Nutritional Countermeasures Targeting Reactive Oxygen Species in Cancer: From Mechanisms to Biomarkers and Clinical Evidence. Antioxid. Redox Signal. 2013, 19, 2157-2196. [CrossRef]

57. Sadowska-Bartosz, I.; Bartosz, G. Effect of Antioxidants Supplementation on Aging and Longevity. Biomed Res. Int. 2014, 2014. [CrossRef]

58. Dimitrios, B. Sources of Natural Phenolic Antioxidants. Trends Food Sci. Technol. 2006, 17, 505-512. [CrossRef]

59. Călinoiu, L.F.; Vodnar, D.C. Whole Grains and Phenolic Acids: A Review on Bioactivity, Functionality, Health Benefits and Bioavailability. Nutrients 2018, 10, 1615. [CrossRef]

60. Singh, B.; Singh, J.P.; Kaur, A.; Singh, N. Phenolic Composition and Antioxidant Potential of Grain Legume Seeds: A Review. Food Res. Int. 2017, 101, 1-16. [CrossRef]

61. Ofosu, F.K.; Elahi, F.; Daliri, E.B.M.; Chelliah, R.; Ham, H.J.; Kim, J.H.; Han, S.I.; Hur, J.H.; Oh, D.H. Phenolic Profile, Antioxidant, and Antidiabetic Potential Exerted by Millet Grain Varieties. Antioxidants 2020, 9, 254. [CrossRef]

62. Domínguez-Perles, R.; Baenas, N.; García-Viguera, C. New Insights in (Poly)Phenolic Compounds: From Dietary Sources to Health Evidence. Foods 2020, 9, 543. [CrossRef]

63. Thilakarathna, S.H.; Vasantha Rupasinghe, H.P. Flavonoid Bioavailability and Attempts for Bioavailability Enhancement. Nutrients 2013, 5, 3367-3387. [CrossRef]

64. Wang, Z.; Li, S.; Ge, S.; Lin, S. Review of Distribution, Extraction Methods, and Health Benefits of Bound Phenolics in Food Plants. J. Agric. Food Chem. 2020, 68, 3330-3343. [CrossRef]

65. Arct, J.; Pytkowska, K. Flavonoids as Components of Biologically Active Cosmeceuticals. Clin. Dermatol. 2008, 26, 347-357. [CrossRef]

66. Abdallah, I.I.; Quax, W.J. A Glimpse into the Biosynthesis of Terpenoids. Kne Life Sci. 2017, 3, 81. [CrossRef]

67. Lichtenthaler, H.K. The 1-Deoxy-D-Xilulose-5-Phosphate Pathway of Isoprenoid Biosynthesis in Plants. Annu. Rev. Plant Physiol. Plant Mol. Biol. 1999, 50, 47-65. [CrossRef]

68. Newman, J.D.; Chappell, J. Isoprenoid Biosynthesis in Plants: Carbon Partitioning within the Cytoplasmic Pathway. Crit. Rev. Biochem. Mol. Biol. 1999, 34, 95-106. [CrossRef]

69. Abbas, F.; Ke, Y.; Yu, R.; Yue, Y.; Amanullah, S.; Jahangir, M.M.; Fan, Y. Volatile Terpenoids: Multiple Functions, Biosynthesis, Modulation and Manipulation by Genetic Engineering. Planta 2017, 246, 803-816. [CrossRef]

70. Dudareva, N.; Klempien, A.; Muhlemann, J.K.; Kaplan, I. Biosynthesis, Function and Metabolic Engineering of Plant Volatile Organic Compounds. New Phytol. 2013, 198, 16-32. [CrossRef]

71. Yu, F.; Utsumi, R. Diversity, Regulation, and Genetic Manipulation of Plant Mono- and Sesquiterpenoid Biosynthesis. Cell. Mol. Life Sci. 2009, 66, 3043-3052. [CrossRef]

72. Montesano, D.; Rocchetti, G.; Putnik, P.; Lucini, L. Bioactive Profile of Pumpkin: An Overview on Terpenoids and Their Health-Promoting Properties. Curr. Opin. Food Sci. 2018, 22, 81-87. [CrossRef] 
73. Wang, C.Y.; Chen, Y.W.; Hou, C.Y. Antioxidant and Antibacterial Activity of Seven Predominant Terpenoids. Int. J. Food Prop. 2019, 22, 230-238. [CrossRef]

74. Khan, M.S.A.; Khundmiri, S.U.K.; Khundmiri, S.R.; Al-Sanea, M.M.; Mok, P.L. Fruit-Derived Polysaccharides and Terpenoids: Recent Update on the Gastroprotective Effects and Mechanisms. Front. Pharmacol. 2018, 9, 1-9. [CrossRef]

75. Yan, J.W.; Ban, Z.J.; Lu, H.Y.; Li, D.; Poverenov, E.; Luo, Z.S.; Li, L. The Aroma Volatile Repertoire in Strawberry Fruit: A Review. J. Sci. Food Agric. 2018, 98, 4395-4402. [CrossRef]

76. Liu, F.; Li, S.; Gao, J.; Cheng, K.; Yuan, F. Changes of Terpenoids and Other Volatiles during Alcoholic Fermentation of Blueberry Wines Made from Two Southern Highbush Cultivars. LWT 2019, 109, 233-240. [CrossRef]

77. Ma, Y.; Li, S.; Yin, X.; Xing, Y.; Lin, H.; Xu, Q.; Bi, X.; Chen, C. Effects of Controlled Atmosphere on the Storage Quality and Aroma Compounds of Lemon Fruits Using the Designed Automatic Control Apparatus. Biomed Res. Int. 2019, 2019. [CrossRef]

78. Mele, M.A.; Kang, H.M.; Lee, Y.T.; Islam, M.Z. Grape Terpenoids: Flavor Importance, Genetic Regulation, and Future Potential. Crit. Rev. Food Sci. Nutr. 2021, 61, 1429-1447. [CrossRef]

79. Deng, H.; Chen, S.; Zhou, Z.; Li, X.; Chen, S.; Hu, J.; Lai, Z.; Sun, Y. Transcriptome Analysis Reveals the Effect of Short-Term Sunlight on Aroma Metabolism in Postharvest Leaves of Oolong Tea(Camellia Sinensis). Food Res. Int. 2020, 137. [CrossRef]

80. Eggersdorfer, M.; Wyss, A. Carotenoids in Human Nutrition and Health. Arch. Biochem. Biophys. 2018, 652, 18-26. [CrossRef]

81. Young, A.J.; Lowe, G.L. Carotenoids-Antioxidant Properties. Antioxidants 2018, 7, 28. [CrossRef]

82. Bolhassani, A.; Milani, A.; Basirnejad, M.; Shahbazi, S. Carotenoids: Biochemistry, Pharmacology and Treatment. Br. J. Pharmacol. 2017, 174, 1290. [CrossRef]

83. Rodriguez-Concepcion, M.; Avalos, J.; Bonet, M.L.; Boronat, A.; Gomez-Gomez, L.; Hornero-Mendez, D.; Limon, M.C.; MeléndezMartínez, A.J.; Olmedilla-Alonso, B.; Palou, A.; et al. A Global Perspective on Carotenoids: Metabolism, Biotechnology, and Benefits for Nutrition and Health. Prog. Lipid Res. 2018, 70, 62-93. [CrossRef] [PubMed]

84. Zimmer, J.P.; Hammond, B.R. Possible Influences of Lutein and Zeaxanthin on the Developing Retina. Clin. Opthalmol. 2007, 1, 25-35.

85. Chew, E.Y.; Clemons, T.E.; SanGiovanni, J.P.; Danis, R.P.; Ferris, F.L.; Elman, M.J.; Antoszyk, A.N.; Ruby, A.J.; Orth, D.; Bressler, S.B.; et al. Secondary Analyses of the Effects of Lutein/Zeaxanthin on Age-Related Macular Degeneration Progression AREDS2 Report No. 3. JAMA Ophthalmol. 2014, 132, 142-149. [CrossRef]

86. Walk, A.M.; Khan, N.A.; Barnett, S.M.; Raine, L.B.; Kramer, A.F.; Cohen, N.J.; Moulton, C.J.; Renzi-Hammond, L.M.; Hammond, B.R.; Hillman, C.H. From Neuro-Pigments to Neural Efficiency: The Relationship between Retinal Carotenoids and Behavioral and Neuroelectric Indices of Cognitive Control in Childhood. Int. J. Psychophysiol. 2017, 118, 1-8. [CrossRef]

87. Cheng, H.M.; Koutsidis, G.; Lodge, J.K.; Ashor, A.W.; Siervo, M.; Lara, J. Lycopene and Tomato and Risk of Cardiovascular Diseases: A Systematic Review and Meta-Analysis of Epidemiological Evidence. Crit. Rev. Food Sci. Nutr. 2019, 59, 141-158. [CrossRef] [PubMed]

88. Wan, L.; Tan, H.L.; Thomas-Ahner, J.M.; Pearl, D.K.; Erdman, J.W.; Moran, N.E.; Clinton, S.K. Dietary Tomato and Lycopene Impact Androgen Signaling- and Carcinogenesis-Related Gene Expression during Early TRAMP Prostate Carcinogenesis. Chest 2014, 146, 1228-1239. [CrossRef] [PubMed]

89. Mínguez-Alarcón, L.; Mendiola, J.; López-Espín, J.J.; Sarabia-Cos, L.; Vivero-Salmerón, G.; Vioque, J.; Navarrete-Muñoz, E.M.; Torres-Cantero, A.M. Dietary Intake of Antioxidant Nutrients Is Associated with Semen Quality in Young University Students Hum. Reprod. 2012, 27, 2807-2814. [CrossRef]

90. Palmer, A.C.; West, K.P.; Dalmiya, N.; Schultink, W. The Use and Interpretation of Serum Retinol Distributions in Evaluating the Public Health Impact of Vitamin A Programmes. Public Health Nutr. 2012, 15, 1201-1215. [CrossRef] [PubMed]

91. Saini, R.K.; Keum, Y.S. Tocopherols and Tocotrienols in Plants and Their Products: A Review on Methods of Extraction, Chromatographic Separation, and Detection. Food Res. Int. 2016, 82, 59-70. [CrossRef]

92. Shahidi, F.; de Camargo, A.C. Tocopherols and Tocotrienols in Common and Emerging Dietary Sources: Occurrence, Applications, and Health Benefits. Int. J. Mol. Sci. 2016, 17, 1745. [CrossRef]

93. Mocchegiani, E.; Costarelli, L.; Giacconi, R.; Malavolta, M.; Basso, A.; Piacenza, F.; Ostan, R.; Cevenini, E.; Gonos, E.S.; Franceschi, C.; et al. Vitamin E-Gene Interactions in Aging and Inflammatory Age-Related Diseases: Implications for Treatment. A Systematic Review. Ageing Res. Rev. 2014, 14, 81-101. [CrossRef]

94. Rashid Khan, M.; Ahsan, H.; Siddiqui, S.; Siddiqui, W.A. Tocotrienols Have a Nephroprotective Action against Lipid-Induced Chronic Renal Dysfunction in Rats. Ren. Fail. 2015, 37, 136-143. [CrossRef]

95. Kirmizis, D.; Chatzidimitriou, D. Vascular Health and Risk Management Antiatherogenic Effects of Vitamin e: The Search for the Holy Grail. Vasc. Health Risk Manag. 2009, 5, 767-774. [CrossRef]

96. Minhajuddin, M.; Beg, Z.H.; Iqbal, J. Hypolipidemic and Antioxidant Properties of Tocotrienol Rich Fraction Isolated from Rice Bran Oil in Experimentally Induced Hyperlipidemic Rats. Food Chem. Toxicol. 2005, 43, 747-753. [CrossRef] [PubMed]

97. Kizhakekuttu, T.J.; Widlansky, M.E. Natural Antioxidants and Hypertension: Promise and Challenges. Cardiovasc. Ther. 2010, 28, 20-32. [CrossRef] [PubMed]

98. García-Closas, R.; Berenguer, A.; Tormo, M.J.; Sánchez, M.J.; Quirós, J.R.; Navarro, C.; Arnaud, R.; Dorronsoro, M.; Chirlaque, M.D.; Barricarte, A.; et al. Dietary Sources of Vitamin C, Vitamin E and Specific Carotenoids in Spain. Br. J. Nutr. 2004, 91, 1005-1011. [CrossRef] [PubMed] 
99. Fenech, M.; Amaya, I.; Valpuesta, V.; Botella, M.A. Vitamin C Content in Fruits: Biosynthesis and Regulation. Front. Plant Sci. 2019, 9. [CrossRef]

100. Wang, J.; Zhang, Z.; Huang, R. Regulation of Ascorbic Acid Synthesis in Plants. Plant Signal. Behav. 2013, 8. [CrossRef] [PubMed]

101. Wheeler, G.L.; Jones, M.A.; Smirnoff, N. The Biosynthetic Pathway of Vitamin C in Higher Plants. Nature 1998, 393, 365-369. [CrossRef] [PubMed]

102. Asada, K. The Water-Water Cycle in Chloroplasts: Scavenging of Active Oxygens and Dissipation of Excess Photons. Annu. Rev. Plant Physiol. Plant Mol. Biol. 1999, 50, 601-639. [CrossRef]

103. Foyer, C.H.; Halliwell, B. The Presence of Glutathione and Glutathione Reductase in Chloroplasts: A Proposed Role in Ascorbic Acid Metabolism. Planta 1976, 133, 21-25. [CrossRef]

104. Bilska, K.; Wojciechowska, N.; Alipour, S.; Kalemba, E.M. Ascorbic Acid-the Little-Known Antioxidant in Woody Plants. Antioxidants 2019, 8, 645. [CrossRef] [PubMed]

105. Page, M.; Sultana, N.; Paszkiewicz, K.; Florance, H.; Smirnoff, N. The Influence of Ascorbate on Anthocyanin Accumulation during High Light Acclimation in Arabidopsis Thaliana: Further Evidence for Redox Control of Anthocyanin Synthesis. PlantCell Environ. 2012, 35, 388-404. [CrossRef] [PubMed]

106. Müller-Moulé, P.; Conklin, P.L.; Niyogi, K.K. Ascorbate Deficiency Can Limit Violaxanthin De-Epoxidase Activity in Vivo. Plant Physiol. 2002, 128, 970-977. [CrossRef] [PubMed]

107. Chen, S.-Y.; Chien, C.-T.; Chung, J.-D.; Yang, Y.-S.; Kuo, S.-R. Dormancy-Break and Germination in Seeds of Prunus Campanulata (Rosaceae): Role of Covering Layers and Changes in Concentration of Abscisic Acid and Gibberellins. Seed Sci. Res. 2007, 17, 21-32. [CrossRef]

108. De Tullio, M.C.; Arrigoni, O. The Ascorbic Acid System in Seeds: To Protect and to Serve. Seed Sci. Res. 2003, 13, 249-260. [CrossRef]

109. Sauberlich, H.E. A history of scurvy and vitamin C. In Vitamin C in Health and Disease; Marcel Dekker Inc.: New York, NY, USA, 1997; pp. 1-24. ISBN 0824793137.

110. Ngo, B.; van Riper, J.M.; Cantley, L.C.; Yun, J. Targeting Cancer Vulnerabilities with High-Dose Vitamin C. Nat. Rev. Cancer 2019, 19, 271-282. [CrossRef]

111. Aune, D.; Keum, N.N.; Giovannucci, E.; Fadnes, L.T.; Boffetta, P.; Greenwood, D.C.; Tonstad, S.; Vatten, L.J.; Riboli, E.; Norat, T. Dietary Intake and Blood Concentrations of Antioxidants and the Risk of Cardiovascular Disease, Total Cancer, and All-Cause Mortality: A Systematic Review and Dose-Response Meta-Analysis of Prospective Studies. Am. J. Clin. Nutr. 2018, 108, $1069-1091$. [CrossRef]

112. Bhandari, S.R.; Jo, J.S.; Lee, J.G. Comparison of Glucosinolate Profiles in Different Tissues of Nine Brassica Crops. Molecules 2015, 20, 15827-15841. [CrossRef]

113. Bellostas, N.; Kachlicki, P.; Sørensen, J.C.; Sørensen, H. Glucosinolate Profiling of Seeds and Sprouts of B. Oleracea Varieties Used for Food. Sci. Hortic. 2007, 114, 234-242. [CrossRef]

114. Bhandari, S.R.; Kwak, J.H. Chemical Composition and Antioxidant Activity in Different Tissues of Brassica Vegetables. Molecules 2015, 20, 1228-1243. [CrossRef]

115. Kang, J.Y.; Ibrahim, K.E.; Juvik, J.A.; Kim, D.H.; Kang, W.J. Genetic and Environmental Variation of Glucosinolate Content in Chinese Cabbage. HortScience 2006, 41, 1382-1385. [CrossRef]

116. Pék, Z.; Daood, H.; Nagyné, M.G.; Berki, M.; Tóthné, M.M.; Neményi, A.; Helyes, L. Yield and Phytochemical Compounds of Broccoli as Affected by Temperature, Irrigation, and Foliar Sulfur Supplementation. HortScience 2012, 47, 1646-1652. [CrossRef]

117. Song, L.; Thornalley, P.J. Effect of Storage, Processing and Cooking on Glucosinolate Content of Brassica Vegetables. Food Chem. Toxicol. 2007, 45, 216-224. [CrossRef]

118. Wang, J.; Gu, H.; Yu, H.; Zhao, Z.; Sheng, X.; Zhang, X. Genotypic Variation of Glucosinolates in Broccoli (Brassica Oleracea Var. Italica) Florets from China. Food Chem. 2012, 133, 735-741. [CrossRef]

119. Mitreiter, S.; Gigolashvili, T. Regulation of Glucosinolate Biosynthesis. J. Exp. Bot. 2021, 72, 70-91. [CrossRef]

120. Liu, Z.; Wang, H.; Xie, J.; Lv, J.; Zhang, G.; Hu, L.; Luo, S.; Li, L.; Yu, J. The Roles of Cruciferae Glucosinolates in Disease and Pest Resistance. Plants 2021, 10, 1097. [CrossRef] [PubMed]

121. Rios, J.J.; Agudelo, A.; Moreno, D.A.; Carvajal, M. Growing Broccoli under Salinity: The Influence of Cultivar and Season on Glucosinolates Content. Sci. Agric. 2020, 77. [CrossRef]

122. Cocetta, G.; Mishra, S.; Raffaelli, A.; Ferrante, A. Effect of Heat Root Stress and High Salinity on Glucosinolates Metabolism in Wild Rocket. J. Plant Physiol. 2018, 231, 261-270. [CrossRef]

123. Aghajanzadeh, T.A.; Reich, M.; Kopriva, S.; de Kok, L.J. Impact of Chloride (NaCl, $\mathrm{KCl}$ ) and Sulphate (Na2SO4, K2SO4) Salinity on Glucosinolate Metabolism in Brassica Rapa. J. Agron. Crop Sci. 2018, 204, 137-146. [CrossRef]

124. Shawon, R.A.; Kang, B.S.; Lee, S.G.; Kim, S.K.; Ju Lee, H.; Katrich, E.; Gorinstein, S.; Ku, Y.G. Influence of Drought Stress on Bioactive Compounds, Antioxidant Enzymes and Glucosinolate Contents of Chinese Cabbage (Brassica Rapa). Food Chem. 2020, 308. [CrossRef] [PubMed]

125. Soundararajan, P.; Kim, J.S. Anti-Carcinogenic Glucosinolates in Cruciferous Vegetables and Their Antagonistic Effects on Prevention of Cancers. Molecules 2018, 23, 2983. [CrossRef]

126. Dubey, S.; Guignard, F.; Pellaud, S.; Pedrazzetti, M.; van der Schuren, A.; Gaume, A.; Schnee, S.; Gindro, K.; Dubey, O. Isothiocyanate Derivatives of Glucosinolates as Efficient Natural Fungicides. PhytoFrontiers ${ }^{T M}$ 2021, 1, 40-50. [CrossRef] 
127. Muntean, D.; Ştefănuţ, M.N.; Căta, A.; Buda, V.; Danciu, C.; Bănică, R.; Pop, R.; Licker, M.; Ienaşcu, I.M.C. Symmetrical Antioxidant and Antibacterial Properties of Four Romanian Cruciferous Extracts. Symmetry 2021, 13, 893. [CrossRef]

128. Nam, T.G.; Kim, D.O.; Eom, S.H. Effects of Light Sources on Major Flavonoids and Antioxidant Activity in Common Buckwheat Sprouts. Food Sci. Biotechnol. 2018, 27, 169-176. [CrossRef]

129. Son, K.-H.; Oh, M.-M. Leaf Shape, Growth, and Antioxidant Phenolic Compounds of Two Lettuce Cultivars Grown under Various Combinations of Blue and Red Light-Emitting Diodes. Am. Soc. Hortic. Sci. 2013, 48, 988-995. [CrossRef]

130. Zhang, T.; Shi, Y.; Piao, F.; Sun, Z. Effects of Different LED Sources on the Growth and Nitrogen Metabolism of Lettuce. Plant Cell Tissue Organ Cult. 2018, 134, 231-240. [CrossRef]

131. Li, Q.; Kubota, C. Effects of Supplemental Light Quality on Growth and Phytochemicals of Baby Leaf Lettuce. Environ. Exp. Bot. 2009, 67, 59-64. [CrossRef]

132. Ohashi-Kaneko, K.; Takase, M.; Kon, N.; Fujiwara, K.; Kurata, K. Effect of Light Quality on Growth and Vegetable Quality in Leaf Lettuce, Spinach and Komatsuna. Environ. Control Biol. 2007, 45, 189-198. [CrossRef]

133. Samuoliene, G.; Brazaityte, A.; Sirtautas, R.; Viršile, A.; Sakalauskaite, J.; Sakalauskiene, S.; Duchovskis, P. LED Illumination Affects Bioactive Compounds in Romaine Baby Leaf Lettuce. J. Sci. Food Agric. 2013, 93, 3286-3291. [CrossRef]

134. Długosz-Grochowska, O.; Wojciechowska, R.; Kruczek, M.; Habela, A. Supplemental Lighting with LEDs Improves the Biochemical Composition of Two Valerianella Locusta (L.) Cultivars. Hortic. Environ. Biotechnol. 2017, 58, 441-449. [CrossRef]

135. Wu, M.C.; Hou, C.Y.; Jiang, C.M.; Wang, Y.T.; Wang, C.Y.; Chen, H.H.; Chang, H.M. A Novel Approach of LED Light Radiation Improves the Antioxidant Activity of Pea Seedlings. Food Chem. 2007, 101, 1753-1758. [CrossRef]

136. Samuoliene, G.; Brazaityte, A.; Sirtautas, R.; Sakalauskiene, S.; Jankauskiene, J.; Duchovskis, P.; Novičkovas, A. The Impact of Supplementary Short-Term Red LED Lighting on the Antioxidant Properties of Microgreens. Acta Hortic. 2012, 956, 649-655. [CrossRef]

137. Samuoliene, G.; Brazaityte, A.; Viršile, A.; Jankauskiene, J.; Sakalauskiene, S.; Duchovskis, P. Red Light-Dose or WavelengthDependent Photoresponse of Antioxidants in Herb Microgreens. PLoS ONE 2016, 11. [CrossRef]

138. Piovene, C.; Orsini, F.; Bosi, S.; Sanoubar, R.; Bregola, V.; Dinelli, G.; Gianquinto, G. Optimal Red: Blue Ratio in Led Lighting for Nutraceutical Indoor Horticulture. Sci. Hortic. 2015, 193, 202-208. [CrossRef]

139. Frisch, T.; Motawia, M.S.; Olsen, C.E.; Agerbirk, N.; Møller, B.L.; Bjarnholt, N. Diversified Glucosinolate Metabolism: Biosynthesis of Hydrogen Cyanide and of the Hydroxynitrile Glucoside Alliarinoside in Relation to Sinigrin Metabolism in Alliaria Petiolata. Front. Plant Sci. 2015, 6. [CrossRef]

140. Deng, M.; Qian, H.; Chen, L.; Sun, B.; Chang, J.; Miao, H.; Cai, C.; Wang, Q. Influence of Pre-Harvest Red Light Irradiation on Main Phytochemicals and Antioxidant Activity of Chinese Kale Sprouts. Food Chem. 2017, 222, 1-5. [CrossRef]

141. Qian, H.; Liu, T.; Deng, M.; Miao, H.; Cai, C.; Shen, W.; Wang, Q. Effects of Light Quality on Main Health-Promoting Compounds and Antioxidant Capacity of Chinese Kale Sprouts. Food Chem. 2016, 196, 1232-1238. [CrossRef]

142. Ma, G.; Zhang, L.; Setiawan, C.K.; Yamawaki, K.; Asai, T.; Nishikawa, F.; Maezawa, S.; Sato, H.; Kanemitsu, N.; Kato, M. Effect of Red and Blue LED Light Irradiation on Ascorbate Content and Expression of Genes Related to Ascorbate Metabolism in Postharvest Broccoli. Postharvest Biol. Technol. 2014, 94, 97-103. [CrossRef]

143. Zhou, Y.; Singh, B.R. Red Light Stimulates Flowering and Anthocyanin Biosynthesis in American Cranberry. Plant Growth Regul. 2002, 38, 165-171. [CrossRef]

144. Gałazka-Czarnecka, I.; Korzeniewska, E.; Czarnecki, A.; Kiełbasa, P.; Drózdz, T. Modelling of Carotenoids Content in Red Clover Sprouts Using Light of Different Wavelength and Pulsed Electric Field. Appl. Sci. 2020, 10, 4143. [CrossRef]

145. Cuong, D.M.; Ha, T.W.; Park, C.H.; Kim, N.S.; Yeo, H.J.; Chun, S.W.; Kim, C.; Park, S.U. Effects of LED Lights on Expression of Genes Involved in Phenylpropanoid Biosynthesis and Accumulation of Phenylpropanoids in Wheat Sprout. Agronomy 2019, 9, 307. [CrossRef]

146. Tuan, P.A.; Thwe, A.A.; Kim, Y.B.; Kim, J.K.; Kim, S.J.; Lee, S.; Chung, S.O.; Park, S.U. Effects of White, Blue, and Red LightEmitting Diodes on Carotenoid Biosynthetic Gene Expression Levels and Carotenoid Accumulation in Sprouts of Tartary Buckwheat (Fagopyrum Tataricum Gaertn.). J. Agric. Food Chem. 2013, 61, 12356-12361. [CrossRef]

147. Yeo, H.J.; Park, C.H.; Lee, K.B.; Kim, J.K.; Park, J.S.; Lee, J.-W.; Park, S.U. Metabolic Analysis of Vigna Unguiculata Sprouts Exposed to Different Light-Emitting Diodes. Nat. Prod. Commun. 2018, 13, 1349-1354. [CrossRef]

148. Zoratti, L.; Sarala, M.; Carvalho, E.; Karppinen, K.; Martens, S.; Giongo, L.; Häggman, H.; Jaakola, L. Monochromatic Light Increases Anthocyanin Content during Fruit Development in Bilberry. BMC Plant Biol. 2014, 14. [CrossRef] [PubMed]

149. Fu, X.; Chen, Y.; Mei, X.; Katsuno, T.; Kobayashi, E.; Dong, F.; Watanabe, N.; Yang, Z. Regulation of Formation of Volatile Compounds of Tea (Camellia Sinensis) Leaves by Single Light Wavelength. Sci. Rep. 2015, 5. [CrossRef]

150. Frede, K.; Schreiner, M.; Zrenner, R.; Graefe, J.; Baldermann, S. Carotenoid Biosynthesis of Pak Choi (Brassica Rapa Ssp. Chinensis) Sprouts Grown under Different Light-Emitting Diodes during the Diurnal Course. Photochem. Photobiol. Sci. 2018, 17, 1289-1300. [CrossRef] [PubMed]

151. Moon, J.; Jeong, M.J.; Lee, S.I.; Lee, J.G.; Hwang, H.; Yu, J.; Kim, Y.R.; Park, S.W.; Kim, J.A. Effect of LED Mixed Light Conditions on the Glucosinolate Pathway in Brassica Rapa. J. Plant Biotechnol. 2015, 42, 245-256. [CrossRef]

152. Ma, G.; Zhang, L.; Kato, M.; Yamawaki, K.; Kiriiwa, Y.; Yahata, M.; Ikoma, Y.; Matsumoto, H. Effect of Blue and Red LED Light Irradiation on $\beta$-Cryptoxanthin Accumulation in the Flavedo of Citrus Fruits. J. Agric. Food Chem. 2012, 60, 197-201. [CrossRef] [PubMed] 
153. Kancheva, V.D. Phenolic Antioxidants-Radical-Scavenging and Chain-Breaking Activity: A Comparative Study. Eur. J. Lipid Sci. Technol. 2009, 111, 1072-1089. [CrossRef]

154. Burri, B.J. Beta-Cryptoxanthin as a Source of Vitamin A. J. Sci. Food Agric. 2015, 95, 1786-1794. [CrossRef] [PubMed]

155. Grune, T.; Lietz, G.; Palou, A.; Ross, A.C.; Stahl, W.; Tang, G.; Thurnham, D.; Yin, S.A.; Biesalski, H.K. $\beta$-Carotene Is an Important Vitamin A Source for Humans. J. Nutr. 2010, 140, 2268-2285. [CrossRef]

156. Pérez-gálvez, A.; Viera, I.; Roca, M. Carotenoids and Chlorophylls as Antioxidants. Antioxidants 2020, 9, 505. [CrossRef]

157. Terashima, I.; Fujita, T.; Inoue, T.; Chow, W.S.; Oguchi, R. Green Light Drives Leaf Photosynthesis More Efficiently than Red Light in Strong White Light: Revisiting the Enigmatic Question of Why Leaves Are Green. Plant Cell Physiol. 2009, 50, 684-697. [CrossRef]

158. Smith, H.L.; Mcausland, L.; Murchie, E.H. Don't Ignore the Green Light: Exploring Diverse Roles in Plant Processes. J. Exp. Bot. 2017, 68, 2099-2110. [CrossRef]

159. Battle, M.W.; Jones, M.A. Cryptochromes Integrate Green Light Signals into the Circadian System. Plant Cell Environ. 2020, 43, 16-27. [CrossRef]

160. Schenkels, L.; Saeys, W.; Lauwers, A.; de Proft, M.P. Green Light Induces Shade Avoidance to Alter Plant Morphology and Increases Biomass Production in Ocimum Basilicum L. Sci. Hortic. 2020, 261. [CrossRef]

161. Zheng, C.; Ma, J.Q.; Ma, C.L.; Shen, S.Y.; Liu, Y.F.; Chen, L. Regulation of Growth and Flavonoid Formation of Tea Plants (Camellia Sinensis) by Blue and Green Light. J. Agric. Food Chem. 2019, 67, 2408-2419. [CrossRef]

162. Liu, H.; Fu, Y.; Wang, M.; Liu, H. Green Light Enhances Growth, Photosynthetic Pigments and CO2 Assimilation Efficiency of Lettuce as Revealed by 'Knock out' of the 480-560 Nm Spectral Waveband. Photosynthetica 2017, 55, 144-152. [CrossRef]

163. Bian, Z.; Yang, Q.; Li, T.; Cheng, R.; Barnett, Y.; Lu, C. Study of the Beneficial Effects of Green Light on Lettuce Grown under Short-Term Continuous Red and Blue Light-Emitting Diodes. Physiol. Plant. 2018, 164, 226-240. [CrossRef]

164. Kaiser, E.; Weerheim, K.; Schipper, R.; Dieleman, J.A. Partial Replacement of Red and Blue by Green Light Increases Biomass and Yield in Tomato. Sci. Hortic. 2019, 249, 271-279. [CrossRef]

165. Dou, H.; Niu, G.; Gu, M. Photosynthesis, Morphology, Yield, and Phytochemical Accumulation in Basil Plants Influenced by Substituting Green Light for Partial Red and/or Blue Light. HortScience 2019, 54, 1769-1776. [CrossRef]

166. Zhang, X.; Bian, Z.; Li, S.; Chen, X.; Lu, C. Comparative Analysis of Phenolic Compound Profiles, Antioxidant Capacities, and Expressions of Phenolic Biosynthesis-Related Genes in Soybean Microgreens Grown under Different Light Spectra. J. Agric. Food Chem. 2019, 67, 13577-13588. [CrossRef]

167. Zha, L.; Liu, W.; Yang, Q.; Zhang, Y.; Zhou, C.; Shao, M. Regulation of Ascorbate Accumulation and Metabolism in Lettuce by the Red:Blue Ratio of Continuous Light Using LEDs. Front. Plant Sci. 2020, 11. [CrossRef] [PubMed]

168. Amoozgar, A.; Mohammadi, A.; Sabzalian, M.R. Impact of Light-Emitting Diode Irradiation on Photosynthesis, Phytochemical Composition and Mineral Element Content of Lettuce Cv. Grizzly. Photosynthetica 2017, 55, 85-95. [CrossRef]

169. Li, H.; Tang, C.; Xu, Z.; Liu, X.; Han, X. Effects of Different Light Sources on the Growth of Non-Heading Chinese Cabbage (Brassica Campestris L.). J. Agric. Sci. 2012, 4. [CrossRef]

170. Samuolienè, G.; Viršilè, A.; Brazaitytè, A.; Jankauskienè, J.; Sakalauskienè, S.; Vaštakaitè, V.; Novičkovas, A.; Viškelienė, A.; Sasnauskas, A.; Duchovskis, P. Blue Light Dosage Affects Carotenoids and Tocopherols in Microgreens. Food Chem. 2017, 228, 50-56. [CrossRef]

171. Arakawa, O.; Kikuya, S.; Pungpomin, P.; Zhang, S.; Tanaka, N. Accumulation of Anthocyanin in Apples in Response to Blue Light at $450 \mathrm{Nm}$ : Recommendations for Producing Quality Fruit Color under Global Warming. Eur. J. Hortic. Sci. 2016, 81, 297-302. [CrossRef]

172. Zhang, Y.; Jiang, L.; Li, Y.; Chen, Q.; Ye, Y.; Zhang, Y.; Luo, Y.; Sun, B.; Wang, X.; Tang, H. Effect of Red and Blue Light on Anthocyanin Accumulation and Differential Gene Expression in Strawberry (Fragaria $\times$ Ananassa). Molecules 2018, 23,820 . [CrossRef] [PubMed]

173. Xu, F.; Cao, S.; Shi, L.; Chen, W.; Su, X.; Yang, Z. Blue Light Irradiation Affects Anthocyanin Content and Enzyme Activities Involved in Postharvest Strawberry Fruit. J. Agric. Food Chem. 2014, 62, 4778-4783. [CrossRef]

174. Xu, F.; Shi, L.; Chen, W.; Cao, S.; Su, X.; Yang, Z. Effect of Blue Light Treatment on Fruit Quality, Antioxidant Enzymes and Radical-Scavenging Activity in Strawberry Fruit. Sci. Hortic. 2014, 175, 181-186. [CrossRef]

175. Xie, B.X.; Wei, J.J.; Zhang, Y.T.; Song, S.W.; Su, W.; Sun, G.W.; Hao, Y.W.; Liu, H.C. Supplemental Blue and Red Light Promote Lycopene Synthesis in Tomato Fruits. J. Integr. Agric. 2019, 18, 590-598. [CrossRef]

176. Hammock, H.A.; Kopsell, D.A.; Sams, C.E. Narrowband Blue and Red LED Supplements Impact Key Flavor Volatiles in Hydroponically Grown Basil Across Growing Seasons. Front. Plant Sci. 2021, 12. [CrossRef] [PubMed]

177. Zhang, L.; Ma, G.; Yamawaki, K.; Ikoma, Y.; Matsumoto, H.; Yoshioka, T.; Ohta, S.; Kato, M. Regulation of Ascorbic Acid Metabolism by Blue LED Light Irradiation in Citrus Juice Sacs. Plant Sci. 2015, 233, 134-142. [CrossRef] [PubMed]

178. Park, C.H.; Kim, N.S.; Park, J.S.; Lee, S.Y.; Lee, J.W.; Park, S.U. Effects of Light-Emitting Diodes on the Accumulation of Glucosinolates and Phenolic Compounds in Sprouting Canola (Brassica Napus L.). Foods 2019, 8, 76. [CrossRef] [PubMed]

179. Park, C.H.; Park, Y.E.; Yeo, H.J.; Kim, J.K.; Park, S.U. Effects of Light-Emitting Diodes on the Accumulation of Phenolic Compounds and Glucosinolates in Brassica Juncea Sprouts. Horticulturae 2020, 6, 77. [CrossRef]

180. Li, Y.Y.; Mao, K.; Zhao, C.; Zhao, X.Y.; Zhang, R.F.; Zhang, H.L.; Shu, H.R.; Hao, Y.J. Molecular Cloning and Functional Analysis of a Blue Light Receptor Gene MdCRY2 from Apple (Malus Domestica). Plant Cell Rep. 2013, 32, 555-566. [CrossRef] 
181. Kadomura-Ishikawa, Y.; Miyawaki, K.; Noji, S.; Takahashi, A. Phototropin 2 Is Involved in Blue Light-Induced Anthocyanin Accumulation in Fragaria x Ananassa Fruits. J. Plant Res. 2013, 126, 847-857. [CrossRef]

182. Fraser, P.D.; Romer, S.; Shipton, C.A.; Mills, P.B.; Kiano, J.W.; Misawa, N.; Drake, R.G.; Schuch, W.; Bramley, P.M. Evaluation of Transgenic Tomato Plants Expressing an Additional Phytoene Synthase in a Fruit-Specific Manner. Proc. Natl. Acad. Sci. USA 2002, 99, 1092-1097. [CrossRef]

183. Mao, P.; Duan, F.; Zheng, Y.; Yang, Q. Blue and UV-A Light Wavelengths Positively Affected Accumulation Profiles of Healthy Compounds in Pak-Choi. J. Sci. Food Agric. 2021, 101, 1676-1684. [CrossRef]

184. Wang, Y.; Zhou, B.; Sun, M.; Li, Y.; Kawabata, S. UV-A Light Induces Anthocyanin Biosynthesis in a Manner Distinct from Synergistic Blue + UV-B Light and UV-A/Blue Light Responses in Different Parts of the Hypocotyls in Turnip Seedlings. Plant Cell Physiol. 2012, 53, 1470-1480. [CrossRef]

185. Moreira-Rodríguez, M.; Nair, V.; Benavides, J.; Cisneros-Zevallos, L.; Jacobo-Velázquez, D.A. UVA, UVB Light Doses and Harvesting Time Differentially Tailor Glucosinolate and Phenolic Profiles in Broccoli Sprouts. Molecules 2017, 22, 1065. [CrossRef]

186. Rechner, O.; Neugart, S.; Schreiner, M.; Wu, S.; Poehling, H.M. Different Narrow-Band Light Ranges Alter Plant Secondary Metabolism and Plant Defense Response to Aphids. J. Chem. Ecol. 2016, 42, 989-1003. [CrossRef] [PubMed]

187. Acharya, J.; Rechner, O.; Neugart, S.; Schreiner, M.; Poehling, H.M. Effects of Light-Emitting Diode Treatments on Brevicoryne Brassicae Performance Mediated by Secondary Metabolites in Brussels Sprouts. J. Plant Dis. Prot. 2016, 123, 321-330. [CrossRef]

188. Brazaityte, A.; Viršile, A.; Jankauskiene, J.; Sakalauskiene, S.; Samuoliene, G.; Sirtautas, R.; Novičkovas, A.; Dabašinskas, L.; Miliauskiene, J.; Vaštakaite, V.; et al. Effect of Supplemental UV-A Irradiation in Solid-State Lighting on the Growth and Phytochemical Content of Microgreens. Int. Agrophysics 2015, 29, 13-22. [CrossRef]

189. He, R.; Zhang, Y.; Song, S.; Su, W.; Hao, Y.; Liu, H. UV-A and FR Irradiation Improves Growth and Nutritional Properties of Lettuce Grown in an Artificial Light Plant Factory. Food Chem. 2021, 345. [CrossRef] [PubMed]

190. Chen, Y.; Li, T.; Yang, Q.; Zhang, Y.; Zou, J.; Bian, Z.; Wen, X. UVA Radiation Is Beneficial for Yield and Quality of Indoor Cultivated Lettuce. Front. Plant Sci. 2019, 10. [CrossRef] [PubMed]

191. Caldwell, C.R.; Britz, S.J. Effect of Supplemental Ultraviolet Radiation on the Carotenoid and Chlorophyll Composition of Green House-Grown Leaf Lettuce (Lactuca Sativa L.) Cultivars. J. Food Compos. Anal. 2006, 19, 637-644. [CrossRef]

192. Lee, M.J.; Son, J.E.; Oh, M.M. Growth and Phenolic Compounds of Lactuca Sativa L. Grown in a Closed-Type Plant Production System with UV-A, -B, or -C Lamp. J. Sci. Food Agric. 2014, 94, 197-204. [CrossRef]

193. Mariz-Ponte, N.; Mendes, R.J.; Sario, S.; Melo, P.; Santos, C. Moderate UV-A Supplementation Benefits Tomato Seed and Seedling Invigoration: A Contribution to the Use of UV in Seed Technology. Sci. Hortic. 2018, 235, 357-366. [CrossRef]

194. Guo, J.; Wang, M.H. Ultraviolet A-Specific Induction of Anthocyanin Biosynthesis and PAL Expression in Tomato (Solanum Lycopersicum L.). Plant Growth Regul. 2010, 62, 1-8. [CrossRef]

195. Dyshlyuk, L.; Babich, O.; Prosekov, A.; Ivanova, S.; Pavsky, V.; Chaplygina, T. The Effect of Postharvest Ultraviolet Irradiation on the Content of Antioxidant Compounds and the Activity of Antioxidant Enzymes in Tomato. Heliyon 2020, 6. [CrossRef]

196. Lee, M.J.; Son, J.E.; Oh, M.M. Growth and Phenolic Content of Sowthistle Grown in a Closed-Type Plant Production System with a UV-A or UV-B Lamp. Hortic. Environ. Biotechnol. 2013, 54, 492-500. [CrossRef]

197. Zhang, Z.Z.; Che, X.N.; Pan, Q.H.; Li, X.X.; Duan, C.Q. Transcriptional Activation of Flavan-3-Ols Biosynthesis in Grape Berries by UV Irradiation Depending on Developmental Stage. Plant Sci. 2013, 208, 64-74. [CrossRef] [PubMed]

198. Nguyen, C.T.T.; Kim, J.; Yoo, K.S.; Lim, S.; Lee, E.J. Effect of Prestorage UV-A, -B, and -C Radiation on Fruit Quality and Anthocyanin of "Duke" Blueberries during Cold Storage. J. Agric. Food Chem. 2014, 62, 12144-12151. [CrossRef] [PubMed]

199. Zhao, Y.; Dong, W.; Wang, K.; Zhang, B.; Allan, A.C.; Lin-Wang, K.; Chen, K.; Xu, C. Differential Sensitivity of Fruit Pigmentation to Ultraviolet Light between Two Peach Cultivars. Front. Plant Sci. 2017, 8. [CrossRef] [PubMed]

200. Mosadegh, H.; Trivellini, A.; Ferrante, A.; Lucchesini, M.; Vernieri, P.; Mensuali, A. Applications of UV-B Lighting to Enhance Phenolic Accumulation of Sweet Basil. Sci. Hortic. 2018, 229, 107-116. [CrossRef]

201. Nascimento, L.B.D.S.; Brunetti, C.; Agati, G.; Iacono, C.L.; Detti, C.; Giordani, E.; Ferrini, F.; Gori, A. Short-Term Pre-Harvest Uv-b Supplement Enhances the Polyphenol Content and Antioxidant Capacity of Ocimum Basilicum Leaves during Storage. Plants 2020, 9, 797. [CrossRef]

202. Ioannidis, D.; Bonner, L.; Johnson, C.B. UV-B Is Required for Normal Development of Oil Glands in Ocimum Basilicum L. (Sweet Basil). Ann. Bot. 2002, 90, 453-460. [CrossRef]

203. Chang, X.; Alderson, P.G.; Wright, C.J. Enhanced UV-B Radiation Alters Basil (Ocimum Basilicum L.) Growth and Stimulates the Synthesis of Volatile Oils. J. Hortic. For. 2009, 1, 27-31.

204. Faseela, P.; Puthur, J.T. The Imprints of the High Light and UV-B Stresses in Oryza Sativa L. 'Kanchana' Seedlings Are Differentially Modulated. J. Photochem. Photobiol. B Biol. 2018, 178, 551-559. [CrossRef]

205. Moreira-Rodríguez, M.; Nair, V.; Benavides, J.; Cisneros-Zevallos, L.; Jacobo-Velázquez, D.A. UVA, UVB Light, and Methyl Jasmonate, Alone or Combined, Redirect the Biosynthesis of Glucosinolates, Phenolics, Carotenoids, and Chlorophylls in Broccoli Sprouts. Int. J. Mol. Sci. 2017, 18, 2330. [CrossRef]

206. Chen, Z.; Ma, Y.; Weng, Y.; Yang, R.; Gu, Z.; Wang, P. Effects of UV-B Radiation on Phenolic Accumulation, Antioxidant Activity and Physiological Changes in Wheat (Triticum Aestivum L.)Seedlings. Food Biosci. 2019, 30. [CrossRef]

207. Wang, H.; Gui, M.; Tian, X.; Xin, X.; Wang, T.; Li, J. Effects of UV-B on Vitamin C, Phenolics, Flavonoids and Their Related Enzyme Activities in Mung Bean Sprouts (Vigna Radiata). Int. J. Food Sci. Technol. 2017, 52, 827-833. [CrossRef] 
208. Dolzhenko, Y.; Bertea, C.M.; Occhipinti, A.; Bossi, S.; Maffei, M.E. UV-B Modulates the Interplay between Terpenoids and Flavonoids in Peppermint (Mentha $\times$ piperita L.). J. Photochem. Photobiol. B Biol. 2010, 100, 67-75. [CrossRef]

209. Assumpção, C.F.; Assis, R.Q.; Hermes Poletto, V.S.; Castagna, A.; Ranieri, A.; Neugart, S.; Flôres, S.H.; de Oliveira Rios, A. Application of Supplemental UV-B Radiation in Pre-Harvest to Enhance Health-Promoting Compounds Accumulation in Green and Red Lettuce. J. Food Process. Preserv. 2019, 43. [CrossRef]

210. Rodríguez-Calzada, T.; Qian, M.; Strid, Å.; Neugart, S.; Schreiner, M.; Torres-Pacheco, I.; Guevara-González, R.G. Effect of UV-B Radiation on Morphology, Phenolic Compound Production, Gene Expression, and Subsequent Drought Stress Responses in Chili Pepper (Capsicum Annuum L.). Plant Physiol. Biochem. 2019, 134, 94-102. [CrossRef] [PubMed]

211. Sakalauskaite, J.; Viskelis, P.; Dambrauskiene, E.; Sakalauskiene, S.; Samuoliene, G.; Brazaityte, A.; Duchovskis, P.; Urbonavičiene, D. The Effects of Different UV-B Radiation Intensities on Morphological and Biochemical Characteristics in Ocimum Basilicum L. J. Sci. Food Agric. 2013, 93, 1266-1271. [CrossRef]

212. Mewis, I.; Schreiner, M.; Nguyen, C.N.; Krumbein, A.; Ulrichs, C.; Lohse, M.; Zrenner, R. UV-B Irradiation Changes Specifically the Secondary Metabolite Profile in Broccoli Sprouts: Induced Signaling Overlaps with Defense Response to Biotic Stressors. Plant Cell Physiol. 2012, 53, 1546-1560. [CrossRef]

213. Scattino, C.; Castagna, A.; Neugart, S.; Chan, H.M.; Schreiner, M.; Crisosto, C.H.; Tonutti, P.; Ranieri, A. Post-Harvest UV-B Irradiation Induces Changes of Phenol Contents and Corresponding Biosynthetic Gene Expression in Peaches and Nectarines. Food Chem. 2014, 163, 51-60. [CrossRef] [PubMed]

214. Sgherri, C.; Scattino, C.; Pinzino, C.; Tonutti, P.; Ranieri, A.M. Ultraviolet-B Radiation Applied to Detached Peach Fruit: A Study of Free Radical Generation by EPR Spin Trapping. Plant Physiol. Biochem. 2015, 96, 124-131. [CrossRef] [PubMed]

215. Santin, M.; Lucini, L.; Castagna, A.; Rocchetti, G.; Hauser, M.T.; Ranieri, A. Comparative "Phenol-Omics" and Gene Expression Analyses in Peach (Prunus Persica) Skin in Response to Different Postharvest UV-B Treatments. Plant Physiol. Biochem. 2019, 135, 511-519. [CrossRef]

216. Santin, M.; Lucini, L.; Castagna, A.; Chiodelli, G.; Hauser, M.-T.; Ranieri, A. Post-Harvest UV-B Radiation Modulates Metabolite Profile in Peach Fruit. Postharvest Biol. Technol. 2018, 139, 127-134. [CrossRef]

217. Castagna, A.; Dall'Asta, C.; Chiavaro, E.; Galaverna, G.; Ranieri, A. Effect of Post-Harvest UV-B Irradiation on Polyphenol Profile and Antioxidant Activity in Flesh and Peel of Tomato Fruits. Food Bioprocess Technol. 2014, 7, 2241-2250. [CrossRef]

218. Castagna, A.; Chiavaro, E.; Dall'Asta, C.; Rinaldi, M.; Galaverna, G.; Ranieri, A. Effect of Postharvest UV-B Irradiation on Nutraceutical Quality and Physical Properties of Tomato Fruits. Food Chem. 2013, 137, 151-158. [CrossRef]

219. Liu, C.; Han, X.; Cai, L.; Lu, X.; Ying, T.; Jiang, Z. Postharvest UV-B Irradiation Maintains Sensory Qualities and Enhances Antioxidant Capacity in Tomato Fruit during Storage. Postharvest Biol. Technol. 2011, 59, 232-237. [CrossRef]

220. Martínez-Zamora, L.; Castillejo, N.; Artés-Hernández, F. Postharvest UV-B and Photoperiod with Blue + Red LEDs as Strategies to Stimulate Carotenogenesis in Bell Peppers. Appl. Sci. 2021, 11, 3736. [CrossRef]

221. Srilaong, V.; Aiamla-or, S.; Soontornwat, A.; Shigyo, M.; Yamauchi, N. UV-B Irradiation Retards Chlorophyll Degradation in Lime (Citrus Latifolia Tan.) Fruit. Postharvest Biol. Technol. 2011, 59, 110-112. [CrossRef]

222. DeLong, J.M.; Steffen, K.L. Photosynthetic Function, Lipid Peroxidation, and-Tocopherol Content in Spinach Leaves during Exposure to UV-B Radiation. Can. J. Plant Sci. 1997, 77, 453-459. [CrossRef]

223. Carletti, P.; Masi, A.; Wonisch, A.; Grill, D.; Tausz, M.; Ferretti, M. Changes in Antioxidant and Pigment Pool Dimensions in UV-B Irradiated Maize Seedlings. Environ. Exp. Bot. 2003, 50, 149-157. [CrossRef]

224. Jain, K.; Kataria, S.; Guruprasad, K.N. Changes in Antioxidant Defenses of Cucumber Cotyledons in Response to UV-B and to the Free Radical Generating Compound AAPH. Plant Sci. 2003, 165, 551-557. [CrossRef]

225. Hagen, S.F.; Borge, G.I.A.; Bengtsson, G.B.; Bilger, W.; Berge, A.; Haffner, K.; Solhaug, K.A. Phenolic Contents and Other Health and Sensory Related Properties of Apple Fruit (Malus Domestica Borkh., Cv. Aroma): Effect of Postharvest UV-B Irradiation. Postharvest Biol. Technol. 2007, 45, 1-10. [CrossRef]

226. Santin, M.; Ranieri, A.; Hauser, M.-T.; Miras-Moreno, B.; Rocchetti, G.; Lucini, L.; Strid, Å.; Castagna, A. The Outer Influences the Inner: Postharvest UV-B Irradiation Modulates Peach Flesh Metabolome Although Shielded by the Skin. Food Chem. 2021, 338, 127782. [CrossRef] [PubMed]

227. Santin, M.; Castagna, A.; Miras-Moreno, B.; Rocchetti, G.; Lucini, L.; Hauser, M.-T.; Ranieri, A. Beyond the Visible and Below the Peel: How UV-B Radiation Influences the Phenolic Profile in the Pulp of Peach Fruit. A Biochemical and Molecular Study. Front. Plant Sci. 2020, 11. [CrossRef] [PubMed]

228. Johnson, C.B.; Kirby, J.; Naxakis, G.; Pearson, S. Substantial UV-B-Mediated Induction of Essential Oils in Sweet Basil (Ocimum Basilicum L.). Phytochemistry 1999, 51, 507-510. [CrossRef]

229. Duarte-Sierra, A.; Munzoor Hasan, S.M.; Angers, P.; Arul, J. UV-B Radiation Hormesis in Broccoli Florets: Glucosinolates and Hydroxy-Cinnamates Are Enhanced by UV-B in Florets during Storage. Postharvest Biol. Technol. 2020, 168. [CrossRef] 